





\section{Designs for the Calibration of Standards of Mass}




\section{NATIONAL BUREAU OF STANDARDS}

The National Bureau of Standards ${ }^{1}$ was established by an act of Congress March 3, 1901. The Bureau's overall goal is to strengthen and advance the Nation's science and technology and facilitate their effective application for public benefit. To this end, the Bureau conducts research and provides: (1) a basis for the Nation's physical measurement system, (2) scientific and technological services for industry and government, (3) a technical basis for equity in trade, and (4) technical services to promote public safety. The Bureau consists of the Institute for Basic Standards, the Institute for Materials Research, the Institute for Applied Technology, the Institute for Computer Sciences and Technology, the Office for Information Programs, and the Office of Experimental Technology Incentives Program.

THE INSTITUTE FOR BASIC STANDARDS provides the central basis within the United States of a complete and consistent system of physical measurement; coordinates that system with measurement systems of other nations; and furnishes essential services leading to accurate and uniform physical measurements throughout the Nation's scientific community, industry, and commerce. The Institute consists of the Office of Measurement Services, and the following center and divisions:

Applied Mathematics - Electricity - Mechanics - Heat - Optical Physics - Center for Radiation Research - Laboratory Astrophysics ${ }^{2}-$ Cryogenics $^{2}-$ Electromagnetics $^{2}-$ Time and Frequency ${ }^{2}$.

THE INSTITUTE FOR MATERIALS RESEARCH conducts materials research leading to improved methods of measurement, standards, and data on the properties of well-characterized materials needed by industry, commerce, educational institutions, and Government; provides advisory and research services to other Government agencies; and develops, produces, and distributes standard reference materials. The Institute consists of the Office of Standard Reference Materials, the Office of Air and Water Measurement, and the following divisions:

Analytical Chemistry — Polymers - Metallurgy — Inorganic Materials — Reactor Radiation — Physical Chemistry.

THE INSTITUTE FOR APPLIED TECHNOLOGY provides technical services developing and promoting the use of available technology; cooperates with public and private organizations in developing technological standards, codes, and test methods; and provides technical advice services, and information to Government agencies and the public. The Institute consists of the following divisions and centers:

Standards Application and Analysis - Electronic Technology - Center for Consumer Product Technology: Product Systems Analysis; Product Engineering — Center for Building Technology: Structures, Materials, and Safety; Building Environment; Technical Evaluation and Application - Center for Fire Research: Fire Science; Fire Safety Engineering.

THE INSTITUTE FOR COMPUTER SCIENCES AND TECHNOLOGY conducts research and provides technical services designed to aid Government agencies in improving cost effectiveness in the conduct of their programs through the selection, acquisition, and effective utilization of automatic data processing equipment; and serves as the principal focus wthin the executive branch for the development of Federal standards for automatic data processing equipment, techniques, and computer languages. The Institute consist of the following divisions:

Computer Services - Systems and Software - Computer Systems Engineering - Information Technology.

THE OFFICE OF EXPERIMENTAL TECHNOLOGY INCENTIVES PROGRAM seeks to affect public policy and process to facilitate technological change in the private sector by examining and experimenting with Government policies and practices in order to identify and remove Government-related barriers and to correct inherent market imperfections that impede the innovation process.

THE OFFICE FOR INFORMATION PROGRAMS promotes optimum dissemination and accessibility of scientific information generated within NBS; promotes the development of the National Standard Reference Data System and a system of information analysis centers dealing with the broader aspects of the National Measurement System; provides appropriate services to ensure that the NBS staff has optimum accessibility to the scientific information of the world. The Office consists of the following organizational units:

Office of Standard Reference Data - Office of Information Activities — Office of Technical Publications - Library Office of International Standards - Office of International Relations.

\footnotetext{
${ }^{1}$ Headquarters and Laboratories at Gaithersburg, Maryland, unless otherwise noted; mailing address Washington, D.C. 20234.

${ }^{2}$ Located at Boulder, Colorado 80302.
} 


\section{Designs for the Calibration of Standards of . Mass}

\section{tTechnical note}

J. M. Cameron, M. C. Croarkin, and R. C. Raybold

Institute for Basic Standards

National Bureau of Standards

Washington, D.C. 20234

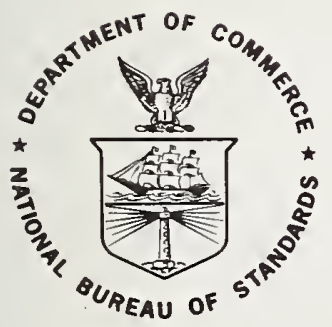

U.S. DEPARTMENT OF COMMERCE, Juanita M. Kreps, Secretary Dr. Sidney Harman, Under Secretary

U.S. NATIONAL BUREAU OF STANDARDS, Ernest Ambler, Acting Director

Issued June 1977 


\section{National Bureau of Standards Technical Note 952}

Nat. Bur. Stand. (U.S.), Tech. Note 952, 64 pages (June 1977)

CODEN: NBTNAE 


\author{
by \\ J. M. Cameron, M. C. Croarkin, R. C. Raybold \\ Office of Measurement Services \\ Institute for Basic Standards \\ National Bureau of Standards
}

This report presents a collection of designs for the intercomparison of sets of weights for use in precision calibration of standards of mass. These include a number of previously unpublished designs which have an additional weight in each set to serve as the check standard for monitoring the performance of the weighing process. Also included are the classical designs of Benoit and Hayford. The complete least squares analysis is presented in integer form (i.e., with a common division) for the most widely used designs; and for the others, the standard deviations are given for various weight combinations when used as an ascending or as a descending series. Designs for sets of nominally equal objects, the 22 . . 11 . . series, the binary sequences, the 52211 series, and the 53211 and some miscellaneous series are given.

Key Words: Design of experiments, least squares, mass calibration, statistical design, weighing design

\title{
INTRODUCTION
}

Calibration of a set of weights consists of assigning values for the unknown weights in terms of the known mass of one or more standards. For high precision work, this involves the use of the balance as a comparator which measures the difference between two objects for two groups of objects) which must have nominally the same mass because of the small "on-scale" range of the comparator. In deriving units which are subdivisions of the basic unit or multiples thereof, a variety of different weighing sets have been used because of convenience or other practical considerations. A typical set is the 5321 series which bridges the range from 10 to 1 . In this paper, designs are presented 
for sets of weights of the same nominal size, for the most common subdivisions currently in use, and for a miscellaneous group included for completeness. In most cases, the designs provide for a check standard, treated as an additional unknown weight, to be used for monitoring the performance of the measuring process.

Precision weighing is usually done by some form of transposition weighing on a two-pan balance and by substitution methods on a one-pan balance. Matters relating to weighing procedures are discussed in $[8,9]$. For the purposes of this report, it will be assumed that a well behaved comparator is available and that measurements of differences in the mass of two objects or groups of objects are corrected for air buoyancy effects and other environmental or procedural factors. It is further assumed that the measurements are uncorrelated in the statistical sense and all are of equal precision. (These latter two assumptions are non-trivial and special care has to be taken to insure their validity so that the random error component of the uncertainty is properly evaluated.)

\section{NEED FOR A CHECK STANDARD}

In a calibration laboratory, it is necessary to have checks on the measurement process to provide assurance that the process measures what it was intended to measure and that it does so with a nearly constant precision [10]. A direct check on the limiting mean of the measurement process is provided if a known weight is calibrated regularly as if it were an unknown test weight. If the value obtained for the weight differs from its accepted value by an amount larger than can be accounted for by the imprecision of measurement, then the process 
would be regarded as being out of control. One is saying that if he cannot calibrate his own weight correctly, he can have little confidence in the values for the calibration of unknown weights derived from the same data.

There is another equally important reason for routine calibration of the same weight--the results on it provide the true measure of the variability of the process. In the course of a year the weighings would have been done under diverse weighing conditions and, hence, the sequence of values would reflect the actual variability of the process--variability which may not be reflected in the internal agreement of one series of measurements.

If an unknown test weight was repeatedly measured, one would expect variability similar to that shown by the check standard. If one has a single measurement on an unknown, it would be like a random selection from the sequence. From the sequence of values on the check standard, one can establish limits to the variability of the process and, because of the equivalence in the method of measurements for both the standard and the unknown, one can legitimately transfer the properties of this sequence to the unknowns.

To establish that the measurement process is in control requires also that the measurements be internally consistent within the limits of random error. If more weighings are made than there are unknowns, then there will be a "closure" error because the values for the observations calculated from "best" values for the weights will differ from that actually observed. The standard deviation computed from these deviations can be tested against the long-run value of this process parameter. 
In summary then, the schedule of measurements for calibration should include provision for a check standard and also for within-run redundancy. The decision as to which one of a number of possible schedules or designs to use for intercomparison of a set of weights depends on items such as the variance associated with individual weights or combinations thereof. The least squares analysis from which the values for the weights and their variances are calculated is presented in the next section. 
We begin then with a set of $n$ observations, $y_{1}, y_{2}, \cdots y_{n}$ involving $k$ objects whose values, $\beta_{1}, \beta_{2}, \ldots \beta_{k}$ are to be determined. The set of observations can be represented by the equations for their expected values, $E\left(y_{i}\right)$,

$$
\begin{aligned}
& E\left(y_{1}\right)=x_{11} \beta_{1}+x_{12} \beta_{2} \cdot x_{1 k} \beta_{k} \\
& E\left(y_{2}\right)=x_{21} \beta_{1}+x_{22} \beta_{2} \cdot x_{2 k} \beta_{k}
\end{aligned}
$$

$$
E\left(y_{n}\right)=x_{n 1} \beta_{1}+x_{n 2} \beta_{2} \cdot \cdot x_{n k} \beta_{k}
$$

or in matrix form $E(y)=x \beta$ where the element, $x_{i j}$, of the $x$ matrix is 0 if the weight is absent, and 1 or -1 depending on the direction of the comparison. In this note we shall adopt the convention of using just the signs so that, for example, all possible comparisons

\begin{tabular}{|c|c|c|c|c|c|c|c|c|}
\hline$B_{1}$ & $\mathrm{~B}_{2}$ & $\mathrm{~B}_{3}$ & $\beta_{4}$ & & & & & \\
\hline+ & - & & & $x=$ & 1 & -1 & 0 & 0 \\
\hline+ & & - & & & 1 & 0 & -1 & 0 \\
\hline+ & & & - & & 1 & 0 & 0 & -1 \\
\hline & + & - & & & 0 & 1 & -1 & 0 \\
\hline & + & & - & & 0 & 1 & 0 & -1 \\
\hline & & + & - & & 0 & 0 & 1 & -1 \\
\hline
\end{tabular}
(ignoring direction) of 4 nominally equal objects will have the representation 
In the least squares analysis one forms the normal equations

$$
x^{\prime} x \hat{\beta}=x^{\prime} y
$$

where the entries in X'X are merely the sums of squares and sums of cross products of the columns of $x$. In the above case, one gets

$$
\left[\begin{array}{cccc}
3 & -1 & -1 & -1 \\
-1 & 3 & -1 & -1 \\
-1 & -1 & 3 & -1 \\
-1 & -1 & -1 & 3
\end{array}\right] \hat{\beta}=\left[\begin{array}{c}
y_{1}+y_{2}+y_{3} \\
-y_{1}+y_{4}+y_{5} \\
-y_{2}-y_{4}+y_{6} \\
y_{3}-y_{5}-y_{6}
\end{array}\right]
$$

where $\hat{\beta}$ is the column vector with elements $\hat{\beta}_{1}, \hat{\beta}_{2}, \hat{\beta}_{3}, \hat{\beta}_{4}$, the caret being used to denote the fact that the values are functions of the observations, anā not the sought-after values, $\beta$.

It can easily be verified in this case that the system of equations is not of full rank (e.g., the column totals are zero) and this is a property of all designs where only differences are measured. In mass calibration, one has one or more standards whose value can be taken as known and these provide the restraint on the system needed to give a unique set of answers. Usually these involve a starting kilogram or a unique summation such as $5+3+2$ which has been determined in a previous series or is the initial unit value for an ascending series such as the $1,2,3,5$ series. One can write the restraint* in the form

$$
r_{1} \beta_{1}+r_{2} \beta_{2} \cdot \cdot+r_{k} \beta_{k}=m
$$

and use the method of Lagrangian multipliers (with multipliers $2 \lambda$ ) to minimize the function

*In all cases treated here a single restraint is sufficient. See Zelen [12] and Goldman and Zelen [6] for a discussion of the general case. 


$$
\left.\Phi=\sum \text { (deviations }\right)^{2}+2 \lambda\left(r_{1} \beta_{1}+\cdot \cdot r_{k} \beta_{k}-m\right)
$$

The normal equations now contain an additional "unknown," namely $\lambda$ and written out in full are as follows:

$$
\begin{aligned}
& \sum x_{1}{ }_{1} \hat{\beta}_{1}+\sum x_{1} x_{2} \hat{\beta}_{2} \cdot \cdot \sum x_{1} x_{k} \hat{\beta}_{k}+r_{1} \lambda=\sum x_{1} y \\
& \sum x_{2} x_{1} \hat{\beta}_{1}+\sum x_{2}{ }_{2} \hat{\beta}_{2} \cdot \cdot \sum x_{2} x_{k} \hat{\beta}_{k}+r_{2} \lambda=\sum x_{2} y \\
& \cdot \\
& \cdot \\
& \sum x_{k} x_{1} \hat{\beta}_{1}+\sum x_{k} x_{2} \hat{\beta}_{2} \cdot \cdot \sum_{x_{k} \hat{\beta}_{k}}+r_{k} \lambda=\sum x_{k} y \\
& r_{1} \hat{\beta}_{1}+r_{2} \hat{\beta}_{2} \cdot \cdot r_{k} \hat{\beta}_{k}=m
\end{aligned}
$$

where

$$
\begin{aligned}
& \sum x_{i} x_{j}=\sum_{k=1}^{n} x_{i k} x_{j k} \\
& \sum x_{i} y=\sum_{k=1}^{n} x_{i k} Y_{k}
\end{aligned}
$$

or in matrix notation

$$
\left[\begin{array}{cc}
x^{\prime} \mathrm{x} & x \\
x^{\prime} & 0
\end{array}\right]\left[\begin{array}{l}
\hat{\beta} \\
\lambda
\end{array}\right]=\left[\begin{array}{l}
x^{\prime} y \\
m
\end{array}\right]
$$

The solution may be written out formally as follows:

$$
\left[\begin{array}{l}
\hat{B} \\
\lambda
\end{array}\right]=\left[\begin{array}{ll}
\mathrm{C} & \mathrm{h} \\
\mathrm{h}^{\prime} & 0
\end{array}\right]\left[\begin{array}{l}
\mathrm{x}^{\prime} \mathrm{y} \\
\mathrm{m}
\end{array}\right]=\left[\begin{array}{cc}
\mathrm{Cx} & \mathrm{h} \\
\mathrm{h}^{\prime} \mathrm{x}^{\prime} & 0
\end{array}\right]\left[\begin{array}{l}
\mathrm{y} \\
\mathrm{m}
\end{array}\right]
$$

where $r^{\prime}=\left(r_{1} r_{2} \cdot \cdot r_{k}\right)$.

To facilitate computation it is convenient to have the values,

$\hat{\beta}$, written out as linear functions of the $y^{\prime} s$ and $m, i . e ., \hat{\beta}=[C X ', h]\left[\begin{array}{l}y \\ m\end{array}\right]$. This leads to a set of multipliers of the observations of the form 


$$
\begin{aligned}
& \hat{\beta}_{1}=g_{11} y_{1}+g_{12} y_{2} \cdots \cdot g_{1 n} y_{n}+h_{1} m \\
& \cdot \\
& \cdot \\
& \hat{\beta}_{k}=g_{k 1} y_{1}+g_{k 2} y_{2} \cdots \cdot g_{k n} y_{n}+h_{k} m
\end{aligned}
$$

These multipliers, $g_{i j}$ and $h_{i}$, are given in Appendix $B$ in transposed form for some of the designs. The matrix $\mathrm{C}$ is important because the variances and covariances of the estimates are given by

$$
\operatorname{variance}\left(\hat{\beta}_{i}\right)=c_{i i} \sigma^{2} \text {, Covariance }\left(\hat{\beta}_{i}, \hat{\beta}_{j}\right)=c_{i j} \sigma^{2}
$$

The quantity, $\sigma^{2}$, is the variance (square of the long run value of the standard deviation) associated with the process. In a set of $\mathrm{n}$ observations on $k$ items and $r=1$ restraints one has $n-k+r=n-k+1$ degrees of freedom for a standard deviation, $s$, formed by

$$
\begin{gathered}
s^{2}=\frac{1}{n-k+1} \sum(\text { deviations })_{i}^{2} \\
\text { (deviation) }{ }_{i}=y_{i}-\left(x_{i 1} \hat{\beta}_{1}+x_{i 2} \hat{\beta}_{2} \cdots x_{i k} \hat{\beta}_{k}\right)
\end{gathered}
$$

One can write these deviations as a function of the observations by noting that the predicted values are just $\hat{X} \hat{\beta}$ and the deviations are thus

$$
\begin{aligned}
\operatorname{dev} & =y-x \hat{\beta}=y-x\left[C X^{\prime}, h\right]\left[\begin{array}{l}
y \\
m
\end{array}\right]=y-\left[x C X^{\prime}, 0\right]\left[\begin{array}{l}
y \\
m
\end{array}\right] \\
& =\left[I-X C X^{\prime}\right] y
\end{aligned}
$$

which can be written as

$$
\begin{aligned}
& \operatorname{dev}_{1}=d_{11} y_{1}+d_{12} y_{2} \cdot \cdot d_{1 n} y_{n} \\
& \cdot \\
& \cdot \\
& \operatorname{dev}_{n}=d_{n 1} y_{1}+d_{n 2} y_{2} \cdot \cdot d_{n n} y_{n}
\end{aligned}
$$


The array of coefficients, $d_{i j}$ ' is given in Appendix $B$ for some of the designs. Weights are often used in combination and one needs to know the standard deviation for the various sums. For a sum of two items, $\hat{\beta}_{i}$ and $\hat{\beta}_{j}$, one has

$$
\operatorname{Var}\left(\hat{\beta}_{i}+\hat{\beta}_{j}\right)=\operatorname{Var}\left(\hat{\beta}_{i}\right)+\operatorname{Var}\left(\hat{\beta}_{j}\right)+2 \operatorname{Cov}\left(\hat{\beta}_{i}, \hat{\beta}_{j}\right)
$$

and for a linear combination

$$
\begin{gathered}
L=\ell_{1} \hat{\beta}_{1}+\ell_{2} \hat{\beta}_{2} \cdot l_{k} \hat{\beta}_{k} \\
\text { Variance }(L)=\ell^{\prime} C l \sigma^{2}
\end{gathered}
$$

where $l^{\prime}=\left(l_{1}, l_{2} \cdot \cdot l_{k}\right), c$ comes from the inverse of the matrix of normal equations [see equation (6)]. In Appendix A each design has a list of the factors $D_{i}$ for computing the standard deviations for all usual weight combinations, $L_{i}$ where $\operatorname{variance}\left(L_{i}\right)=D_{i}^{2} \sigma^{2}$.

\section{DESIGNS FOR WEIGHING}

The criteria for good weighing designs depend to some extent on the use intended for the resulting values. For example, if the weights are to be used independently of each other, then one would want the standard deviation $\left[\sigma \sqrt{C_{i i}}\right.$ from formula (8)] for the value for each unknown weight to be the minimum possible. If the weights are to be used in combination, then one wants the variance of all appropriate linear functions to be as small as possible.

Further, the desirability of a design depends somewhat on the restraint being used. In some cases, one's judgment of a design changes depending on whether one starts with a summation as known (e.g., $5+3+2$ ) and works down, or with a unit as known and works up (e.g., by use of a 1, 2, 3, 5 series). For a given number of measurements 
only a finite set of possible designs exist for a series and only occasionally is one of these designs uniformly and undeniably "best".

The designs are grouped into categories in Appendix A: A. Designs for Nominally Equal Groups, B. Designs for the 22 . . 11 . . Series, C. The 5, 3, 2, 1 and 5, 2, 2, 1 Series, D. Binary and Miscellaneous Series, and E. Desiqns for Direct Reading. The two most widely known collections of weighing designs are those of Hayford [7] and Benoit [1] which, although they do not make provision for a check standard, are listed in this appendix. In Appendix $B$ the complete analysis is given for five of the most commonly used designs. For the others, the complete analysis is on file with the authors, and the factors for computing the standard deviations for different weight combinations are given in Appendix A. A. DESIGNS FOR NOMINALLY EQUAL GROUPS

A.1 All distinct intercomparisons. If $\mathrm{k}$ weights are to be intercompared by measuring the difference between weights of the $k(k-1) / 2$ distinct pairings, then a general analysis can be written out as a function of the number of weights that are regarded as known and used as the restraint. The inverse of the normal equations with the sum of the first $m$ of the $k$ weights taken as known is as follows:

$$
\left[\begin{array}{ccc}
\mathrm{kI}-\mathrm{J} & -\mathrm{J} & \exists \\
-J & \mathrm{kI}-\mathrm{J} & 0 \\
z^{\prime} & 0 & 0
\end{array}\right]^{-1}=\frac{1}{\mathrm{mk}}\left[\begin{array}{ccc}
\mathrm{mI}-\mathrm{J} & 0 & \mathrm{k} z \\
0 & \mathrm{mI}+\mathrm{J} & \mathrm{k} z \\
\mathrm{k} z^{\prime} & \mathrm{k} z^{\prime} & 0
\end{array}\right]
$$

where $z^{\prime}=(1,1, \ldots .1)$ and $J$ is a matrix of all ones and the matrices on the diagonal are of dimension $m \times m,(k-m) \times(k-m)$, and $1 \times l$.

Thus the standard deviation of the value for weights within the restraint is $\sigma \sqrt{\frac{m-1}{m k}}$ and for the unknowns, $\sigma \sqrt{\frac{m+1}{m k}}$. The standard deviation of a sum of $h$ unknowns is $\sigma \sqrt{\frac{h(h+m)}{m k}}$. 
The $\hat{\beta}_{i}$ are given by

$$
\begin{array}{ll}
\hat{\beta}_{i}=\frac{T_{i}}{k}-\frac{\sum_{1}^{m} T_{i}}{m k}+\frac{k}{m} & \text { for weights within restraint } \\
\hat{\beta}_{i}=\frac{T_{i}}{k}+\frac{\sum_{+1}^{k} T_{i}}{m k}+\frac{K}{m} & \text { for unknown weights }
\end{array}
$$

where $T_{i}$ is the sum of the $y$ values invlving $\beta_{i}$ in the positive sense minus the sum of $y$ values involving $\beta_{i}$ in the negative sense (e.g., if $E(y)=\beta_{i}-\beta_{j}$, then $y$ would be added to $T_{i}$ but subtracted from $T_{j}$ ), and $K$ is the value of the restraint $\underset{l}{m} \beta=K)$.

The standard deviation $\mathrm{s}$ is given by

$$
\begin{aligned}
\mathrm{s}^{2} & =\frac{2}{(\mathrm{k}-1)(\mathrm{k}-2)}\left\{\sum \mathrm{dev}^{2}\right\} \\
& =\frac{2}{(\mathrm{k}-1)(\mathrm{k}-2)} \quad\left\{\sum \mathrm{y}_{i}^{2}-\frac{\sum \mathrm{T}_{\mathrm{i}}^{2}}{\mathrm{k}}\right\}
\end{aligned}
$$

Designs for which a linear drift with time is balanced out are also included (see [4] for details of the analysis).

A.2 Subsets of all distinct intercomparisons. For large $\mathrm{k}$ (say $k \geq 6$ ) the number of possible pairings becomes large enough that the time involved in completing the measurements leads to a degradation of the precision as environmental changes, operator, fatigue, etc., become important. For that reason, subsets of the $k(k-1) / 2$ pairings are used to form the design.

In some of the designs the sum of all weights is taken as the restraint. This is appropriate when the design is used to monitor within group behavior. In others, there is an implied grouping into two classes the sum for one of which is taken as the restraint. 


\section{A.3 Designs involving grouping of weights. When differences}

between groups of two or more weights are measured, a reduction in the variance of the values can be achieved in comparison with an equal number of differences between single weights. However, for large $\mathrm{k}$ the problems of identifying and handling the groupings may outweigh the possible gain in efficiency. Bose and Cameron [2, 3] have tabulated all designs up to $k=13$ and give methods of construction for $k \leq 50$, for the special case of designs balanced so that all weights appear equally often with each other on the same pan and a similar property holds for their occurrence in opposite pans. Partially balanced designs have been developed by Suryanarayana and Chakravarti [5, 11] . B. DESIGNS FOR THE $22 . . .111 . .$. SERIES

When weights of nominal size 1 and 2 are involved, the construction and analysis of the designs does not possess the simplicity and symmetry of the case of all equal weights. The designs given under Section B in Appendix A are a listing of those in common use. It is not known how close they are to an "optimum" design.

\section{THE 5,3,2,1 AND 5,2,2,1 SERIES}

The most commonly used sequences for weight sets are the $5,3,2,1$ and the 5,2,2,1. These series permit one to achieve nominal values from one to ten and are the basic series for calibrating weight sets from 1 kilogram down to one milligram. The designs with the check standard $[\mathrm{C} 2, \mathrm{Cl0}]$ are the ones used for all the calibrations of such series at the National Bureau of Standards, and the complete analysis for each of these two designs is given in Appendix B. A complete example from mass calibration at NBS is given for the $5,3,2,1,1,1$ series on page 14 . 


\section{BINARY AND MISCELLANEOUS SERIES}

Binary series used for pound sets and some other miscellaneous series used at NBS are included for completeness.

\section{E. DESIGNS FOR DIRECT READING WITH CONSTANT LOAD}

When a single pan balance is used as a direct reading device, the time required to complete a set of measurements can be greatly reduced, often with a significant reduction in the variance associated with the measurements. To eliminate the effects of a linear drift in the measurements, the set of weighings are repeated in reverse order, e.g., $A, B, C, D, D, C, B, A$ for the four nominally equal weights $A, B, C$, and $D$. The designs are, of course, applicable for groups of weights which are nominally equal as shown in the tables for the $5,2,2,1$ series.

An example is given of the use of these direct reading designs in mass calibration on page 17 .

\section{TREND ELIMINATION}

When responses are time dependent due to temperature and atmospheric changes, proper ordering can make the values for the weights independent of any drift effect. The designs A.1.3, A.2.5, A.2.2, A.2.4, E.1, and E. 2 have this property. If one wishes to use the trend eliminating property of the design (they are valid as given, of course), then one can account for a drift effect of the form . . . -3 $-,-2 \Delta,-\Delta, 0, \Delta$, $2 \Delta, 3 \Delta$. . if $\mathrm{n}$ is odd or by .. $-5 \Delta,-3 \Delta,-\Delta, \Delta, 3 \Delta, 5 \Delta$. . if

$\mathrm{n}$ is even. This will not change the computations for the weights or their variances. However, the degrees of freedom are reduced by one and the deviations will be different. An example of this usage is Design E.1 given in Tables 9 and 10. See [4] for details of the analysis. 
As an example of the calibration process employed in the mass laboratory at NBS, consider six weights $(50,30,20,10,10$ and 10 grams) which are to be calibrated using Design C.2. The complete analysis for this design is given in Table 5 in Appendix $B$.

The sum of the 50,30 and 20 gram weights, estimated from a previous series, forms the restraint, and one of the 10 gram weights is an NBS standard.

If the calibration is done as a double substitution weighing on a one pan balance, the given observations after converting the balance readings to milligrams are:

$$
\begin{aligned}
& y_{1}=.370 \\
& y_{2}=-.499 \\
& y_{3}=-.074 \\
& y_{4}=-.079 \\
& y_{5}=.395 \\
& y_{6}=.395 \\
& y_{7}=-.454 \\
& y_{8}=.405 \\
& y_{9}=.495 \\
& y_{10}=.095 \\
& y_{11}=.490
\end{aligned}
$$

The restraint given is $\mathrm{m}=0.862$

Denote the value of the correction to nominal size of the weights $50,30,20,10,10$ and 10 grams by $\beta_{1}, \cdot . \beta_{6}$ respectively. Using 
the multipliers given under "Parameter Values,"

the least squares estimates of the $\beta_{i}$ 's as functions of the observations are:

$$
\begin{gathered}
\hat{\beta}_{1}=\frac{1}{920}\left\{100\left(y_{1}+y_{2}+y_{3}+y_{4}\right)+60 y_{5}-20\left(y_{6}+y_{7}+y_{8}+\right.\right. \\
\left.\left.y_{9}+y_{10}+y_{11}\right)+460 m\right\}=.395
\end{gathered}
$$

Note that $\hat{\beta}_{1}, \hat{\beta}_{2}$ and $\hat{\beta}_{3}$ necessarily sum to $\mathrm{m}$.

The deviations or differences between the observed and calculated values can be computed using the multipliers given under "Deviations" in Table 5. For example, the deviation corresponding to $y_{1}$ is given by

$$
\begin{aligned}
& \operatorname{dev}_{1}=\frac{1}{184}\left\{98 y_{1}-17\left(y_{2}+y_{3}\right)-40 y_{4}-24 y_{5}-38 y_{6}+\right. \\
& \left.54 y_{7}+8\left(y_{8}+y_{9}\right)+31 y_{10}-15 y_{11}\right\}=.016
\end{aligned}
$$




$$
\text { Similarly, } \begin{aligned}
\operatorname{dev}_{2} & =-.001 \\
\operatorname{dev}_{3} & =-.003 \\
\operatorname{dev}_{4} & =-.007 \\
\operatorname{dev}_{5} & =-.005 \\
\operatorname{dev}_{6} & =-.002 \\
\operatorname{dev}_{7} & =.001 \\
\operatorname{dev}_{8} & =.007 \\
\operatorname{dev}_{9} & =-.006 \\
\operatorname{dev}_{10} & =.021 \\
\operatorname{dev}_{11} & =-.010
\end{aligned}
$$

The standard deviation for this calibration is

$$
\mathbf{s}=\left\{\frac{1}{6} \sum_{i=1}^{11} \operatorname{dev}_{i}^{2}\right\}^{\frac{1}{2}}=.013
$$

and would be used as an estimate of the process standard deviation if that were not already established.

From the "Inverse" of normal equations we can compute the variance for each estimate or linear combination in terms of the process standard deviation $\sigma$. For example,

$$
\begin{aligned}
& \mathrm{V}\left(\hat{\beta}_{1}\right)=\frac{50}{920} \sigma^{2} \\
& \mathrm{~V}\left(\hat{\beta}_{2}\right)=\frac{82}{920} \sigma^{2} \\
& \mathrm{~V}\left(\hat{\beta}_{3}\right)=\frac{64}{920} \sigma^{2} \\
& \mathrm{~V}\left(\hat{\beta}_{1}+\hat{\beta}_{2}\right)=\frac{1}{920}\{50+82-34-34\} \sigma^{2}=\frac{64}{920} \sigma^{2}
\end{aligned}
$$

The usual correction for buoyancy has not been applied to these data for the purpose of this example since all the weights have the same density with the exception of the check standard. 
In order to eliminate time dependency in a mass series, a schedule was developed as in Table 10 in Appendix B which balances out the drift effect. In this example, the corrections to four kilogram weights are to be computed using $n=8$ observations. Since $n$ is even, the drift can be represented by $-7 \Delta,-5 \Delta,-3 \Delta,-\Delta, \Delta, 3 \Delta, 5 \Delta, 7 \Delta$. In addition to four parameter values, $\beta_{1}, \beta_{2}, \beta_{3}$ and $\beta_{4}$, for the weights and $\Delta$ for drift, a value for the tare weight $T$ is computed. $T$ always appears negatively in the design because a direct reading is actually the difference between the unknown weight and the tare weight in the balance.

The correction to the third weight is taken as known, namely $\mathrm{m}=11.906$, and assuming for the purpose of this example, that any effects due to temperature or air density are negligible, the observations are:

$$
\begin{aligned}
& y_{1}=39.112 \\
& y_{2}=44.697 \\
& y_{3}=38.655 \\
& y_{4}=44.150 \\
& y_{5}=44.150 \\
& y_{6}=38.685 \\
& y_{7}=44.778 \\
& y_{8}=39.207
\end{aligned}
$$

Using the multipliers given under "Parameter Values" in Table 10, the least squares estimates of the parameters are given by: 


$$
\begin{aligned}
& \hat{\beta}_{1}=\frac{1}{2}\left(y_{1}-y_{3}-y_{6}+y_{8}\right)+m=12.3955 \\
& \hat{\beta}_{2}=\frac{1}{2}\left(y_{2}-y_{3}-y_{6}+y_{7}\right)+m=17.9735 \\
& \hat{\beta}_{3}=m \quad=11.9060 \\
& \hat{\beta}_{4}=\frac{1}{2}\left(-y_{3}+y_{4}+y_{5}-y_{6}\right)+m=17.3860 \\
& \hat{T}=\frac{1}{2}\left(-y_{3}-y_{6}\right)+m \quad=-26.7640 \\
& \hat{\Delta}=\frac{1}{168}\left(-7 y_{1}-5 y_{2}-3 y_{3}-y_{4}+y_{5}+3 y_{6}+5 y_{7}+7 y_{8}\right)=.0069
\end{aligned}
$$

Associated variances in terms of the process standard deviation $\sigma$ are as follows:

$$
\begin{aligned}
& \mathrm{V}\left(\hat{\beta}_{1}\right)=\sigma^{2} \\
& \mathrm{~V}\left(\hat{\beta}_{2}\right)=\sigma^{2} \\
& \mathrm{~V}\left(\hat{\beta}_{3}\right)=0 \\
& \mathrm{~V}\left(\hat{\beta}_{4}\right)=\sigma^{2} \\
& \mathrm{~V}(\hat{T})=\frac{1}{2} \sigma^{2} \\
& \mathrm{~V}(\hat{\Delta})=\frac{1}{168} \sigma^{2}
\end{aligned}
$$

The deviations or differences between the observed and calculated values can be computed using the multipliers under "Deviations" in Table 10. For example,

$$
\operatorname{dev}_{1}=\frac{1}{168}\left\{35\left(y_{1}-y_{2}+y_{7}-y_{8}\right)+21\left(y_{6}-y_{3}\right)+7\left(y_{5}-y_{4}\right)\right\}=.001
$$

Similarly,

$$
\begin{aligned}
& \operatorname{dev}_{2}=-.006 \\
& \operatorname{dev}_{3}=.006 \\
& \operatorname{dev}_{4}=.007
\end{aligned}
$$




$$
\begin{aligned}
& \operatorname{dev}_{5}=-.007 \\
& \operatorname{dev}_{6}=-.006 \\
& \operatorname{dev}_{7}=.006 \\
& \operatorname{dev}_{8}=-.001
\end{aligned}
$$

The standard deviation $s$ for this experiment is

$$
s=\left\{\frac{1}{3} \sum_{i=1}^{8} \mathrm{dev}_{i}{ }^{2}\right\}^{1 / 2}=.009
$$

and would be used in an F-test to verify that this run had a standard deviation consistent with the process standard deviation $\sigma$. 


\section{APPENDIX A}

\section{LIST OF DESIGNS}

A. Designs for Nominally Equal Groups

A.1 All Distinct Intercomparisons
A. 1.1 .
$k=3$
$\mathrm{n}=3$

${ }^{\star}$ A. 1.2 .

$k=4$

$\mathrm{n}=6$

A. 1. 3 .

$\mathrm{k}=4$

$\mathrm{n}=8$

(Cameron-Hailes)

Trend Elimination
A. 1.4 .
$\mathrm{k}=5$
$\mathrm{n}=10$

A. 1.5 .

$\mathrm{k}=5$

$\mathrm{n}=10$

(Cameron-Hailes)

Trend Elimination
A. 1.6 .
$k=6$
$\mathrm{n}=15$

A. 2 Subsets of All Distinct Intercomparisons
A. 2.1
$k=6$
$\mathrm{n}=8$
A. 2.2
$\mathrm{k}=6$
$\mathrm{n}=12$
Trend Elimination
A. 2.3
$\mathrm{k}=7$
$\mathrm{n}=10$
A. 2.4
$k=7$
$\mathrm{n}=14$ Trend Elimination
A. 2.5
$\mathrm{k}=8$
$n=8$
A. 2.6
$k=8$
$\mathrm{n}=12$
A. 2.7
$\mathrm{k}=8$
$\mathrm{n}=15$
A. 2.8
$k=8$
$\mathrm{n}=16$
Trend Elimination
A. 2.9
$\mathrm{k}=9$
$\mathrm{n}=12$
A. 2.10
$\mathrm{k}=10$
$\mathrm{n}=10$
A. 2.11
$k=10$
$\mathrm{n}=12$
A. 2.12
$k=10$
$\mathrm{n}=15$

*Complete analysis for $1,1,1,1$ design given in Tables 1 and 2 in Appendix B. 
A. 3 Designs Involving Grouping of Weights. $v=$ no. of weights in each group.
A. $3.1 \quad k=6$
$\mathrm{n}=10$
$\mathrm{v}=3$
(Bose-Cameron)

A. $3.2 \quad k=6$

$\mathrm{n}=15$

$\mathrm{v}=2$

(Bose-Cameron)

A. $3.3 \quad k=7$

$\mathrm{n}=7$

$\mathrm{v}=3$

(Bose-Cameron)

A. $3.4 k=8$

$\mathrm{n}=7$

$v=4$

(Bose-Cameron)

A. $3.5 \quad k=8$

$\mathrm{n}=14$

$v=2$

(Bose-Cameron)

A. $3.6 \mathrm{k}=9$

$\mathrm{n}=9$

$v=4$

(Bose-Cameron)
A. $3.7 \quad k=9$
$\mathrm{n}=12$
$v=3$
(Bose-Cameron)

B. $2,2, \ldots, 1,1, \ldots$ Designs
B. $1 \quad 2,1,1,1$
$k=4$
$n=6$
B. $2 \quad 2,1,1,1,1$
$k=5$
$\mathrm{n}=13$
*B. $3 \quad 2,2,1,1$
$\mathrm{k}=4 \quad \mathrm{n}=6$
B. $4 \quad 2,2,1,1,1$
$\mathrm{k}=5 \quad \mathrm{n}=10$
B. $5 \quad 2,2,1,1,1,1$
$k=6$
$\mathrm{n}=15$
B. $6 \quad 2,2,1,1,1,1,1$
$\mathrm{k}=7$
$\mathrm{n}=10$
B. 7
$2,2,1,1,1,1,1,1$
$\mathrm{k}=8$
$n=16$
B. 8
$2,2,2,1,1,1$
$k=6$
$n=12$
B. $9,2,2,2,1,1,1$
$\mathrm{k}=6 \quad \mathrm{n}=15$
B. $10 \quad 2,2,2,1,1,1,1$
$k=7$
$\mathrm{n}=12$
B. $112,2,2,2,1,1$
$\mathrm{k}=6$
$n=11$

*Complete analysis for 2,2,1,1 design is given in Tables 3 and 4 in Appendix B. 
C. $5,3,2,1$ and $5,2,2,1$ series

$\begin{array}{lllll}\text { C.1 } & 5,3,2,1,1 & \mathrm{k}=5 & \mathrm{n}=8 & \text { (Hayford) } \\ \text { *C. } & 5,3,2,1,1,1 & \mathrm{k}=6 & \mathrm{n}=11 & \\ \mathrm{C.} 3 & 5,3,2,2,1,1 & \mathrm{k}=6 & \mathrm{n}=11 & \\ \text { C. } 4 & 5,3,2,2,1,1 & \mathrm{k}=6 & \mathrm{n}=12 & \\ \text { C. } 5 & 5,5,3,2,1,1 & \mathrm{k}=6 & \mathrm{n}=12 & \\ \text { C. } 6 & 5,5,3,2,1,1,1 & \mathrm{k}=7 & \mathrm{n}=15 & \\ \text { C. } 7 & 5,2,1,1,1 & \mathrm{k}=5 & \mathrm{n}=7 & \text { (Hayford) } \\ \text { C. } 8 & 5,2,2,1,1 & \mathrm{k}=5 & \mathrm{n}=7 & \text { (Hayford) } \\ \text { C. } 9 & 5,2,2,1,1 & \mathrm{k}=5 & \mathrm{n}=8 & \text { (Benoit) } \\ \text { *. } 10 & 5,2,2,1,1,1 & \mathrm{k}=6 & \mathrm{n}=8 & \text { (H }\end{array}$

D. Binary and Miscellaneous Series

$\begin{array}{lllll}\text { D. } & 4,2,2,1,1 & \mathrm{k}=5 & \mathrm{n}=6 \\ \text { D. } & 4,2,2,1,1 & \mathrm{k}=5 & \mathrm{n}=10 & \\ \text { D. } 3 & 4,2,2,1,1 & \mathrm{k}=5 & \mathrm{n}=11 & \text { (Benoit) } \\ \text { D. } 4 & 4,2,2,1,1,1 & \mathrm{k}=6 & \mathrm{n}=10 & \\ \text { D. } 5 & 4,4,2,1,1 & \mathrm{k}=5 & \mathrm{n}=9 & \text { (Benoit) } \\ \text { D. } 6 & 4,4,2,2,1,1 & \mathrm{k}=6 & \mathrm{n}=9 & \\ \text { D. } 7 & 4,4,2,2,1,1,1 & \mathrm{k}=7 & \mathrm{n}=14 & \end{array}$

*Complete analysis for 5,3,2,1,1,1 design in Tables 5 and 6 in Appendix B. **Complete analysis for $5,2,2,1,1,1$ design in Tables 7 and 8 in Appendix B. 

D. $84,3,2,1,1$
$k=5$
$n=8$
(Hayford)
D. $9 \quad 4,3,2,1,1$
$\mathrm{k}=5 \quad \mathrm{n}=9$
(Benoit)
D. $10 \quad 10,4,3,2,1,1$
$k=6$
$\mathrm{n}=10$
(Hayford)
D.11 $10,5,2,1,1,1$
$k=6$
$n=8$
(Hayford)
D. $1210,5,2,2,1,1$
$k=6$
$n=8$
(Hayford)
D. $1310,5,3,2,1,1$
$k=6$
$n=10$
(Hayford)
D. $145,4,3,2,1$
$k=5$
$n=7$
(Hayford)
D. $1510,5,4,3,2,1$
$k=6$
$n=10$
(Hayford)
D.16 $6,5,4,3,2,1$
$\mathrm{k}=6$
$n=9$
(Hayford)
D. $17 \quad 10,6,5,1,3,2,1$
$k=7$
$\mathrm{n}=12$
(Hayford)

E. Direct Readings

* E.l 4 nominally equal weights

Trend elimination

E. $2 \quad 2,2,1,1$

Trend elimination

*Complete analysis for direct reading design $1,1,1,1$ is given in Tables 9 and 10 in Appendix $B$. 
Description of Designs

Each design lists $k$, the number of weights; $n$, the number of measurements; and d.f., the degrees of freedom associated with the standard deviation.

The identification or nominal size of each weight $\beta_{i}$ is given next to the heading "Observations." $Y(1), Y(2), .$. . denotes the measurements where + indicates the weight is present positively, and - indicates the weight is present negatively.

For example, Design A.l.I involves three equal weights. If used as a starting design for a $1 \mathrm{~kg}$ to $\mathrm{l} \mathrm{mg}$ set, the three weights would be kilograms, and the first observation $Y(1)$ would be the difference between the first and second kilograms.

Two restraints are listed although others are possible. Usually "Restraint A" is appropriate for descending series involving, for example, $5+3+2$ which would be calibrated as a "Ten" weight in the higher series involving 50, 30, 20, 10. For ascending series, "Restraint $B^{\prime \prime}$ is usually a single unit weight.

In the case of three equal weights, Restraint A takes the sum of two kilograms as known; Restraint B takes the single third weight as the reference standard.

"Factors for Computing Standard Deviations" give the multipliers needed to calculate the standard deviations of linear combinations of the weights. "Wt" identifies the total weight combination or load $\mathrm{L}_{i}$ where

$$
L_{i}=\sum_{i=1}^{k} \ell_{i} \beta_{i}, \ell_{i}=0 \text { or } I
$$


The next two columns under Restraints $A$ and $D$ list the factors $D_{i}$ where $D_{i}$ is calculated so that

$$
\operatorname{Variance}\left(L_{i}\right)=D_{i}{ }^{2} \sigma^{2}
$$

The remaining columns, under the nominal sizes of the weights, show the actual weights involved in the combinations, i.e. a + indicates $\ell_{i}=1$ and a blank indicates $l_{i}=0$.

\section{Selection of the Appropriate Design}

The selection of the appropriate design is usually dictated by the set of weights to be calibrated and the reference standards one has available. There is occasionally some flexibility as, for example, if one were working up from $1 \mathrm{~kg}$ to $100 \mathrm{~kg}$ from a single reference kilogram. If either the $1,1,1,1,2$ Series (Design B.2) or the 1,1,1,2,2 Series (Design B.4) were usable one would make the decision on the basis of the standard deviation of $\sum 5$, the $5 \mathrm{~kg}$ summation. In design B.2 the factor for computing the standard deviation is 1.6733 , whereas in B.4 it is 2.1909. [Even if one compares the two standard deviations on an equal number of observation basis ( $n=13 \mathrm{vs} \cdot \mathrm{n}=10$ ) one would have 1.6733 vs. $1.9215(=2.1909 \sqrt{10 / 13})]$. The advantage clearly is with design B.2 because in the next series, $\sum 5,5,5,5,10$, the uncertainty associated with the starting standard $\sum 5$ is smaller.

When the standard deviation for the weight combinations of interest (computed using the standard deviation associated with the measurement process) exceeds the tolerance given by the requirements, then one has to consider the feasibility of repeating a design to reduce the standard deviation factors by $\frac{1}{\sqrt{2}}$ (or $\frac{1}{\sqrt{n}}$ if $\mathrm{n}$ repetitions are made). 


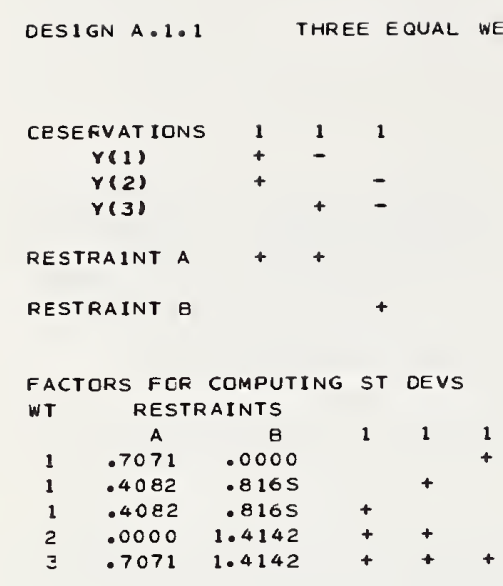

$\begin{array}{llr}\text { DESIGN A.1.3 FOUR EQUAL WEIGHTS } & \begin{array}{r}K=4 \\ \text { TRENO ELIMINATION * }\end{array} \\ & \text { (CAMERON-HAILES) } & \text { D.F. }=\end{array}$

\begin{tabular}{|c|c|c|c|}
\hline OESERVATIONS & 1 & 1 & 1 \\
\hline$Y(1)$ & + & & \\
\hline$r(2)$ & - & & + \\
\hline$Y(3)$ & & + & - \\
\hline$Y(4)$ & & - & \\
\hline$Y(s)$ & & & - \\
\hline$Y(6)$ & - & & + \\
\hline$Y(7)$ & + & - & \\
\hline$Y(8)$ & & + & \\
\hline
\end{tabular}

RESTRA INT A

RESTRAINT B

FACTCRS FCR COMPUTING ST DEVS

WT RESTRAINTS

\begin{tabular}{|c|c|c|c|c|c|c|}
\hline \multirow[t]{2}{*}{$N T$} & \multicolumn{2}{|c|}{ RESTRAI } & \multirow{2}{*}{1} & \multirow{2}{*}{1} & \multirow[b]{2}{*}{1} & \\
\hline & A & B & & & & 1 \\
\hline 1 & .5204 & .0000 & & & & + \\
\hline 1 & .5204 & $.645 \mathrm{~S}$ & & & + & \\
\hline 1 & .3227 & .5774 & & + & & \\
\hline 1 & .3227 & $.645 S$ & + & & & \\
\hline 2 & .0000 & 1.0408 & + & + & & \\
\hline$z$ & .5204 & 1.5275 & + & + & + & \\
\hline 4 & . 816S & 1.5275 & + & + & + & + \\
\hline
\end{tabular}

*see page 13 .

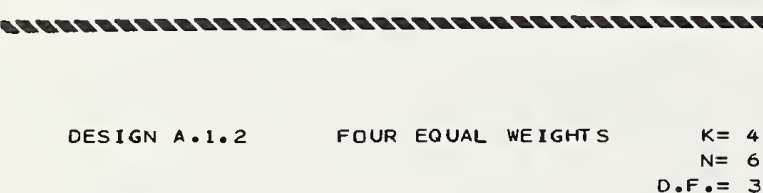

$\begin{array}{lllll}\text { OESERVATIONS } & 1 & 1 & 1 & 1 \\ Y(1) & + & - & & \\ Y(2) & + & & - & \\ Y(3) & + & & & - \\ Y(4) & & + & - & \\ Y(5) & & + & & - \\ Y(6) & & & + & -\end{array}$

RESTRA INT A

RESTRAINT $\theta$

FACTORS FCR COMPUTING ST OEVS

\begin{tabular}{|c|c|c|c|c|c|c|}
\hline \multirow[t]{2}{*}{ WT } & \multicolumn{2}{|c|}{ RESTRAINTS } & \multirow[b]{2}{*}{1} & \multirow[b]{2}{*}{1} & \multirow[b]{2}{*}{1} & \multirow[b]{2}{*}{1} \\
\hline & $A$ & B & & & & \\
\hline 1 & .6124 & .0000 & & & & + \\
\hline 1 & .6124 & .7071 & & & + & \\
\hline 1 & .3536 & .7071 & & + & & \\
\hline 1 & .3536 & .7071 & + & & & \\
\hline$\varepsilon$ & .0000 & 1.2247 & + & + & & \\
\hline 3 & .6124 & 1.7321 & + & + & + & \\
\hline 4 & 1.0000 & 1.7321 & + & + & + & + \\
\hline
\end{tabular}

DES $1 \mathrm{GN} \mathrm{A.1.4}$

FIVE EQUAL WEIGHTS

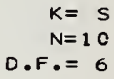

OBSERVATIONS

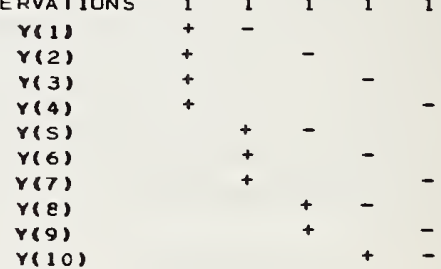

RESTRAINT A

RESTRAINT $B$

FACTORS FCR COMPUTING ST DEVS

WT RESTRAINTS

$$
\begin{array}{cc}
\text { A } & \text { B } \\
.5477 & .0000 \\
.5477 & .6325 \\
.5477 & .6325 \\
.3162 & .6325 \\
.3162 & .6325 \\
.0000 & 1.0954 \\
.5477 & 1.5492 \\
.8944 & 2.0000 \\
1.2247 & 2.000 C
\end{array}
$$


$\begin{array}{lll}\text { DESIGN A.1.5 FIVE EQUAL WEIGHTS } & K=5 \\ & \text { TREND ELIMINATION * } & \mathrm{H}=10\end{array}$ (CAMERON-HAILES)

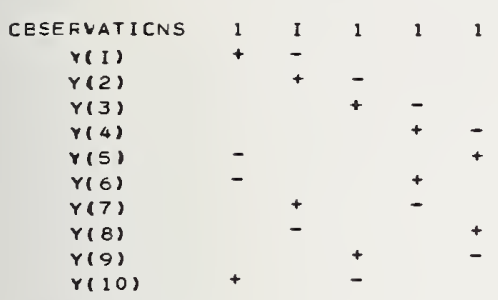

RESTRAINT A

RESTRAINT 8

FACTORS FCR COMPUTING ST OEVS

WT RESTRAINTS

\begin{tabular}{|c|c|c|c|c|c|c|}
\hline & $A$ & $\mathrm{~B}$ & 1 & 1 & 1 & 1 \\
\hline 1 & .5477 & .0000 & & & & \\
\hline$I$ & .5477 & .6325 & & & & + \\
\hline 1 & .5477 & .6325 & & & + & \\
\hline 1 & .3162 & .6325 & & + & & \\
\hline 1 & $.31 \in 2$ & .6325 & + & & & \\
\hline 2 & .0000 & 1.0954 & + & + & & \\
\hline$\Xi$ & .5477 & 1.5492 & + & + & + & \\
\hline 4 & .8944 & 2.0000 & + & + & + & + \\
\hline E & I. 2247 & 2.0000 & + & + & + & + \\
\hline
\end{tabular}

* See page 13.
OES IGN A.2. I

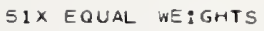

$k=6$ $N=8$ O.F. $=3$

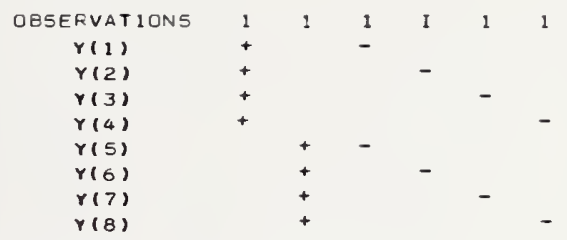

RESTRAINT A

RESTRAINT

FACTORS FOF COMPUTINE ST DEVS

WT RESTRAINTS

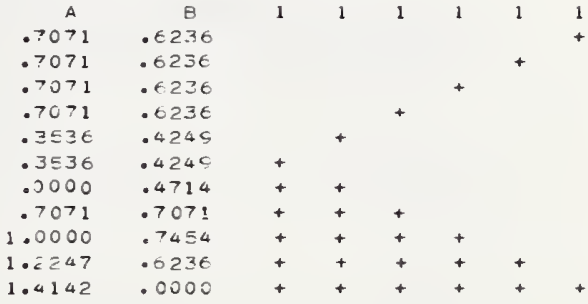

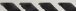

SIX EOUAL NEIGHTS

$k=6$ $N=15$ $0 . F .=10$

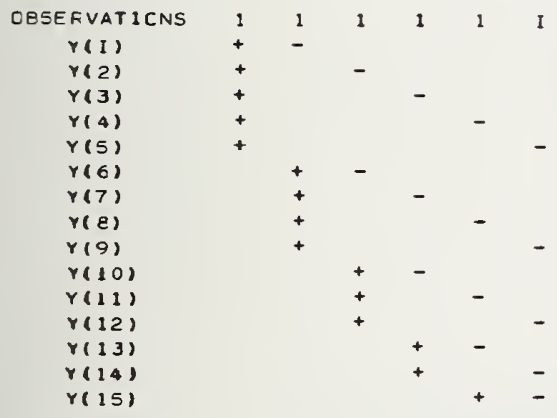

RESTRAINTA ++

RESTRAINT 8

FACTORS FCR COMPUTING ST DEVS WT RESTRAINTS

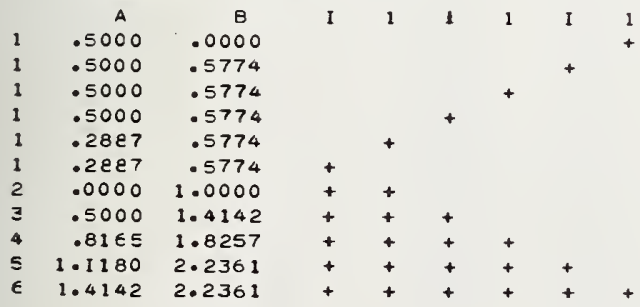

$\begin{array}{lll}\text { CESIGN A.2.2 } & \text { SIX EQLAL HEIGHTS } & K=\epsilon \\ & \text { TRENO ELIMINATION * } & N=12\end{array}$

DESEFVATIONS 1 I 111211

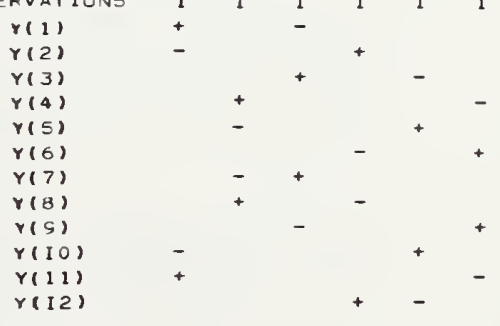

FEESTFA INT A

RESTRAINT 3

FACTCRS FCR COMFUTING ST CEVS

WT RFSTRAINTS

$$
\begin{array}{cc}
A & B \\
.5401 & .0000 \\
.5401 & .7071 \\
.5401 & .6455 \\
.5401 & .6455 \\
.3536 & .6455 \\
.3536 & .6455 \\
.000 C & 1.0801 \\
.5401 & 1.5546 \\
.8165 & 2.0000 \\
1.1365 & 2.5495 \\
1.4142 & 2.5495
\end{array}
$$

*See page 13 


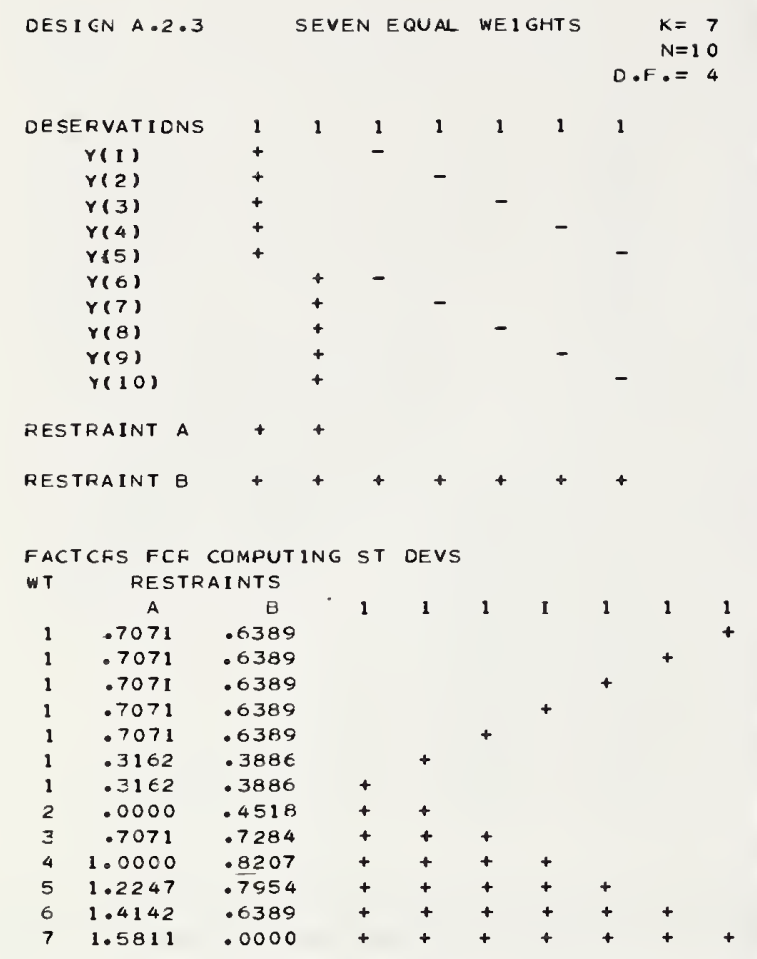

DESIGN A.2.5 EIGHT EQUAL WEIGHTS K= 8 $\begin{aligned} N & =8 \\ D . F . & =1\end{aligned}$

CESERVAT ICNS

$$
\begin{aligned}
& Y(1) \\
& Y(2) \\
& Y(3) \\
& Y(4) \\
& Y(5) \\
& Y(\in) \\
& Y(7) \\
& Y(8)
\end{aligned}
$$

RESTRAINT A

RESTRAINT B

FACTORS FOR CDMPUTING ST DEVS WT RESTRAINTS

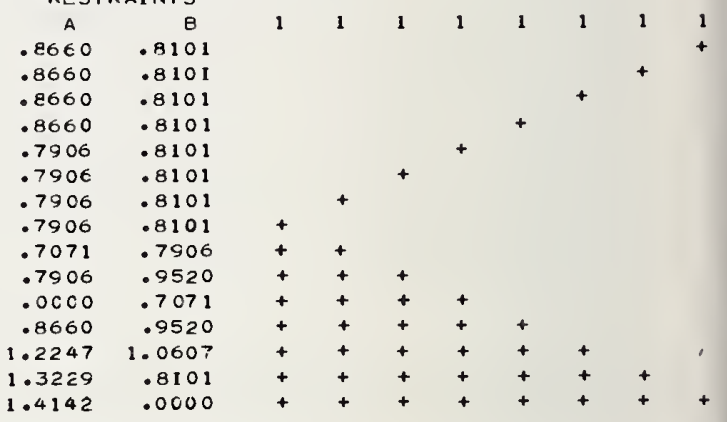

DESIGN A.2.6 EIGHT EQUAL WEIGHTS

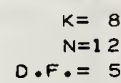

OBSERVAT ICNS

Y ( 1$)$

$\checkmark(2)$

$r(3)$

$Y(4)$

$Y(5)$

$Y(6)$

$Y(7)$

$r(8)$

$Y(9)$

$Y(10)$

Y(1)

$r(12)$

RESTRAINT A

RESTRAINT B

FACTDRS FCR COMPUTING ST DEVS

W T

$\begin{array}{cc}\text { RESTRAINTS } & \text { A } \\ .7071 & .6495 \\ .7071 & .6495 \\ .7071 & .6495 \\ .7071 & .6495 \\ .7071 & .6495 \\ .7071 & .6495 \\ .2887 & .3608 \\ .2887 & .3608 \\ .0000 & .4330 \\ .7071 & .7395 \\ 1.0000 & .8660 \\ 1.2247 & .8927 \\ 1.4142 & .8292 \\ 1.5811 & .6495 \\ 1.7321 & .0000\end{array}$




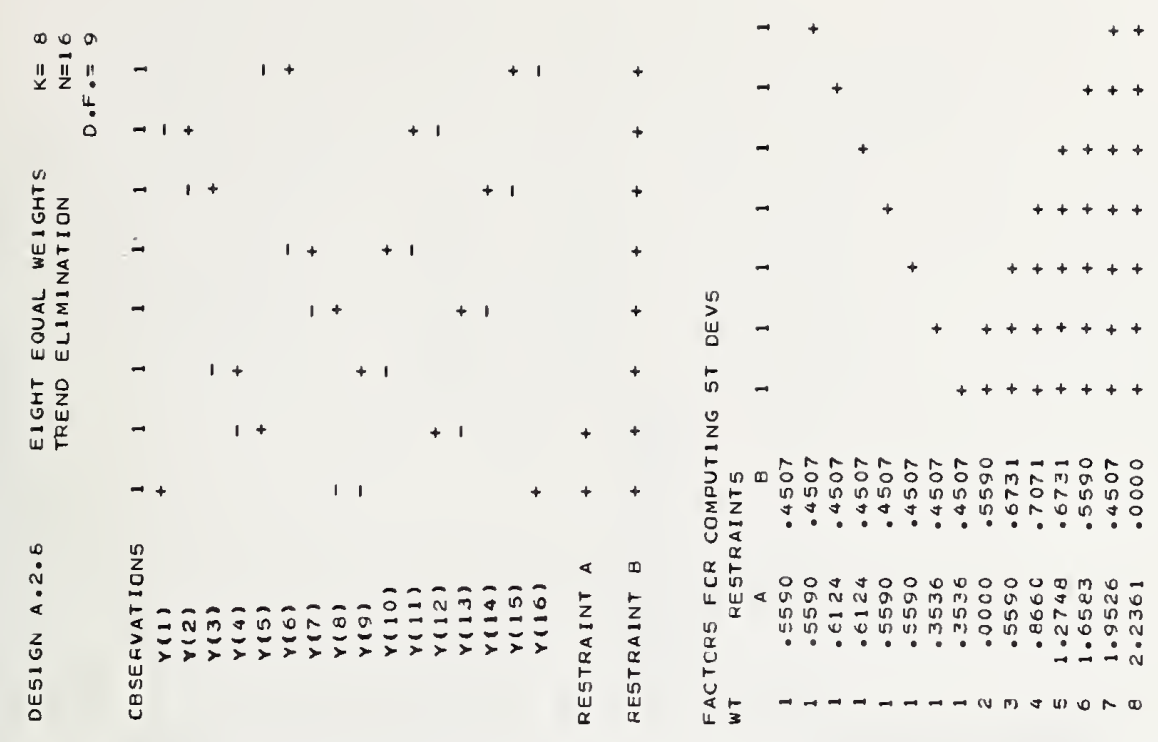

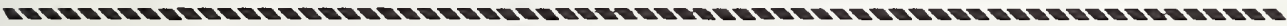

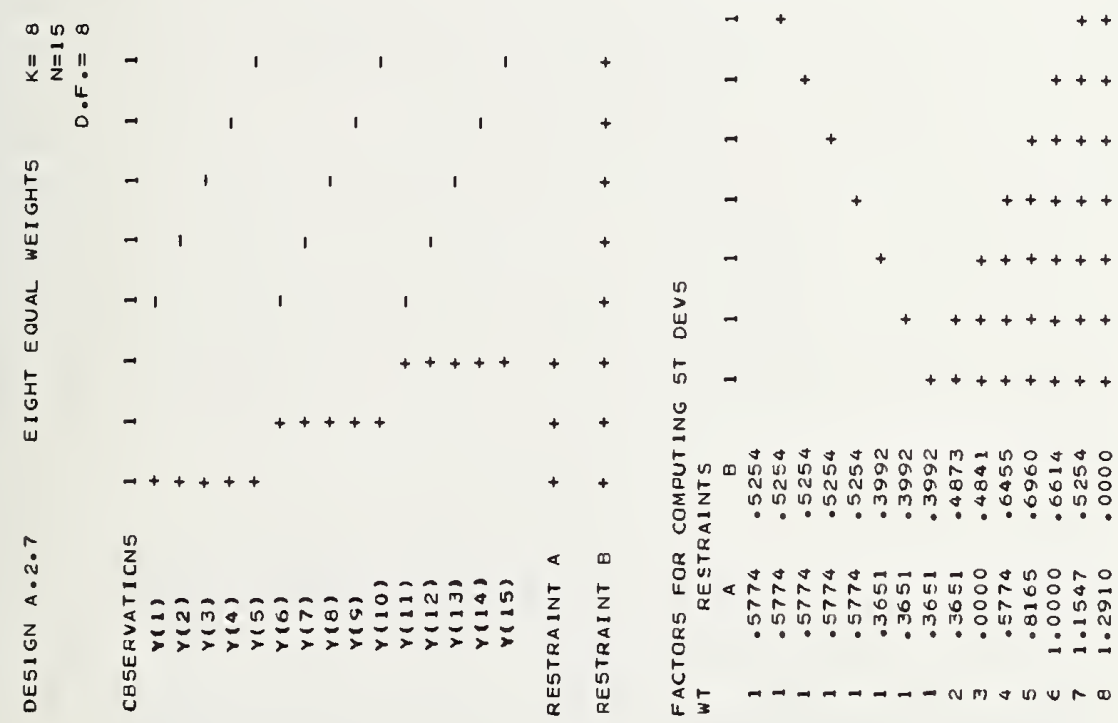




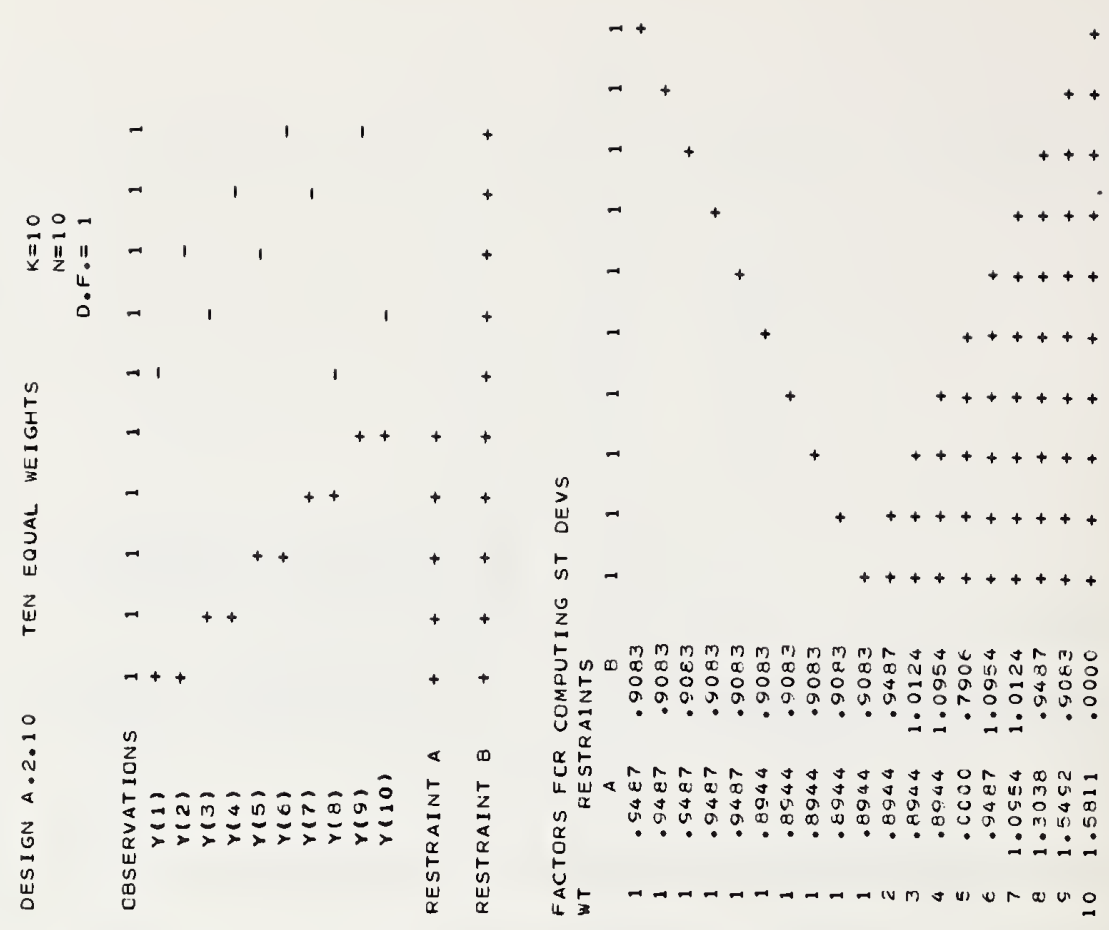

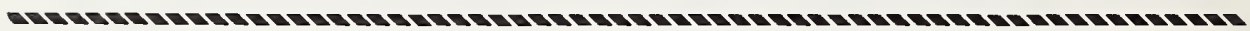

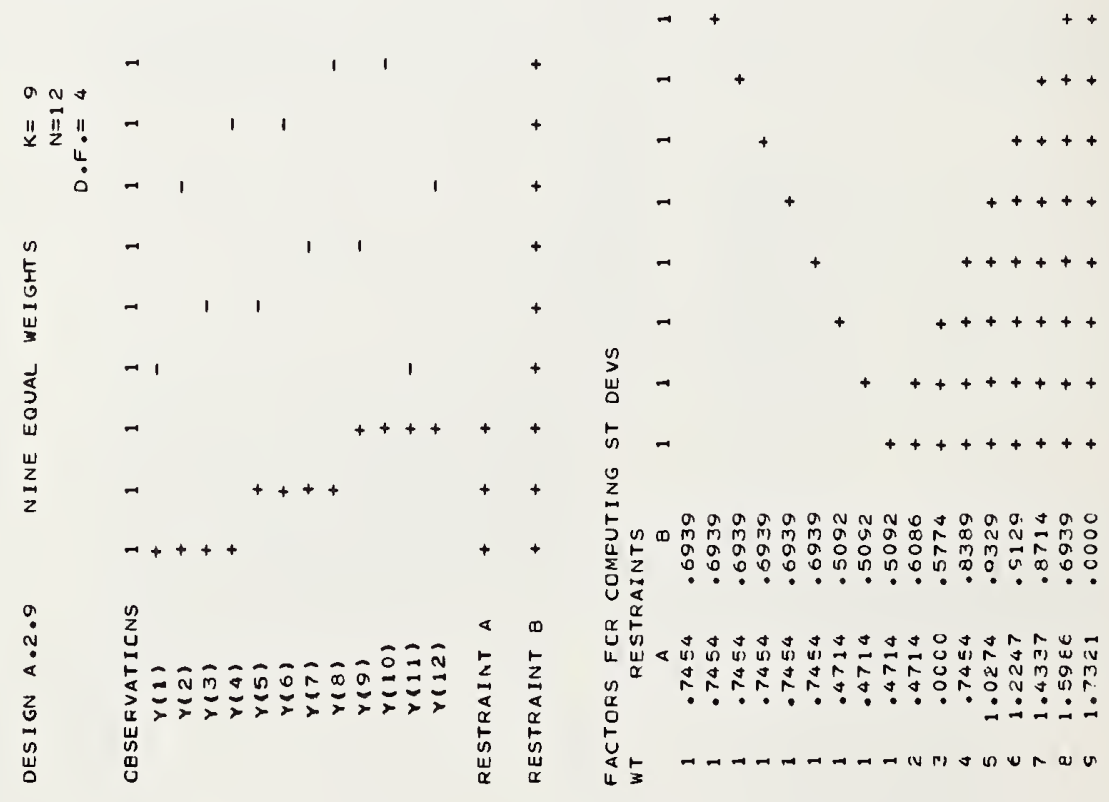




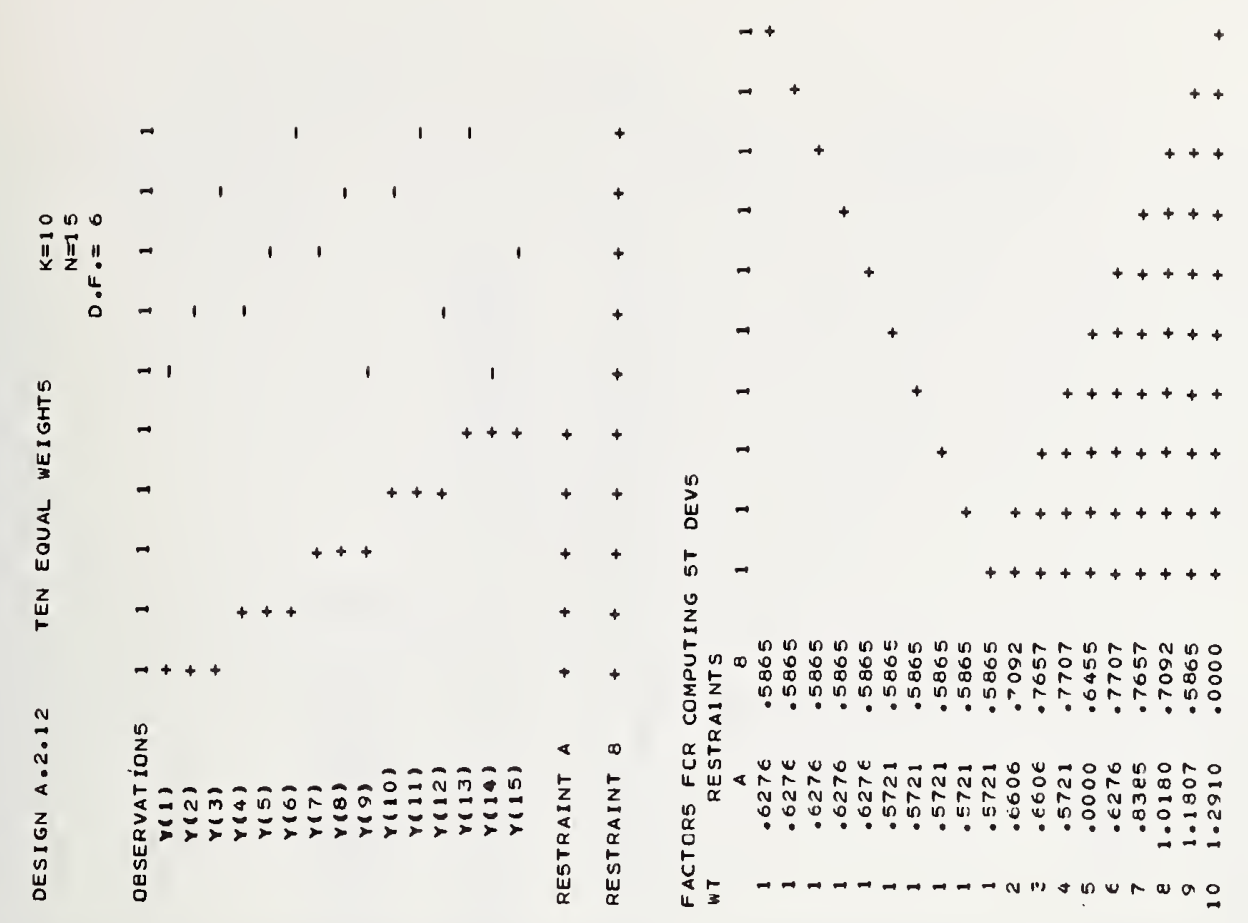

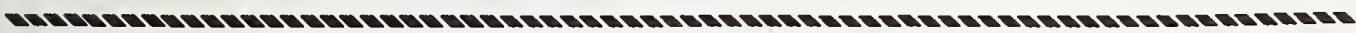

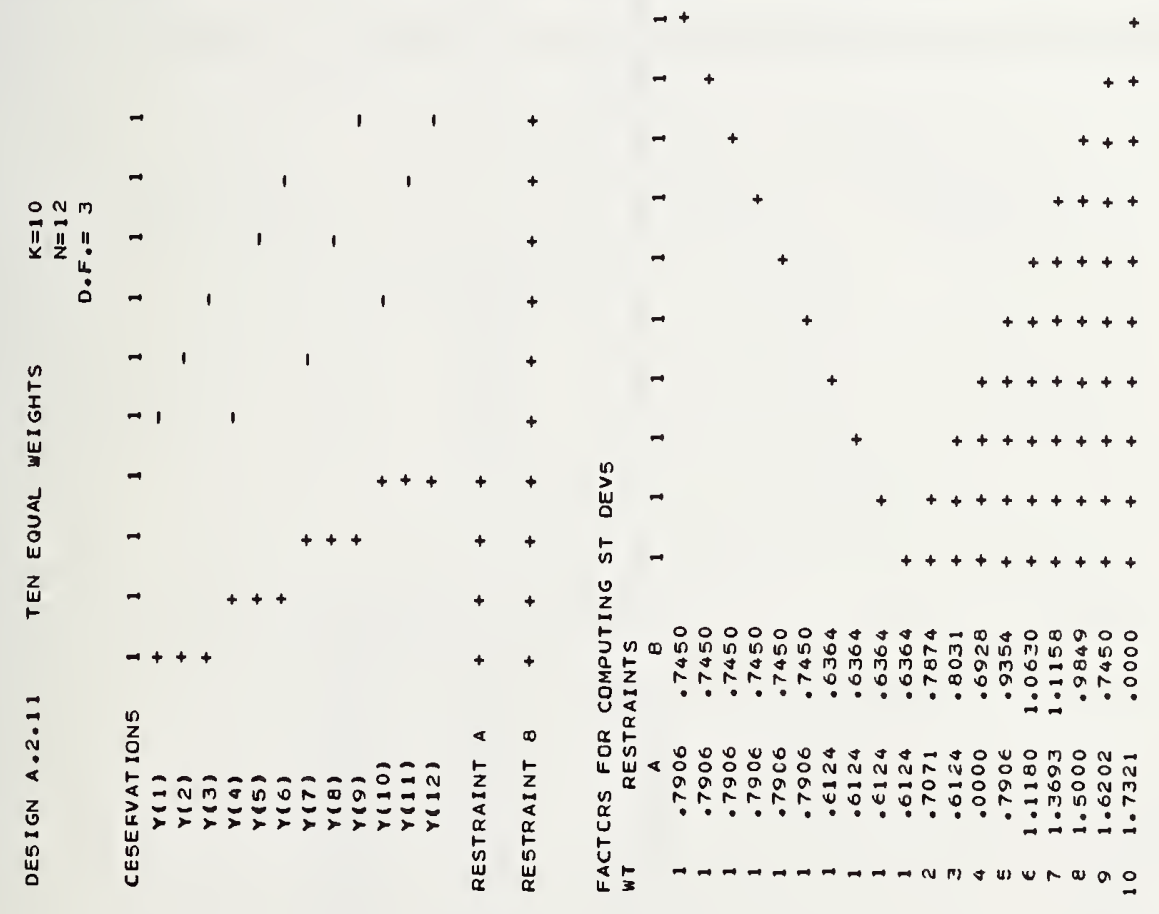




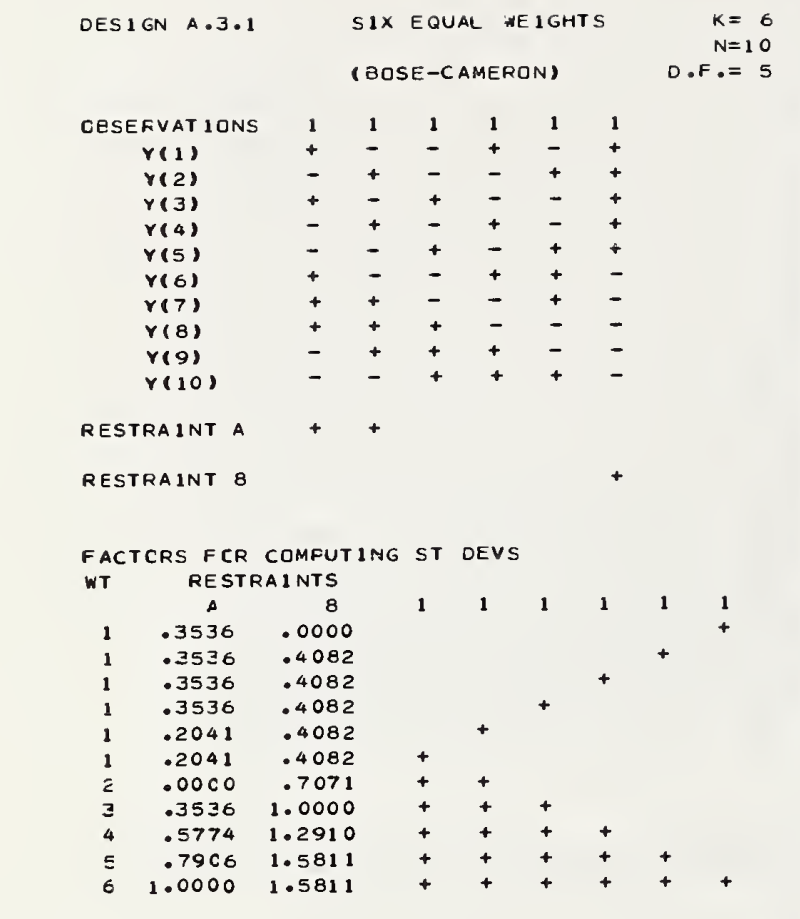

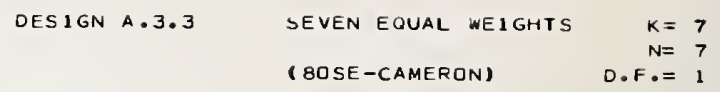

$\begin{array}{cccccccc}\text { C8SEFVATIONS } & 1 & 1 & 1 & 1 & 1 & 1 & 1 \\ Y(1) & + & + & - & + & + & - & \\ Y(2) & & + & + & - & + & - & - \\ Y(3) & - & & + & + & - & + & - \\ Y(4) & - & - & & + & + & - & + \\ Y(5) & + & - & - & & + & + & - \\ Y(6) & - & + & - & - & & + & + \\ Y(7) & + & - & + & - & - & & +\end{array}$

RESTFAINT A ++

RESTRA INT 8

FACTORS FCR COMPUTING ST DEVS

WT RESTRAINTS
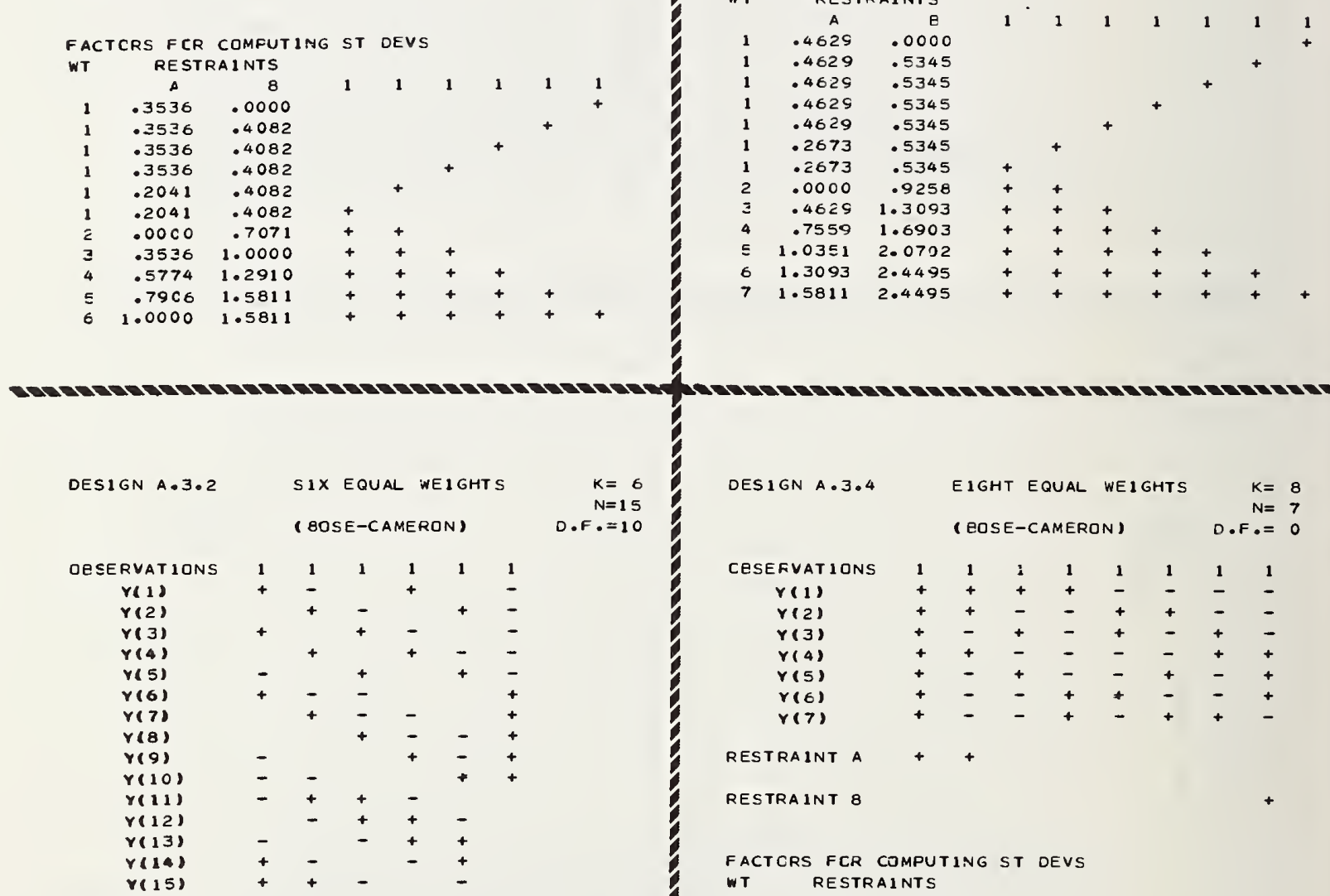

RESTRAINTA ++

RESTRAINT $B$

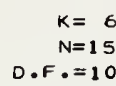

FACTOFS FOR COMPUTING ST DEVS

WT RESTRAINTS

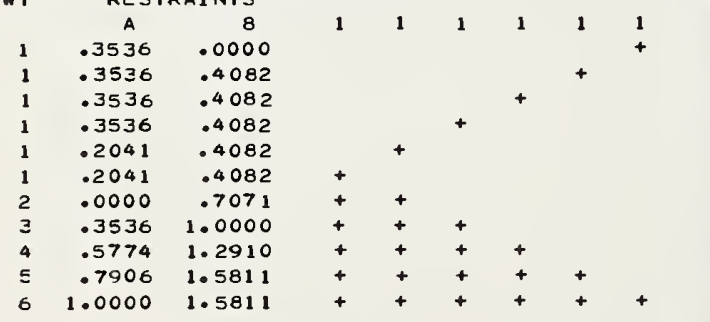

DESIGN A.3.4 EIGHT EQUAL WEIGHTS $\begin{array}{r}K=8 \\ N=7\end{array}$

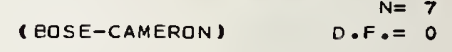

\begin{tabular}{|c|c|c|c|c|c|c|c|}
\hline CESEFVATIONS & 1 & 1 & : & 1 & 1 & 1 & 1 \\
\hline$r(1)$ & + & + & + & + & - & - & - \\
\hline$Y(2)$ & + & + & - & - & + & + & - \\
\hline$Y(3)$ & + & - & + & - & + & - & + \\
\hline$r(4)$ & + & + & - & - & - & - & + \\
\hline$Y(5)$ & + & - & + & - & - & + & - \\
\hline$r(6)$ & + & - & - & + & + & - & - \\
\hline$r(7)$ & + & - & - & + & - & + & + \\
\hline
\end{tabular}

RESTRAINT A

RESTRAINT 8

FACTCRS FCR COMPUTING ST DEVS

WT RESTRAINTS

\begin{tabular}{|c|c|c|c|c|c|c|c|c|}
\hline A & $B$ & 1 & 1 & 1 & 1 & 1 & 1 & 1 \\
\hline .4330 & .0000 & & & & & & & \\
\hline .4330 & .5000 & & & & & & & + \\
\hline .4330 & .5000 & & & & & & + & \\
\hline .4330 & .5000 & & & & & + & & \\
\hline $.43 \geq 0$ & .5000 & & & & + & & & \\
\hline .4330 & .5000 & & & + & & & & \\
\hline .2500 & .5000 & & + & & & & & \\
\hline .2500 & .5000 & + & & & & & & \\
\hline .0000 & .8660 & + & + & & & & & \\
\hline $.433 \mathrm{C}$ & 1.2247 & + & + & + & & & & \\
\hline .7071 & 1.5811 & + & + & + & + & & & \\
\hline .9682 & 1.9365 & + & + & + & + & + & & \\
\hline 1.2247 & 2.2913 & + & + & + & + & + & + & \\
\hline 1.4790 & E. 6458 & + & + & + & + & + & + & + \\
\hline 1.7321 & 2.6458 & + & + & + & + & + & + & + \\
\hline
\end{tabular}




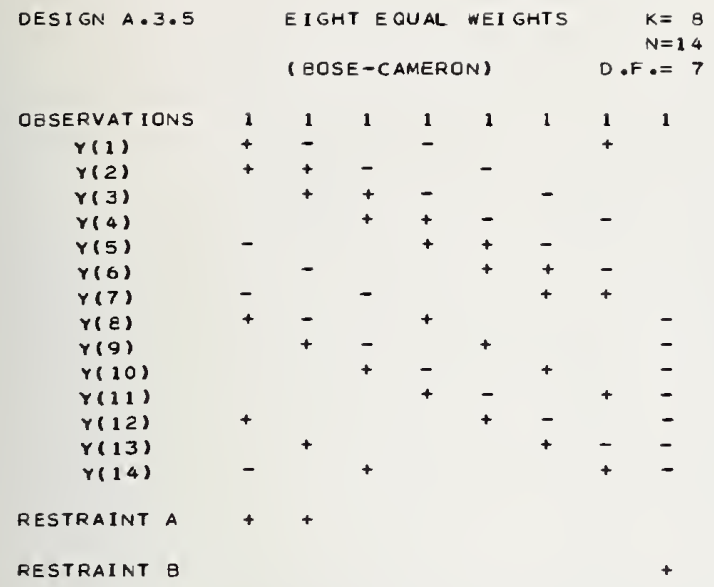

\begin{tabular}{|c|c|c|c|c|c|c|c|c|c|}
\hline & A & B & 1 & 1 & 1 & 1 & 1 & 1 & 1 \\
\hline 1 & .4330 & .0000 & & & & & & & \\
\hline 1 & .4330 & .5000 & & & & & & & + \\
\hline i & .4330 & .5000 & & & & & & + & \\
\hline 1 & .4330 & .5000 & & & & & + & & \\
\hline 1 & .4330 & .5000 & & & & + & & & \\
\hline 1 & .4320 & .5000 & & & + & & & & \\
\hline 1 & .2500 & .5000 & & + & & & & & \\
\hline$i$ & .2500 & .5000 & + & & & & & & \\
\hline $\bar{c}$ & $.00 \mathrm{CC}$ & .8660 & + & + & & & & & \\
\hline$\exists$ & .4330 & 1.2247 & + & + & + & & & & \\
\hline 4 & .7071 & 1.5811 & + & + & + & + & & & \\
\hline 5 & .9682 & 1.9365 & + & + & + & + & + & & \\
\hline$\epsilon$ & 1.2247 & 2.2913 & + & + & + & + & + & + & \\
\hline 7 & 1.4790 & $2.645 \mathrm{e}$ & + & + & + & + & + & + & + \\
\hline$\varepsilon$ & 1.7321 & 2.6458 & + & + & + & + & + & + & + \\
\hline
\end{tabular}




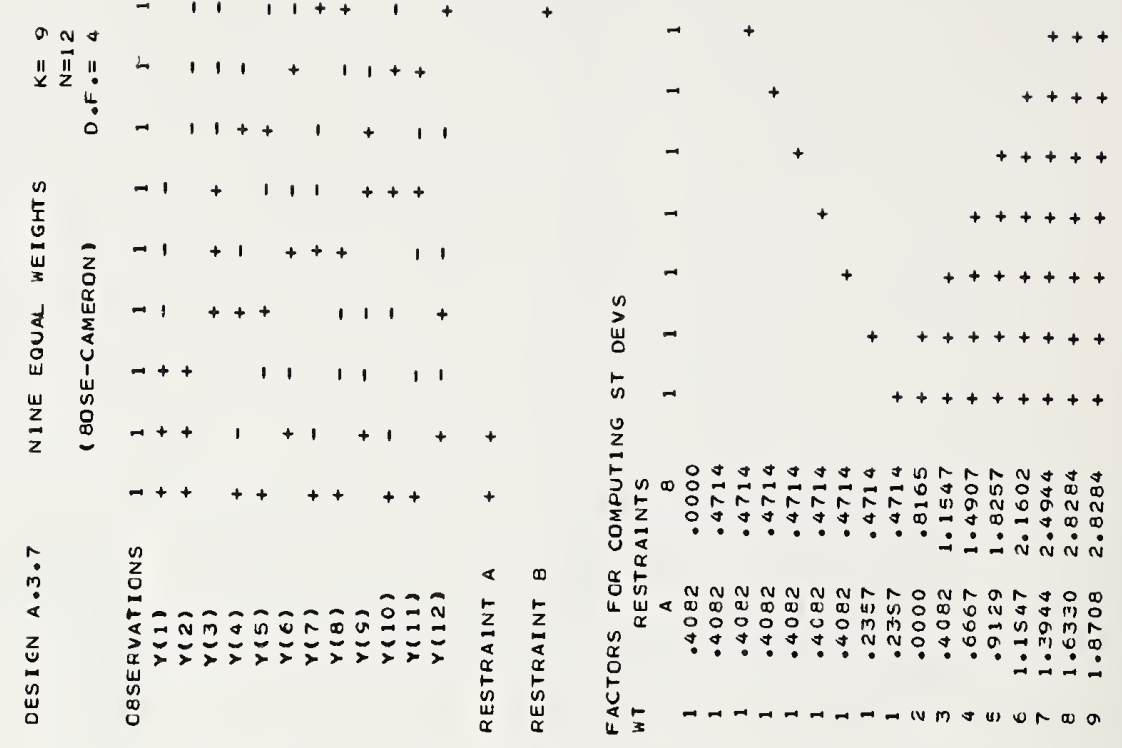

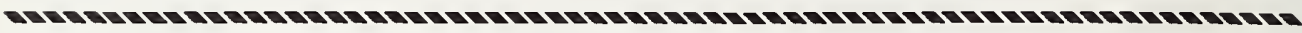

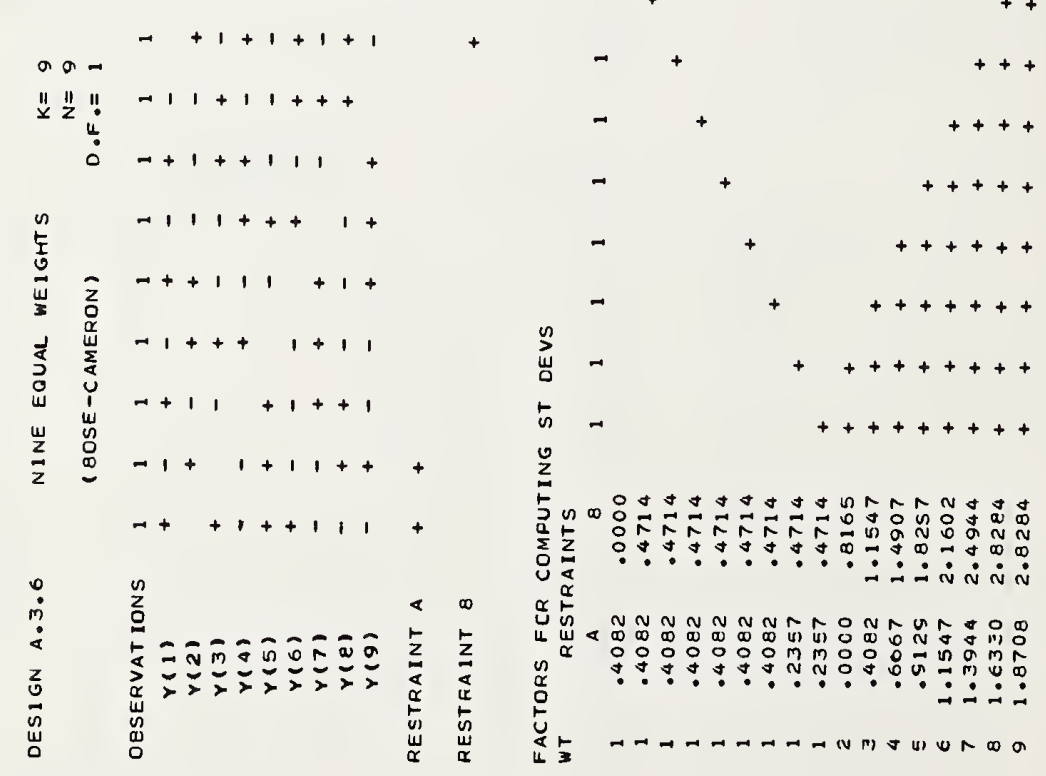



$\begin{array}{llr}2.1 .1 .1 & K=4 \\ & \text { (HAYFORD) } & N=6 \\ & \text { D.F. }=3\end{array}$

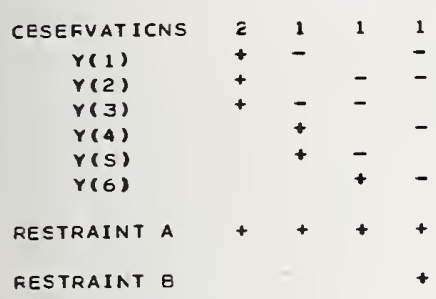

FACTORS FOR COMPUTING ST DEVS WT RESTRAINTS

\begin{tabular}{|c|c|c|c|c|c|c|}
\hline$T$ & $R E \subseteq T$ & AINTS & & & & \\
\hline & A & B & 2 & 1 & 1 & 1 \\
\hline 1 & .4243 & .0000 & & & & + \\
\hline 1 & .4243 & .7071 & & & + & \\
\hline 1 & .4243 & .7071 & & + & & \\
\hline $\bar{\varepsilon}$ & - $34 \in 4$ & 1.0000 & + & & & \\
\hline 3 & .4650 & 1.5811 & + & + & & \\
\hline 4 & $.424 \Xi$ & $2 \cdot 1213$ & + & + & + & \\
\hline$\leq$ & .0000 & 2.1213 & + & + & + & + \\
\hline
\end{tabular}

DESIGN $8.3 \quad 2,2,1,1 \quad K=4$

$N=6$ $D \cdot F \cdot=3$

$\begin{array}{lllll}\text { OESERVATIONS } & 2 & 2 & 1 & 1 \\ Y(1) & + & - & + & - \\ Y(2) & + & - & - & + \\ Y(3) & + & - & & \\ Y(4) & + & & - & - \\ Y(S) & & + & - & - \\ Y(E) & & & + & -\end{array}$

RESTRAINTA ++

RESTRAINT B

FACTORS FCR COMPUTING ST DEVS

WT RESTRAINTS

$\begin{array}{cccccc}\text { A } & 8 & 2 & 2 & 1 & 1 \\ .4564 & .0000 & & & & + \\ .4564 & .5774 & & & + & \\ .2672 & .9512 & & + & & \\ .2673 & .9512 & + & & & \\ .5289 & 1.3801 & + & & + & \\ .0000 & 1.8257 & + & + & & \\ .4564 & 2.2361 & + & + & + & \\ .7071 & 2.2361 & + & + & + & +\end{array}$

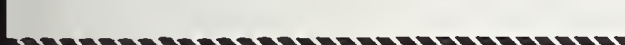

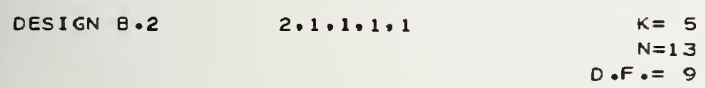

$\begin{array}{cc}A & B \\ .3347 & .0000 \\ .2683 & .4472 \\ .2683 & .4472 \\ .2683 & .4472 \\ .2191 & .6325 \\ .2966 & 1.0000 \\ .2683 & 1.3416 \\ .0000 & 1.6733 \\ .3347 & 1.6733\end{array}$

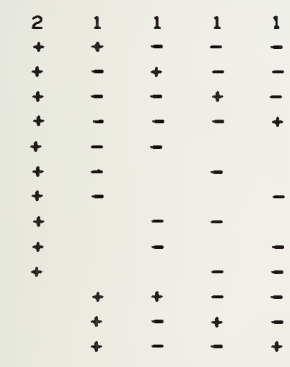

$\begin{array}{lllll}2 & 1 & 1 & 1 & 1\end{array}$

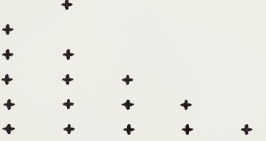

DES IGN $8 \cdot 4$

$$
2 \cdot 2 \cdot 1 \cdot 1 \cdot 1
$$

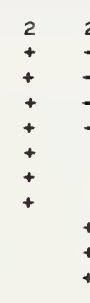

RESTRAINT A

RESTRAINT 8

FACTORS FOR COMPUTING ST DEVS

WT RESTRAINTS

$\begin{array}{ccccccc}A & B & 2 & 2 & 1 & 1 & 1 \\ .4382 & .0000 & & & & & + \\ .4382 & .6325 & & & & + & \\ .3347 & .6325 & & & + & \\ .2710 & .6634 & & + & & \\ .2710 & .8634 & + & & & \\ .271 C & 1.3548 & + & & + & \\ .3347 & 1.6733 & + & + & & \\ .0000 & 2.1909 & + & + & + & \\ .4382 & 2.6833 & + & + & + & + \\ .6066 & 2.6833 & + & + & + & +\end{array}$




\begin{tabular}{|c|c|c|c|c|c|c|}
\hline DESIGA 8.5 & & 2,2 & , 1 &, 1 & & \\
\hline OESER VAT I ONS & 2 & 2 & 1 & 1 & 1 & 1 \\
\hline$Y(1)$ & + & + & - & - & - & - \\
\hline$r(2)$ & + & - & + & + & - & - \\
\hline$Y(3)$ & + & - & + & - & + & - \\
\hline$r(4)$ & + & - & + & - & - & + \\
\hline$r(5)$ & + & - & - & + & + & - \\
\hline$Y(6)$ & + & - & - & + & - & + \\
\hline$Y(7)$ & + & - & - & - & + & + \\
\hline$Y(8)$ & + & & + & - & - & - \\
\hline$r(9)$ & + & & - & + & - & - \\
\hline$Y(10)$ & & + & - & - & + & - \\
\hline$Y(11)$ & & + & - & - & + & + \\
\hline$Y(12)$ & + & & - & - & + & - \\
\hline$Y(13)$ & + & & - & - & - & + \\
\hline$Y(14)$ & & + & + & - & - & - \\
\hline$Y(15)$ & & + & - & + & - & - \\
\hline
\end{tabular}

RESTRAINTA + + + +

RESTRAINT B

FACTCRS FCR COMPUTING ST DEVS WT RESTRAINTS

$\begin{array}{cccccccc}A & 0 & 2 & 2 & 1 & 1 & 1 & 1 \\ .2614 & .0000 & & & & & & + \\ .2614 & .3536 & & & & & + & \\ .2614 & .3536 & & & & + & \\ .2082 & .3536 & & & + & & \\ .2051 & .5456 & & + & & & \\ .2051 & .5456 & + & & & & \\ .2051 & .8229 & + & & + & & \\ .2082 & 1.0408 & + & + & & & \\ .0000 & 1.3070 & + & + & + & & \\ .2614 & 1.5679 & + & + & + & + & \\ .3851 & 1.8257 & + & + & + & + & + & \\ .4899 & 1.8257 & + & + & + & + & + & +\end{array}$

\begin{tabular}{|c|c|c|c|c|c|c|c|}
\hline OESI GN $B . \epsilon$ & & 2. & 1 & 1.1 & & & \\
\hline OBSERVATIONS & 2 & 2 & 1 & 1 & 1 & 1 & 1 \\
\hline$V(1)$ & + & - & + & - & - & + & \\
\hline$r(2)$ & + & - & & + & - & - & + \\
\hline$Y(3)$ & + & - & + & & + & - & - \\
\hline$Y(4)$ & + & - & - & + & & + & - \\
\hline$Y(5)$ & + & - & - & - & + & & + \\
\hline$Y(6)$ & + & + & - & - & - & - & \\
\hline$r(7)$ & + & + & - & - & - & & - \\
\hline$Y(B)$ & + & + & - & - & & - & - \\
\hline$r(9)$ & + & + & - & & - & - & - \\
\hline$Y(10)$ & + & + & & - & - & - & 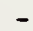 \\
\hline
\end{tabular}

DESIGN 8.7

$$
2,2,1,1,1,1,1,1
$$

$k=8$ $N=16$ D.F. $=10$

DESERVAT IONS $Y(1)$

$Y(2)$

$Y(3)$

$Y(4)$

$Y(5)$

$Y(\in)$

$Y(7)$

$Y(8)$

$Y(9)$

Y (1 10$)$

$Y(11)$

$Y(12)$

$Y(13)$

$Y(14)$

$Y(15)$

$r(16)$

PESTFAINT A

RESTRAINT B

FACTORS FCR COMPUTING ST DEVS

WT FESTRAINTS

$$
\begin{array}{cc}
A & P \\
.2550 & .00 C 0 \\
.2550 & .3536 \\
.2550 & .3536 \\
.2550 & .3536 \\
.2550 & .3536 \\
.20 C 0 & .3536 \\
.1871 & .5244 \\
.1871 & .5244 \\
.1971 & .8062 \\
.2000 & 1.0070 \\
.0 C C C & 1.2749 \\
.2550 & i .5411 \\
.3674 & 1.802 B \\
.4583 & . .0610 \\
.5385 & 2.0184 \\
.6124 & 2.3194
\end{array}
$$

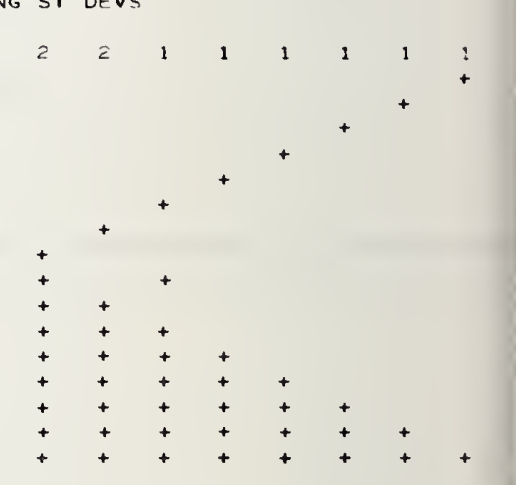

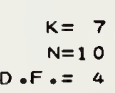

$F .=4$

RESTFAINT A

RESTRAINT B

FACTCRS FCR COMFUTING ST DEVS

WT RESTRAINTS

$\begin{array}{cc}A & 0 \\ .4000 & .0000 \\ .4000 & .5774 \\ .4000 & .5774 \\ .4000 & .5774 \\ .3055 & .5774 \\ .2708 & .7958 \\ .2708 & .7958 \\ .2708 & 1.2780 \\ .3055 & 1.5275 \\ .0000 & 2.0000 \\ .4000 & 2.4495 \\ .5538 & 2.8868 \\ .6633 & 3.3166 \\ .7483 & 3.3166\end{array}$

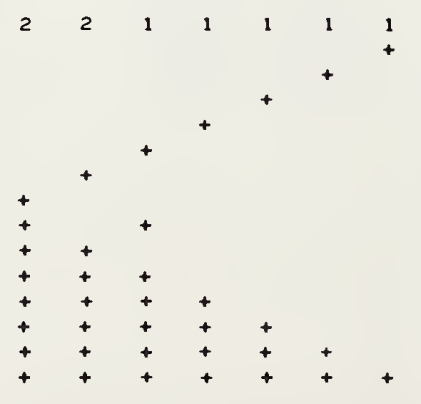




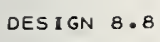

CESERVATIDNS

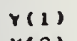

$Y(2)$

$Y(3)$

Y(4)

$Y(5)$

$r(6)$

$Y(7)$

$Y(8)$

$Y(9)$

$Y(10)$

$Y(11)$

$r(12)$

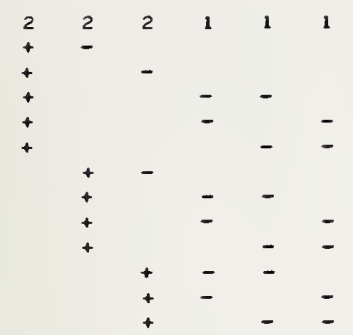

RESTRAINT A + +

FESTRAINT 8

FACTORS FCR COMPUTING ST DEVS

WT RESTRAINTS

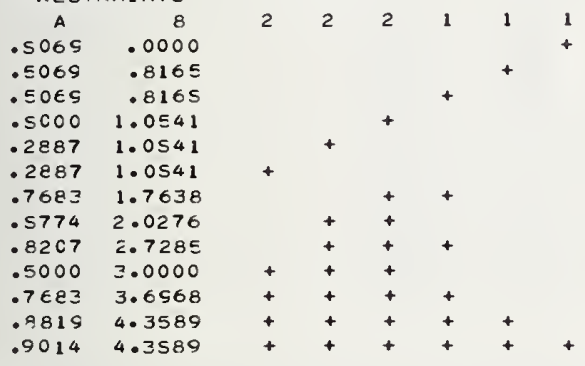

$.9014 \quad 4.3589$
DESIGN 8.10

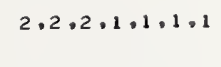

$K=7$
$N=12$ D.F. $=6$

OESERVAT ICNS

$Y(1)$

$r(2)$

$r(3)$

$r(4)$

$Y(5)$

$Y(6)$

$Y(7)$

$r(8)$

$Y(9)$

$Y(10)$

$Y(11)$

$r(12)$

REST'RA INT A

RESTRAINT 8

FACTOFS FCR CDMPUTING ST DEVS

WT RESTRAINTS

$\begin{array}{cc}\text { A } & \text { 8 } \\ .4183 & .0000 \\ .4183 & .5774 \\ .4183 & .5774 \\ .4183 & .5774 \\ .5477 & .8944 \\ .3162 & .8544 \\ .3162 & .8944 \\ .7583 & 1.3416 \\ .6325 & 1.6737 \\ .8216 & 2.1134 \\ .5477 & 2.4495 \\ .7583 & 2.8868 \\ .9309 & 3.3166 \\ 1.0840 & 3.7417 \\ 1.2247 & 3.7417\end{array}$

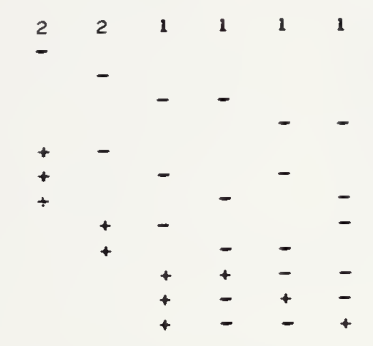

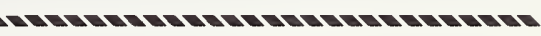

DES IGN $8 \cdot 9$

$2 \cdot 2 \cdot 2 \cdot 1 \cdot 1,1$

$K=6$ $N=15$ $D, F \cdot=10$

CESERVAT 1 CNS

$Y(1)$

$Y(2)$

$r(3)$

$\checkmark(4)$

$r(5)$

$Y(6)$

$Y(7)$

$Y(8)$

$r(9)$

$r(10)$

$Y(11)$

$Y(12)$

$r(13)$

$r(14)$

$Y(15)$

RESTRAINT A + *

RESTRAINT B

FACTDRS FCR CDMPUTING ST DEVS RESTRAINTS

\begin{tabular}{|c|c|c|c|c|c|c|}
\hline$A$ & 8 & 2 & 2 & 2 & 1 & 1 \\
\hline .3815 & .0000 & & & & & \\
\hline .3819 & .5774 & & & & & + \\
\hline .3819 & .5774 & & & & 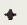 & \\
\hline $.500 \mathrm{C}$ & - $21 \in S$ & & & + & & \\
\hline .2887 & .2165 & & + & & & \\
\hline - ¿E\& 7 & - $21 \in 5$ & + & & & & \\
\hline .6922 & 1.2910 & & & + & + & \\
\hline .5774 & 1.5275 & & + & + & & \\
\hline .7500 & 2.0000 & & + & + & + & \\
\hline .5000 & $2 \cdot 2361$ & + & + & + & & \\
\hline $.6 \subseteq 22$ & 2.7080 & + & + & + & + & \\
\hline - $21 \in 5$ & $2 \cdot 1 \in 2 Z$ & + & + & + & + & + \\
\hline .9014 & 3.1623 & + & + & + & + & + \\
\hline
\end{tabular}

DES $1 \mathrm{GN}$ E.11
$K=6$ D. $F=6$

CESEFVAT IONS

$Y(1)$

$r(2)$

$\checkmark(3)$

$\checkmark(4)$

$Y(5)$

$r(6)$

$Y(7)$

$Y(8)$

$r(9)$

Y(10)

Y ( 111$)$

RESTRAINTA + +

RESTRAINT 8

FACTORS FOR COMPUTING ST DEVS

NT RESTRAINTS

$\begin{array}{cccccccc}\text { A } & 8 & 2 & 2 & 2 & 2 & 1 & 1 \\ .5701 & .0000 & & & & & & + \\ .5701 & 1.0000 & & & & & + & \\ .5477 & 1.1832 & & & & + & \\ .5477 & 1.1832 & & & + & & \\ .3162 & 1.1832 & & + & & & \\ .3162 & 1.1832 & + & & & & \\ .8515 & 2.0976 & & & & + & + \\ .8944 & 2.2804 & & & + & + & \\ 1.1511 & 3.1937 & & & + & + & + \\ .9487 & 3.3764 & & + & + & + & \\ 1.1937 & 4.2895 & & + & + & + & + \\ .8944 & 4.4721 & + & + & + & + & \\ 1.1511 & 5.3852 & + & + & + & + & + \\ 1.2247 & 5.3852 & + & + & + & + & + & +\end{array}$




\begin{tabular}{|c|c|c|c|c|c|}
\hline \multirow{2}{*}{ OES $1 \mathrm{GNC} \cdot 1$} & \multicolumn{5}{|c|}{$5 \cdot 3 \cdot 2 \cdot 1 \cdot 1$} \\
\hline & \multicolumn{4}{|c|}{ (HAYFORD) } & \\
\hline OESEFVAT IONS & 5 & 3 & 2 & 1 & 1 \\
\hline$Y(1)$ & + & - & - & + & - \\
\hline$r(2)$ & + & - & - & - & + \\
\hline$v(3)$ & + & - & - & & \\
\hline$r(4)$ & + & - & & - & - \\
\hline$r(5)$ & & + & - & - & \\
\hline$Y(6)$ & & + & - & & 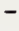 \\
\hline$Y(7)$ & & & + & - & - \\
\hline$Y(A)$ & & & & + & \\
\hline
\end{tabular}

RESTRAINTA + + +

RESTRAINT 8

FACTORS FOR COMPUTING $5 T$ DEVS

$W T$
1
1
2
3
4
5
6
7
8
5
10

\begin{tabular}{|c|c|c|c|c|c|}
\hline \multicolumn{2}{|c|}{ RESTRAINTS } & \multirow[b]{2}{*}{5} & \multirow[b]{2}{*}{3} & \multirow[b]{2}{*}{2} & \multirow[b]{2}{*}{1} \\
\hline A & B & & & & \\
\hline .4175 & .0000 & & & & \\
\hline .4175 & .5345 & & & & + \\
\hline .3546 & .9258 & & & + & \\
\hline .3338 & 1.3093 & & + & & \\
\hline .5237 & 1.6903 & & + & & + \\
\hline .2673 & 2.0702 & + & & & \\
\hline .5237 & 2.4495 & + & & & + \\
\hline .2338 & 2.9277 & + & & + & \\
\hline $.354 \epsilon$ & 3.3381 & + & + & & \\
\hline .5632 & 3.7033 & + & + & & + \\
\hline .0000 & 4.1748 & + & + & + & \\
\hline
\end{tabular}

DESIGN C.3

$$
5 \cdot 3 \cdot 2 \cdot 2 \cdot 1 \cdot 1
$$

OESERVAT 1 ONS

$\begin{array}{lllllll}R V A T 1 O N S & 5 & 3 & 2 & 2 & 1 & 1 \\ Y(1) & + & - & + & - & - & - \\ Y(2) & + & - & - & + & - & - \\ Y(3) & + & - & - & - & + & + \\ Y(4) & + & - & - & & + & - \\ Y(5) & + & - & & - & + & - \\ Y(6) & + & - & - & & - & + \\ Y(7) & + & - & & - & - & + \\ Y(8) & + & - & & & - & - \\ Y(9) & + & & - & - & - & \\ Y(10) & + & & - & - & & - \\ Y(11) & & & + & - & & \end{array}$

RESTRAINT A

RESTRA1NT 8

FACTCRS FCR COMPUTING $5 T$ DEVS

WT RESTRAINTS

$\begin{array}{cc}A & 8 \\ .3592 & .0000 \\ .3552 & .4714 \\ .4259 & .7553 \\ .3625 & .7553 \\ .3835 & 1.2536 \\ .6116 & 1.1123 \\ .6130 & 1.4254 \\ .2266 & 1.7412 \\ .4790 & 2.0893 \\ .3835 & 2.4199 \\ .3625 & 2.9493 \\ .4711 & 3.2708 \\ .0000 & 3.5922\end{array}$

\begin{tabular}{|c|c|c|c|c|c|c|}
\hline CES I GN C.2 & & 5. & 2. & 1. & & \\
\hline CBSERVAT IONS & 5 & 3 & 2 & 1 & 1 & 1 \\
\hline$r(1)$ & + & - & $\underline{-}$ & + & - & \\
\hline$Y(2)$ & + & - & - & & + & - \\
\hline$r(3)$ & + & - & - & - & & + \\
\hline$Y(4)$ & + & - & - & & & \\
\hline$Y(5)$ & + & & - & - & - & - \\
\hline$V(6)$ & & + & - & + & - & - \\
\hline$Y(7)$ & & + & - & - & + & - \\
\hline$r(8)$ & & + & - & - & - & + \\
\hline$Y(9)$ & & & + & - & - & \\
\hline$Y(10)$ & & & + & - & & - \\
\hline$r(11)$ & & & + & & - & - \\
\hline
\end{tabular}

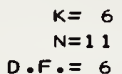

RESTRAINTA +++

RESTRAINT 8

FACTORS FOR COMPUTING $5 T$ DEVS WT RESTRAINTS

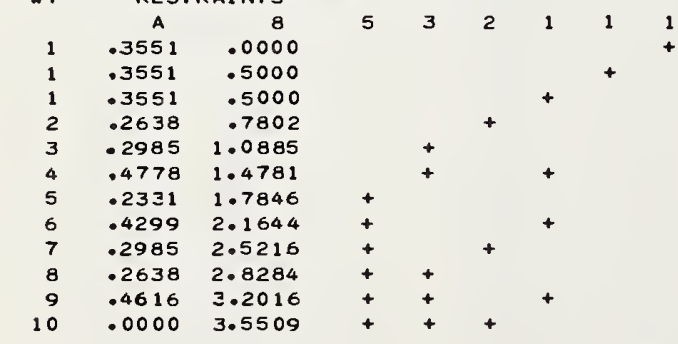

\section{gen}

DE51GN C.4

$5 \cdot 3 \cdot 2 \cdot 2 \cdot 1 \cdot 1$

$K=6$

D.F.: $=7$

CBSEFVAT 1 CNS

$r(1)$
$r(2)$
$r(3)$
$r(4)$
$r(5)$
$r(6)$
$r(7)$
$Y(8)$
$r(9)$
$r(10)$
$r(11)$
$r(12)$

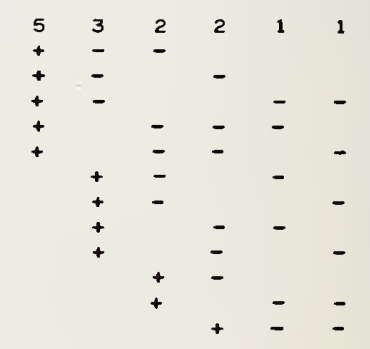

RESTRAINT A

RESTRAINT 8

FAC TORS FCR COMFUTING $5 T$ DEVS

WT RESTRAINTS

$$
\begin{array}{cc}
A & 8 \\
.4796 & .0000 \\
.4756 & .8165 \\
.4055 & 1.0541 \\
.3127 & 1.0541 \\
.2848 & 1.4530 \\
.6173 & 1.7638 \\
.4372 & 2.0276 \\
.2887 & 2.3805 \\
.5888 & 3.1091 \\
.5608 & 3.3830 \\
.3127 & 3.8006 \\
.6119 & 4.5216
\end{array}
$$
$.0000 \quad 4.7958$ 


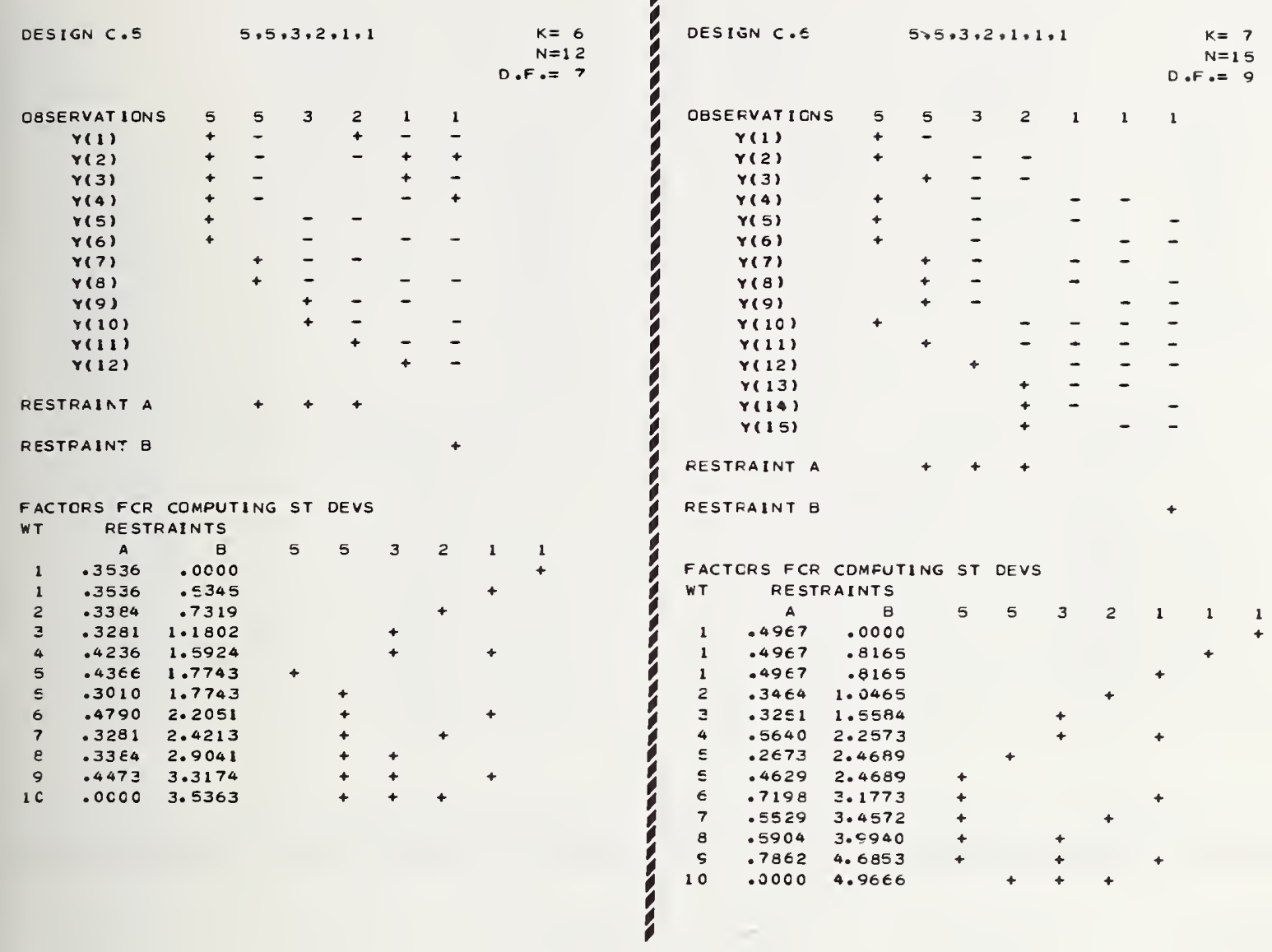




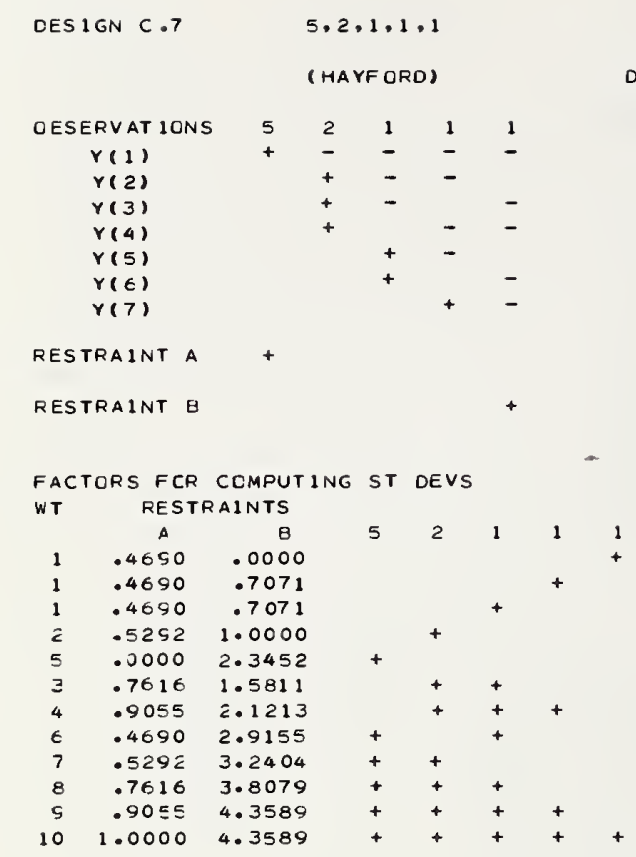

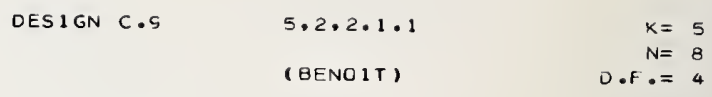

$\begin{array}{llllll}\text { CESERVAT ICNS } & 5 & 2 & 2 & 1 & 1 \\ Y(1) & + & - & - & - & \\ Y(2) & + & - & - & & - \\ Y(3) & & + & - & + & - \\ Y(4) & & + & - & - & + \\ Y(5) & & + & - & & \\ Y(6) & & + & & - & - \\ Y(7) & & & + & - & - \\ Y(8) & & & & + & -\end{array}$

RESTRAINT A

RESTRAINT B

FACTCRS FOR COMPUTING ST DEVS

WT RESTRAINTS

$\begin{array}{cc}A & \Xi \\ .4140 & .0000 \\ .3780 & .5345 \\ .3381 & .9258 \\ .3381 & .9258 \\ .4140 & 1.3093 \\ .4140 & 1.7728 \\ .3780 & 2.0702 \\ .4140 & 2.4495 \\ .4140 & 2.9277 \\ .3381 & 3.2950 \\ .3780 & 3.7796 \\ .0300 & 4.1404\end{array}$

4.1404

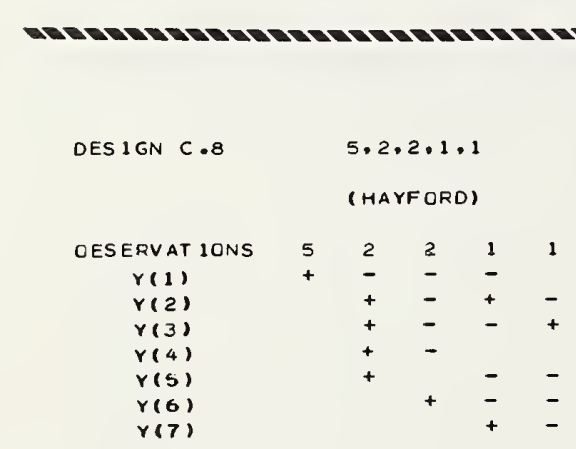

RESTRAINTA ++++

FESTRAINT B

FACTORS FCR COMPUTING ST DEVS WT RESTRAINTS

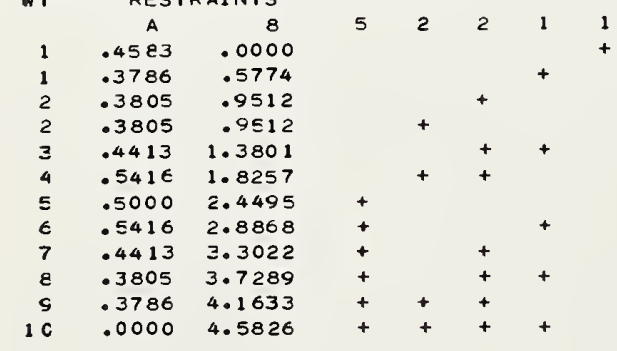

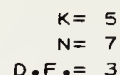

DES IGN C.10

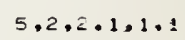

$K=5$

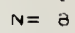

D.F. $=3$

OESERVATIONS

$$
\begin{aligned}
& r(1) \\
& r(2) \\
& r(3) \\
& r(4) \\
& r(5) \\
& r(6) \\
& r(7) \\
& r(8)
\end{aligned}
$$

FESTRAINT A

RESTRAINT B

FACTORS FCR COMPUTING ST CEVS WT RESTRAINTS

$\begin{array}{cc}A & E \\ .4645 & .0000 \\ .4645 & .5345 \\ .4326 & .5345 \\ .3854 & 1.1339 \\ .3854 & 1.1339 \\ .3761 & 1.4639 \\ .5555 & 2.2039 \\ .3273 & 2.1712 \\ .5555 & 2.5355 \\ .3761 & 3.2514 \\ .3654 & 3.5457 \\ .4326 & 4.3200 \\ .0000 & 4.6445\end{array}$




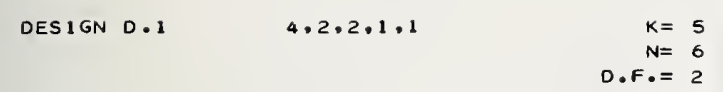

$\begin{array}{llllll}\text { CBSEFVATIONS } & 4 & 2 & 2 & 1 & 1 \\ Y(1) & + & - & - & + & - \\ Y(2) & + & - & - & - & + \\ Y(3) & + & - & & - & - \\ Y(4) & + & & - & - & - \\ Y(5) & & + & - & + & - \\ Y(6) & & + & - & - & +\end{array}$

RESTRAINTA +

RESTRAINT B

FACTORS FCR COMPUTING ST DEVS

WT RESTRAINTS

$\begin{array}{ccccccc}\text { A } & 0 & 4 & 2 & 2 & 1 & 1 \\ .4677 & .0000 & & & & & + \\ .4677 & .5000 & & & & + & \\ .4743 & 1.1619 & & & + & & \\ .4743 & 1.1619 & & + & & & \\ .5646 & 1.4491 & & & + & + \\ .0000 & 1.8708 & + & & & & \\ .4677 & 2.1794 & + & & & + \\ .4743 & 2.9749 & + & & + & \\ .5646 & 3.2558 & + & & + & + \\ .7071 & 4.0620 & + & + & + & \\ .6847 & 4.3301 & + & + & + & + \\ .7906 & 4.3301 & + & + & + & + & +\end{array}$

DESIGN 0.3

$4 \cdot 2 \cdot 2 \cdot 1 \cdot 1$

(BENDIT)

$k=5$

$\mathrm{N}=11$

CESERVATIONS

$\begin{array}{llllll}\text { EVATIONS } & 4 & 2 & 2 & 1 & 1 \\ Y(1) & + & - & - & + & - \\ Y(2) & + & - & - & - & + \\ Y(3) & + & - & - & & \\ Y(4) & + & - & & - & - \\ Y(5) & + & & - & - & - \\ Y(6) & & + & - & + & - \\ Y(7) & & + & - & - & + \\ Y(8) & & + & - & & \\ Y(9) & & + & & - & - \\ Y(10) & & & + & - & - \\ Y(11) & & & & + & -\end{array}$

RESTRAINT A

RESTRAINT B

FACTCRS FOR COMPUTING ST DEVS

WT RESTRAINTS

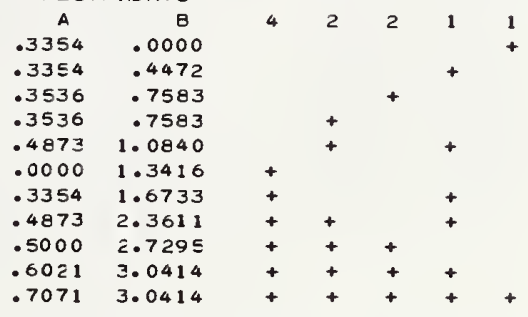

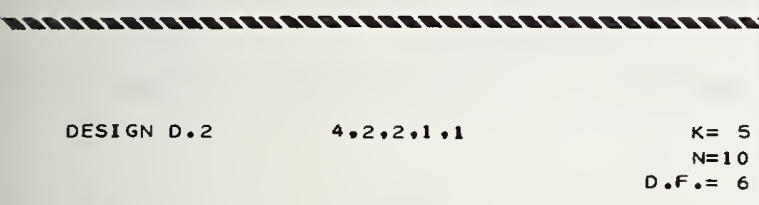

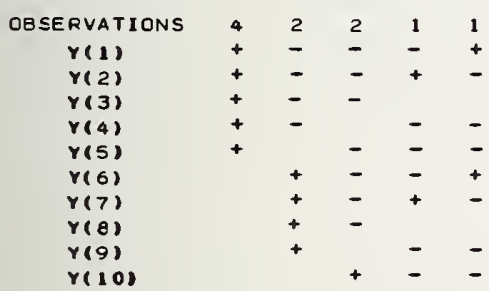

FESTRAINT A +

RESTRAINT B

FACTORS FCR COMPUTING ST DEVS

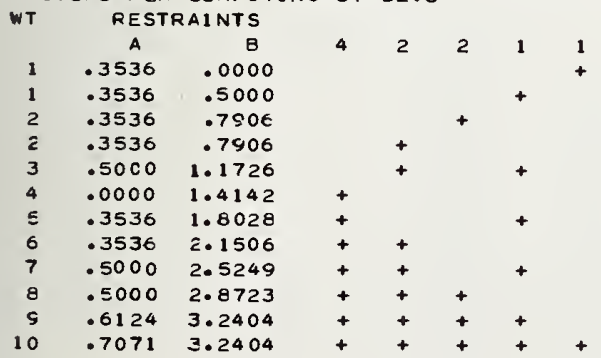

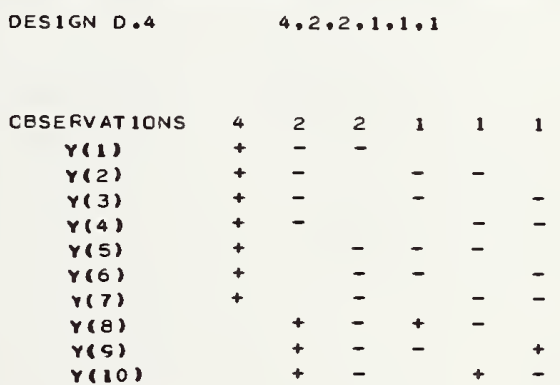

RESTRAINTA +

RESTRAINT B

FACTORS FOR COMPUTING ST DEVS

WT RESTRAINTS

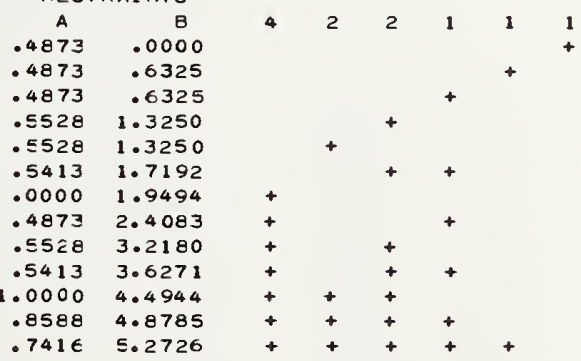


DESIGN D.S

$4 \cdot 4 \cdot 2 \cdot 1 \cdot 1$

(EENOIT)

DESERVAT IONS

$\begin{array}{llllll}\text { ERVATIONS } & 4 & 4 & 2 & 1 & 1 \\ Y(1) & + & - & + & - & - \\ Y(2) & + & - & - & + & + \\ Y(3) & + & - & & + & - \\ Y(4) & + & - & & - & + \\ Y(5) & + & - & & & \\ Y(6) & + & & - & - & - \\ Y(7) & & + & - & - & - \\ Y(8) & & & + & - & - \\ Y(9) & & & & + & -\end{array}$

RESTRAINT A

RESTRAINT B

FACTOFS FCR COMPUTING ST DEVS

WT RESTRAINTS

$$
\begin{array}{cr}
A & B \\
.3651 & .0000 \\
.3651 & .5774 \\
.3651 & .0165 \\
.5164 & 1.2910 \\
.28 C 7 & 1.4873 \\
.28 C 7 & 1.4873 \\
.46 C E & 1.0695 \\
.28 C 7 & 2.2088 \\
.4606 & 2.6855 \\
.3651 & 2.9439 \\
.5164 & 3.4157 \\
.0000 & 3.6515
\end{array}
$$

$K=5$
$N=9$

$\mathrm{D} \cdot \mathrm{F} \cdot=5$

DESIGN D. 7

$K=7$

$N=14$

D.F. $=8$

DBSERVATIONS

Y (1)

$r(2)$

$r(3)$

$r(4)$

$r(5)$

$r(6)$

$Y(7)$

$r(e)$

$r(9)$

$r(10)$

$Y\left(\begin{array}{lll}1 & 1\end{array}\right)$

$r(12)$

$Y(13)$

$r(14)$

RESTRAINT A

RESTRAINT B

FACTORS FOR COMPUTING ST DEVS

WT RESTRAINTS

$\begin{array}{cr}A & B \\ .4830 & .0000 \\ .4330 & .7071 \\ .4830 & .7071 \\ .4472 & 1.1547 \\ .3651 & 1.1547 \\ .5774 & 1.6833 \\ .3237 & 1.8898 \\ .3237 & 1.8898 \\ .6362 & 2.4540 \\ .5521 & 2.9841 \\ .7105 & 3.5220 \\ .3551 & 3.7417 \\ .7071 & 4.3012 \\ .0000 & 4.8305\end{array}$

DESIGN D. 8

\section{$4,3,2,1,1$}

(HAYFDRC)

$K=5$

$N=S$

D.F. $=4$

$\begin{array}{lllllll}\text { OBSERVATICNS } & 4 & 4 & 2 & 2 & 1 & 1 \\ Y(1) & + & - & + & - & + & - \\ Y(2) & + & - & + & - & - & + \\ Y(3) & + & - & - & + & & \\ Y(4) & + & - & + & & - & - \\ Y(5) & + & - & & - & + & + \\ Y(6) & + & & - & & - & - \\ Y(7) & + & & - & - & - & + \\ Y(8) & & + & & - & - & - \\ Y(9) & & + & - & - & + & -\end{array}$

RESTRAINTA ++

RESTRAINT B

FACTORS FGR COMPUTING ST DEVS WT RESTRAINTS

$\begin{array}{cc}\text { A } & \text { B } \\ .3578 & .2560 \\ .3578 & .2560 \\ .3907 & .6345 \\ .3907 & .6345 \\ .5211 & .6776 \\ .5211 & .6776 \\ .2195 & 1.0238 \\ .2195 & 1.0238 \\ .4476 & 1.0667 \\ .4476 & 1.0667 \\ .4058 & 1.5539 \\ .4058 & 1.5539 \\ .5547 & 1.5596 \\ .5547 & 1.5596 \\ .0000 & 2.0000\end{array}$

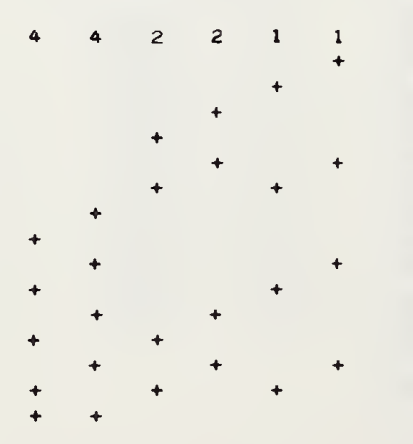

OBSERVAT I CNS

$$
\begin{aligned}
& r(1) \\
& Y(2) \\
& Y(3) \\
& r(4) \\
& Y(5) \\
& Y(6) \\
& r(7) \\
& Y(8)
\end{aligned}
$$$$
Y(8)
$$

RESTRAINT A

RESTRAINT B

FACTCFS FOR COMPUT ING ST DEVS

WT RESTRAINTS

$$
\begin{array}{cc}
A & B \\
.4275 & .0000 \\
.4390 & .6892 \\
.3950 & .9354 \\
.3532 & 1.2649 \\
.3146 & 1.6956 \\
.4677 & 2.2583 \\
.4677 & 2.1154 \\
.4231 & 2.5495 \\
.4180 & 2.9112 \\
.3950 & 3.4496 \\
.4390 & 3.7550 \\
.0000 & 4.2749
\end{array}
$$




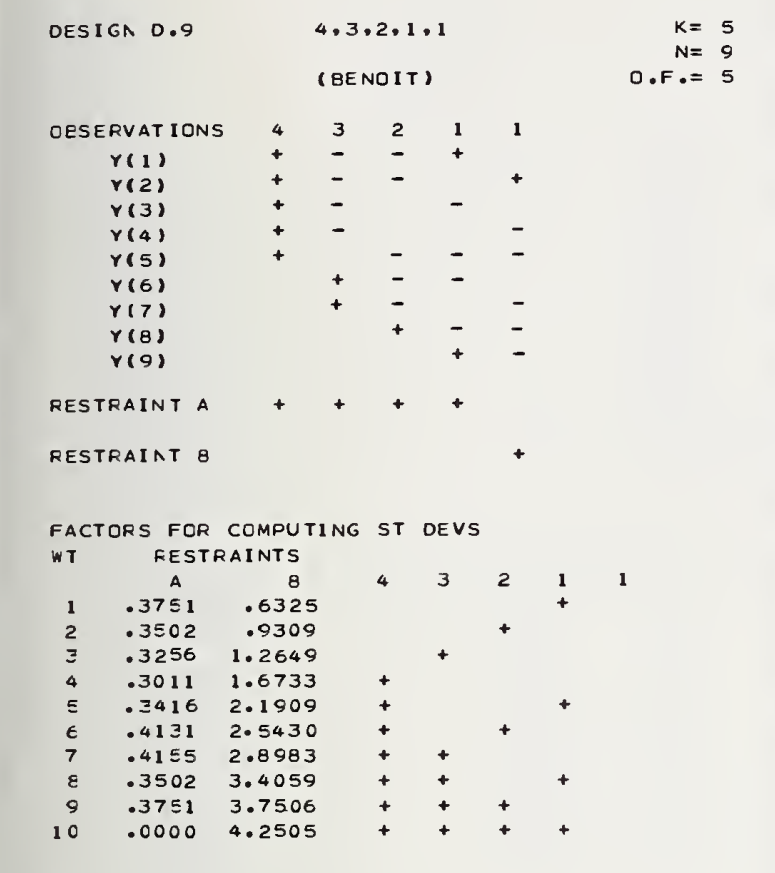

$\begin{array}{llr}\text { OESIGN 0.11 } & 10.5 .2 .1 .1 .1 & K=6 \\ & \text { (HAYFORO) } & 8 \\ & \text { D.F. }=3\end{array}$

$\begin{array}{lllllll}\text { CBSERVATIONS } & 10 & 5 & 2 & 1 & 1 & 1 \\ Y(1) & + & - & - & - & - & - \\ Y(2) & & + & - & - & - & - \\ Y(3) & & & + & - & - & \\ Y(4) & & & + & & - & - \\ Y(5) & & & + & - & & - \\ Y(6) & & & & + & - & \\ Y(7) & & & & + & & - \\ Y(8) & & & & & + & -\end{array}$

RESTRAINTA +

RESTFAINT 8

FACTCRS FCR COMPUTING ST OEVS

WT RESTRAINTS

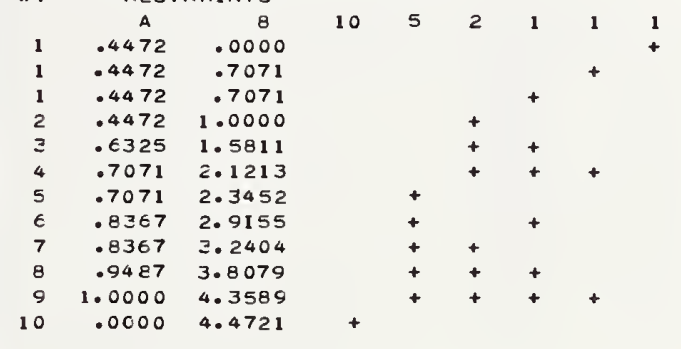

270

WT RESTRALNTS

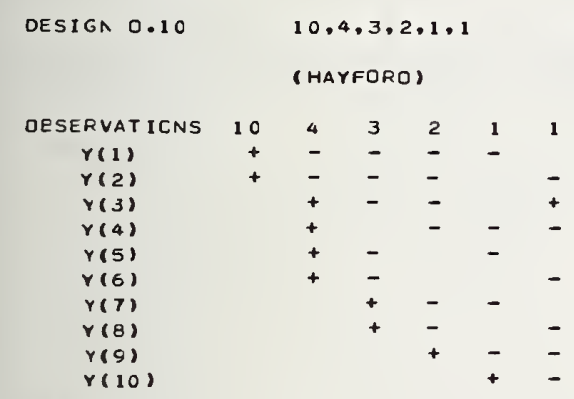

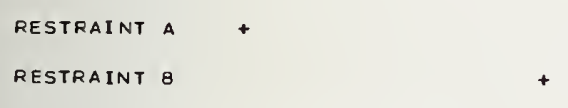

FACTORS FCR COMPUTING ST DEVS

$K=6$ $\mathrm{N}=10$ O.F. = 5

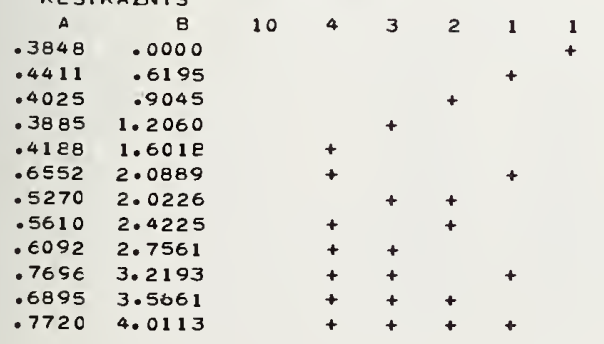

OESIGN 0.12

$10,5,2,2 \cdot 1,1$

$K=6$

(HAYFORD)

$F_{0}=3$

$\begin{array}{lllllll}\text { OESERVATIONS } & 10 & 5 & 2 & 2 & 1 & 1 \\ Y(1) & + & - & - & - & - & \\ Y(2) & & + & - & - & - & \\ Y(3) & & & + & - & + & - \\ Y(4) & & & + & - & - & + \\ Y(5) & & & + & - & & \\ Y(6) & & & + & & - & - \\ Y(7) & & & & + & - & - \\ Y(8) & & & & & + & -\end{array}$

RESTRAINTA +

RESTRAINT 8

FACTCRS FCR COMPUTING ST DEVS

WT RESTRAINTS

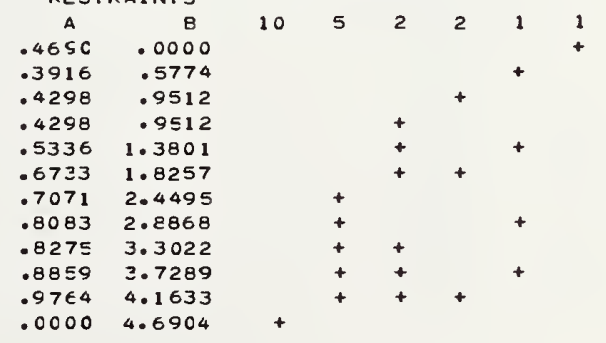




\begin{tabular}{|c|c|c|c|c|c|c|}
\hline \multirow{2}{*}{$\begin{array}{l}\text { DESIGN } 0.13 \\
\text { DESERVATIDNS }\end{array}$} & & ( HA & 0 & 1 & & \\
\hline & 10 & 5 & 3 & 2 & 1 & 1 \\
\hline$Y(1)$ & + & - & - & - & & \\
\hline$Y(2)$ & + & - & - & & - & - \\
\hline$Y(3)$ & & + & - & - & - & + \\
\hline$Y(4)$ & & + & - & - & + & - \\
\hline$Y(5)$ & & + & - & - & & \\
\hline$Y(6)$ & & + & - & & - & - \\
\hline$Y(7)$ & & & + & - & - & \\
\hline$Y(B)$ & & & + & - & & - \\
\hline$Y(9)$ & & & & + & 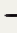 & - \\
\hline$Y(10)$ & & & & & + & - \\
\hline
\end{tabular}

RESTRAINTA +

RESTRAINT B

FACTDRS FCR COMPUTING ST DEVS WT

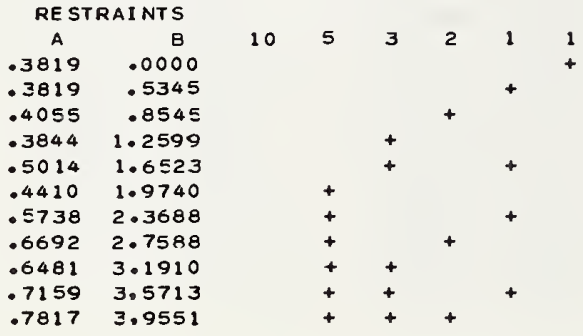

DESIGN D.15

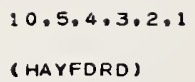

$K=6$ $\mathrm{N}=10$ $D \cdot F \cdot=5$

DBSERVATIONS

$Y(1)$

$Y(2)$

$Y(3)$

$Y(4)$

$r(5)$

$Y(6)$

$Y(7)$

$Y(8)$

$Y(9)$

$Y(10)$

( HAYFORD)

D.F.$=5$

RESTRAINT A *

RESTRAINT B

FACTCRS FCR COMFUTING ST DEVS

WT RESTRAINTS

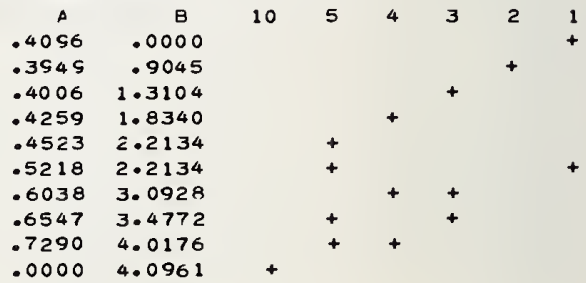

\begin{tabular}{llllll} 
DESIGN D.14 & \multicolumn{7}{c}{5.4 .3 .2 .1} \\
(HAYFORD) \\
$\begin{array}{llllll} & \\
\text { OBSERVATIONS } & 5 & 4 & 3 & 2 & 1 \\
Y(1) & + & - & - & + & \\
Y(2) & + & - & & - & + \\
Y(3) & + & - & & & - \\
Y(4) & + & & - & - & \\
Y(5) & & - & - & - & + \\
Y(6) & & - & - & & - \\
Y(7) & & & + & - & -\end{array}$
\end{tabular}

RESTRAINT A +

RESTRAINT B

FACTDRS FCR CDMPUTING ST DEVS

\begin{tabular}{|c|c|c|c|c|c|c|}
\hline \multirow[t]{2}{*}{ WT } & \multicolumn{2}{|c|}{ RESTRAI NTS } & \multirow[b]{2}{*}{5} & \multirow[b]{2}{*}{4} & \multirow[b]{2}{*}{3} & \multirow[b]{2}{*}{2} \\
\hline & A & $\mathrm{B}$ & & & & \\
\hline 1 & .4775 & .0000 & & & & \\
\hline 2 & .4775 & .4663 & & & & + \\
\hline$\Xi$ & .5912 & .5683 & & & + & \\
\hline 4 & .5912 & .6825 & & + & & \\
\hline 5 & .0000 & .6825 & + & & & \\
\hline$\epsilon$ & .4775 & .6825 & + & & & \\
\hline 7 & .4775 & .8776 & + & & & + \\
\hline 8 & .5912 & .9292 & + & & + & \\
\hline $\mathbf{S}$ & .5912 & 1.1952 & + & + & & \\
\hline 10 & .6752 & 1.1952 & + & + & & \\
\hline
\end{tabular}

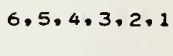

$K=6$

(HAYFDRD)

$\mathrm{N}=9$

D.F. $=4$

CBSERVAT IDNS

$Y(1)$

Y ( 2$)$

$Y(3)$

$Y(4)$

$Y(5)$

$Y(E)$

$Y(7)$

$Y(8)$

$Y(9)$

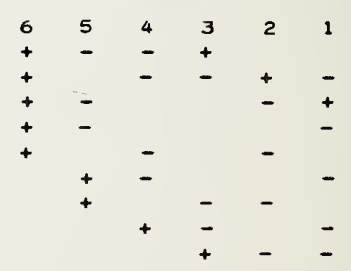

RESTFAINT A +

RESTRAINT B

FACTDRS FCR CDMPUTING ST DEVS

WT RESTRAINTS

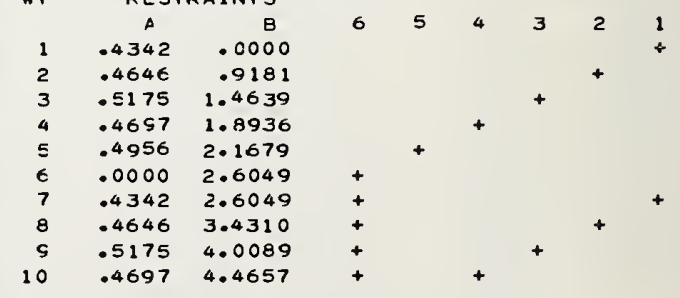




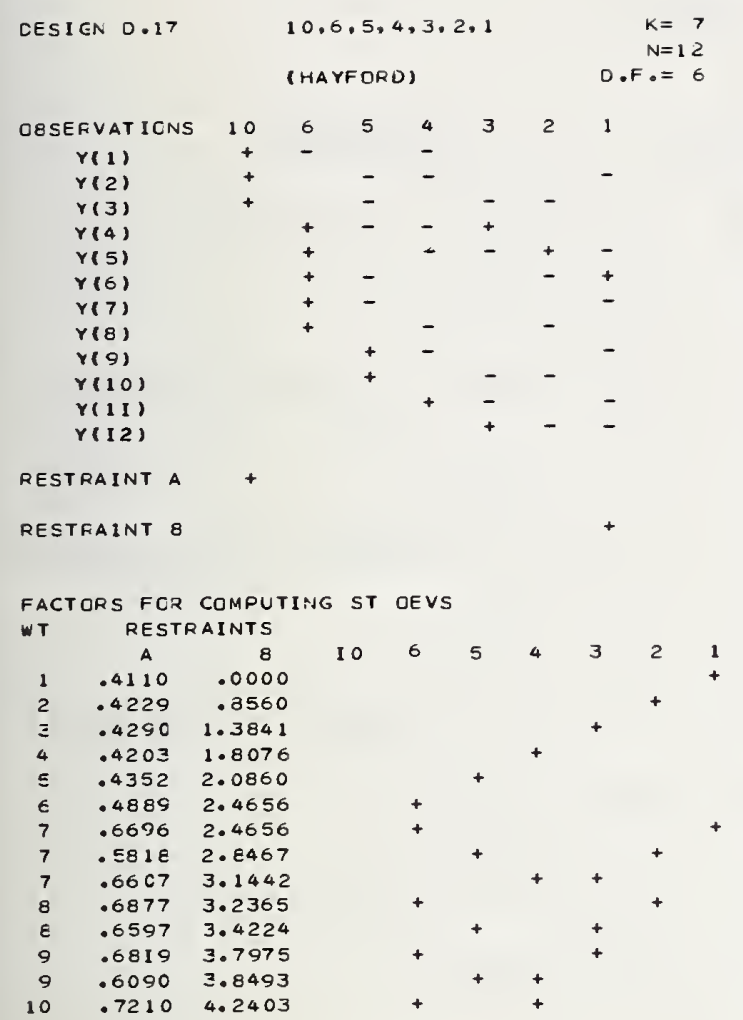




\section{LIST OF TABLES}

Table

$11,1,1,1$

$2 \quad 1,1,1,1$

$3 \quad 2,2,1,1$

$4 \quad 2,2,1,1$

$5 \quad 5,3,2,1,1,1$

$6 \quad 5,3,2,1,1,1$

$7 \quad 5,2,2,1,1,1$

$8 \quad 5,2,2,1,1,1$

$91,1,1,1$ Direct reading

$101,1,1,1$ Direct reading
Design

A.1.2 Sum Two of two weights

A.1.2 One weight

B.3 Sum Four of first two weights

B.3 One weight

C.2 Sum Ten of first three weights

C. 2 One weight

C. 10

Sum Ten of first four weights

C. 10

E.1

E. 1

One weight 
웅

象是

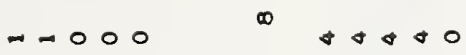

폻

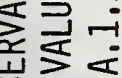

崩

ํํㅇ든중

볼료

兵

능高骂

을요

㟧方

믈리

声㞾岩

$\ddot{न-1}$

㞾

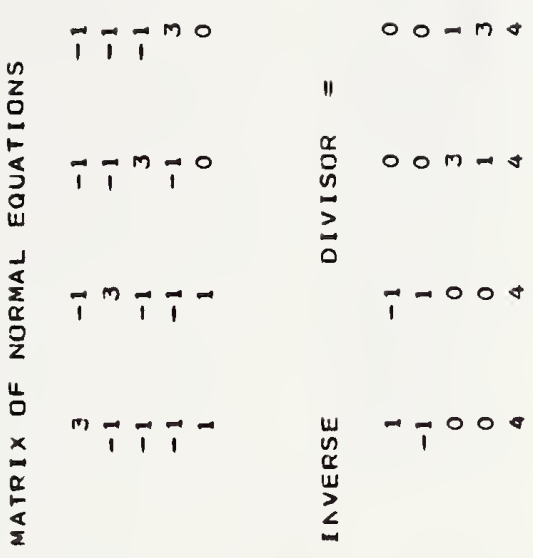

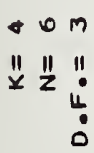

$\infty$

$00-T^{-1}-N$

논

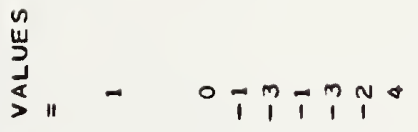

品 $\alpha$

$\stackrel{\text { w }}{\circ} \stackrel{\alpha}{\circ}$

岁

- $\quad$ T7 T

$a n-0 T-n T$

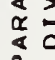

モลำ

$z$
$z$
$\alpha$
$\alpha$
$\sigma$
$w$
$\alpha$
$\alpha$

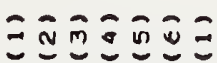
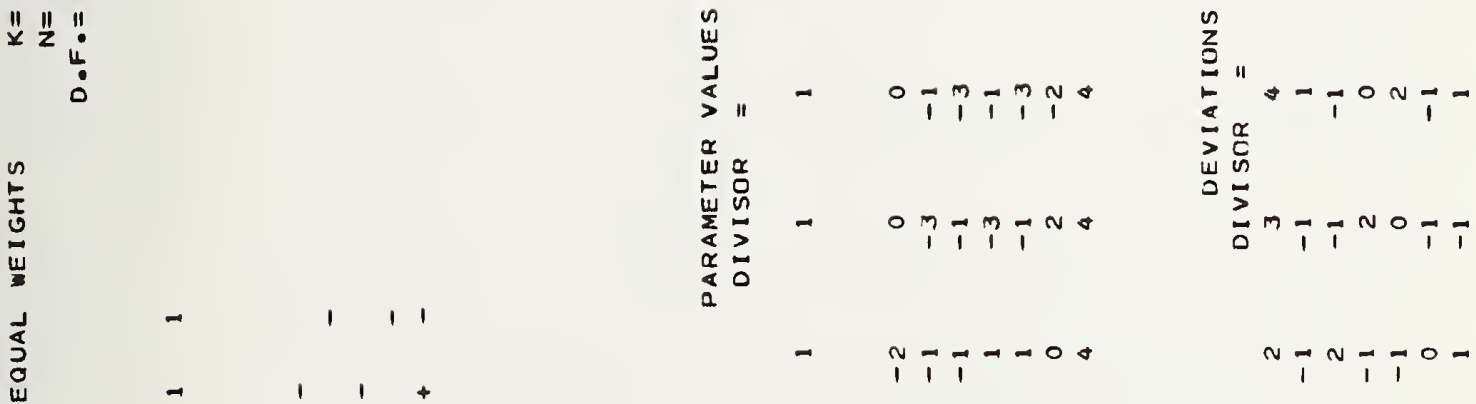

$-\quad h-1 \rightarrow-00$

$n \rightarrow n \rightarrow T^{1}$

号

$-\quad n-7 T^{\circ}$

$-n \rightarrow-7-0$

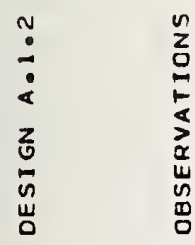

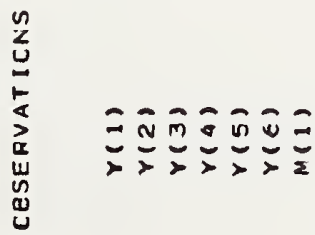

=

ンンンランう 
웅

농리

통
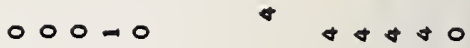

$\sum_{0}$

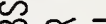

刉受㤀

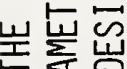

능 重

邑呇

$\ddot{\sim}$

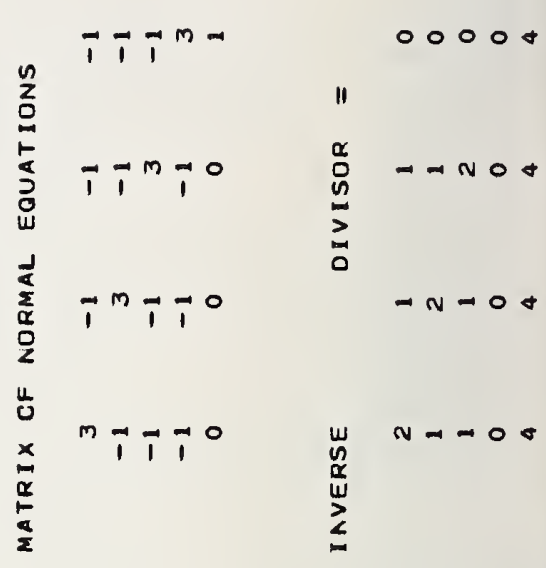

岂

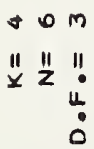

$\stackrel{n}{\frac{4}{3}}$

$-000000$

告

$\stackrel{\alpha}{\omega \alpha}$

w

$\sum_{2}^{2}$

$-\quad 0-\frac{1}{-a n}$

$00-\overline{1}^{-1}$

$\begin{array}{lll}4 & 0 \\ a & 0 & 0\end{array}$
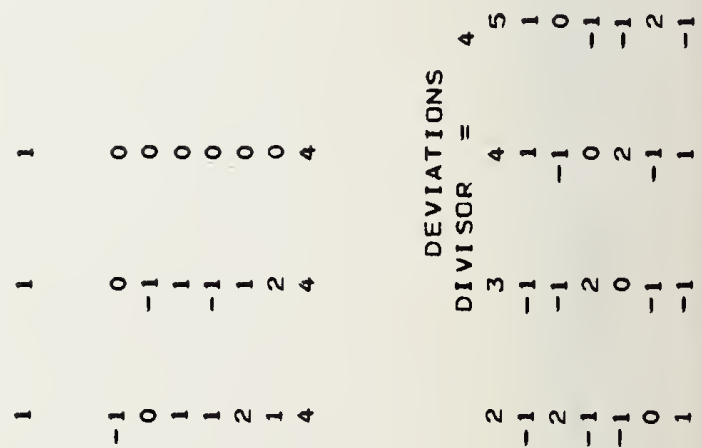

כ)

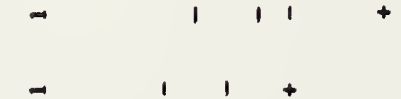

号

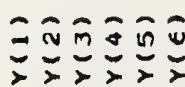

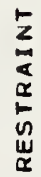

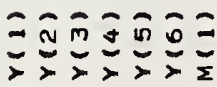

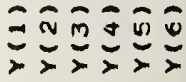

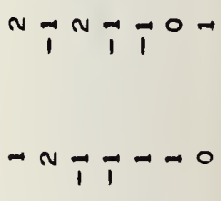

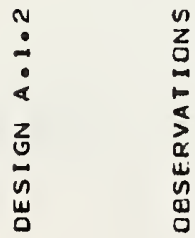

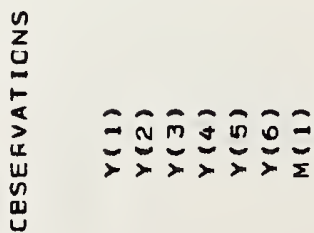


온

事是

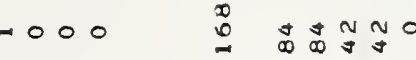

峞

언

ली $\simeq$ z

픈

폴 㟧

岁这呂

œ吢

岌怘

믈

豆㟔㟔

m

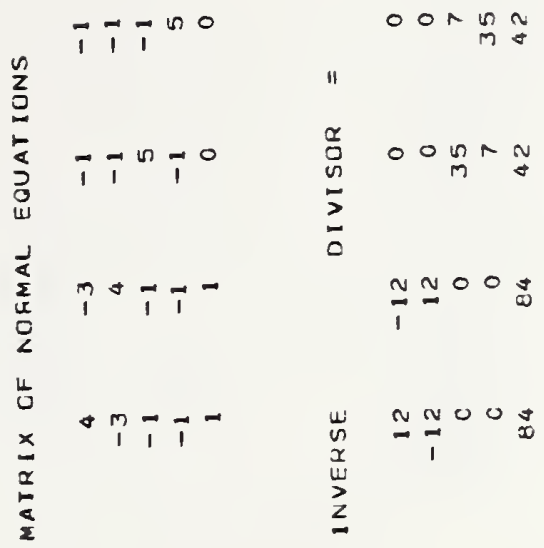

崫

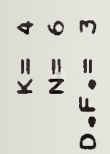
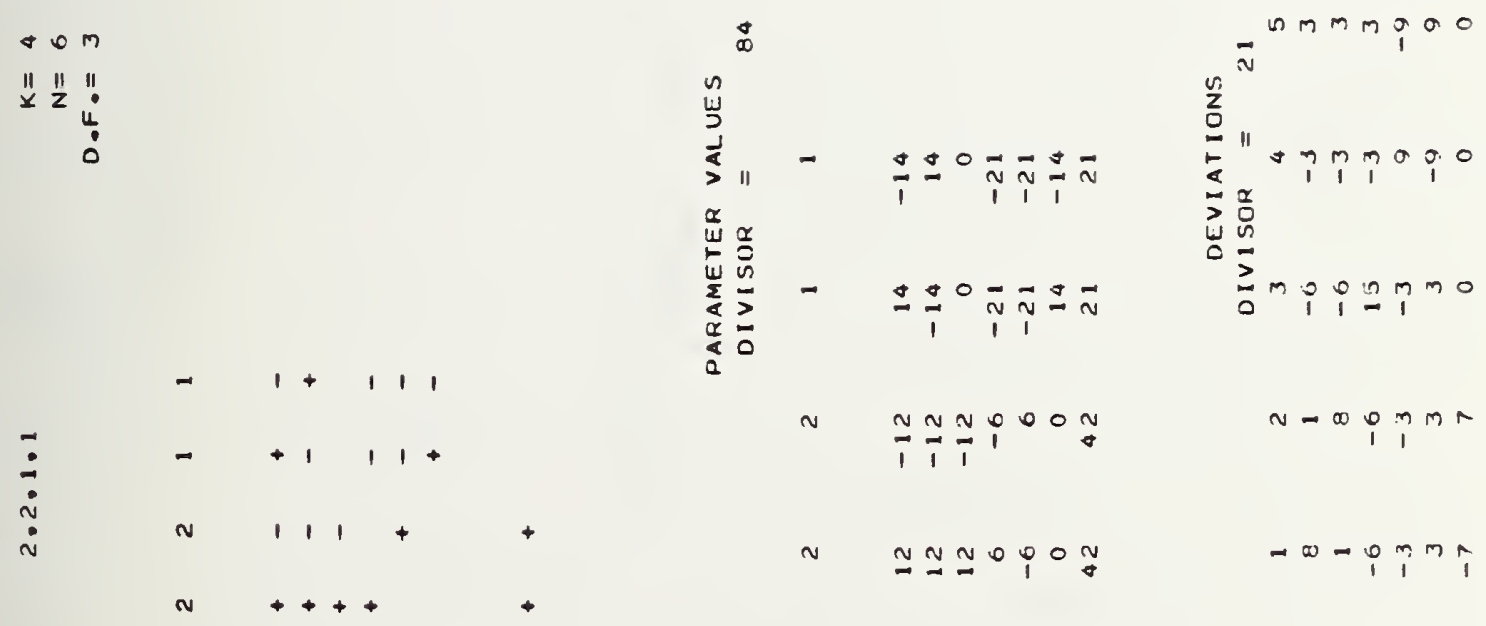

N $\quad \frac{1}{1} \frac{N}{1}$

$n-\infty p_{1}^{1} m+1$

N $\quad$ N N

$-\infty-i i^{m} \hat{i}$

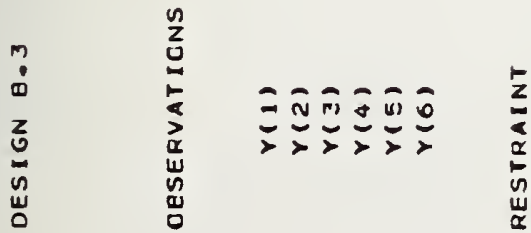

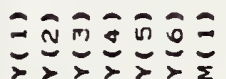

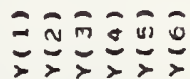


온

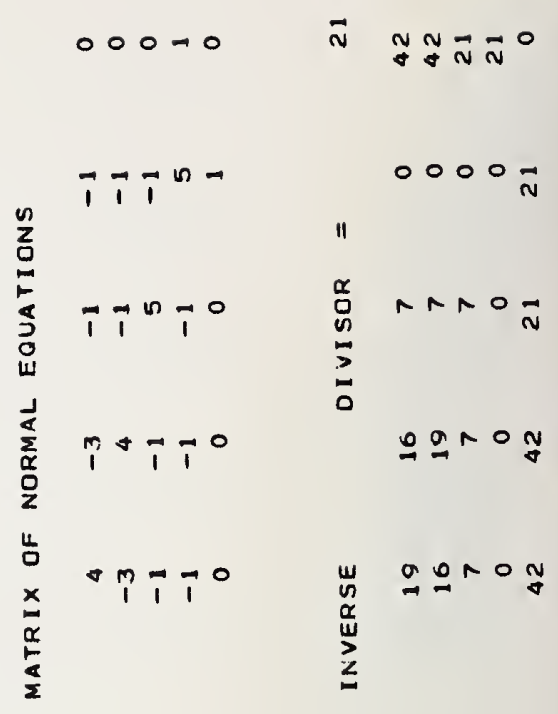

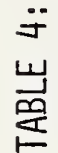

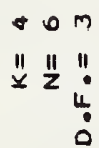

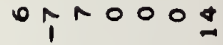

品

$\stackrel{4}{\frac{4}{3}}$

$-000000 \bar{N}$

$\stackrel{\alpha}{w}$

뜬

要

- riogon

$\vec{x}$

nMMMOOO a

N $\frac{1}{1}{ }^{2} \equiv N$

$n-\infty p_{m}^{1} m$

N

otm gar a

$-\infty-p \eta m i$

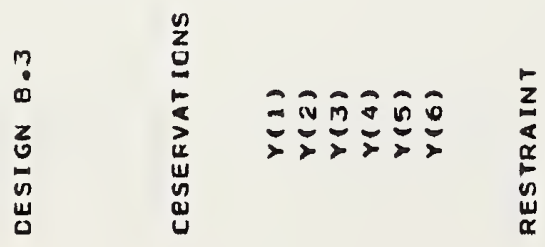

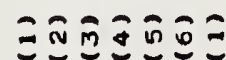

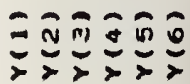


웅

$00000=0$

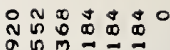

충

1700000

$000000 \%$

1T00000

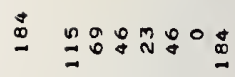

殅崖㟧

능 昰 옹

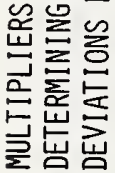

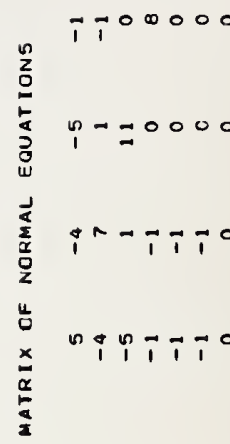

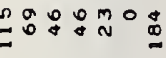

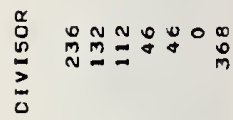

$\ddot{0}$

崌

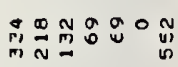

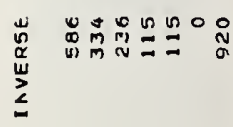

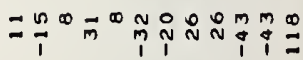

은

a

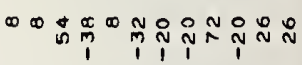

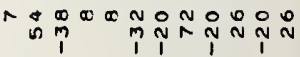

- $00000000000_{\Phi}^{\circ}$

-

$\stackrel{0}{\|}=0$

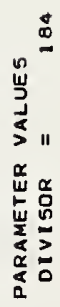

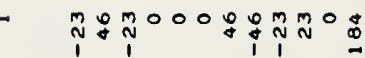

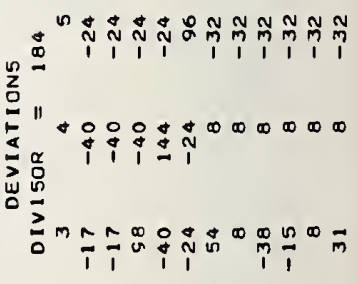

N $\quad \prod_{\text {D }}^{\infty}$

$\frac{1}{2}$

m

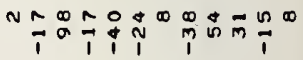

๑

-

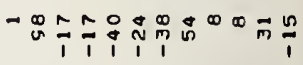

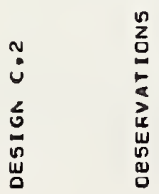

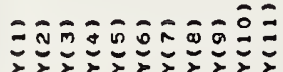


pNNONOO 虽

\begin{tabular}{|c|c|c|c|}
\hline & PNNOONO & & 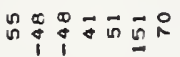 \\
\hline & PNNONOO & $\stackrel{\circ}{\circ}$ & 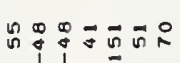 \\
\hline$z_{z}^{n}$ & PNNNOO- & " & 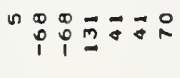 \\
\hline 络 & IONNNN- & $\begin{array}{l}\frac{a}{0} \\
\frac{1}{2}\end{array}$ & : \\
\hline $\begin{array}{l}\frac{\pi}{2} \\
\frac{2}{2} \\
\frac{0}{2}\end{array}$ & inONNN- & & $\operatorname{li}^{\infty}$ \\
\hline $\begin{array}{l}\frac{\omega}{\alpha} \\
\frac{x}{\alpha} \\
\frac{\alpha}{\alpha}\end{array}$ & 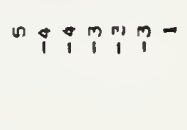 & $\begin{array}{l}\text { w. } \\
\text { w } \\
w \\
\underline{z}\end{array}$ & 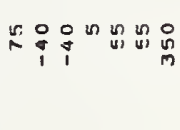 \\
\hline
\end{tabular}

$\operatorname{mat} \cot ^{1}$

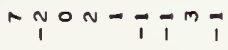

$-\quad \bar{n}-\frac{1}{1} \div=\frac{1}{1}$

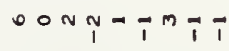

$0 \infty m$

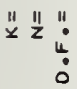
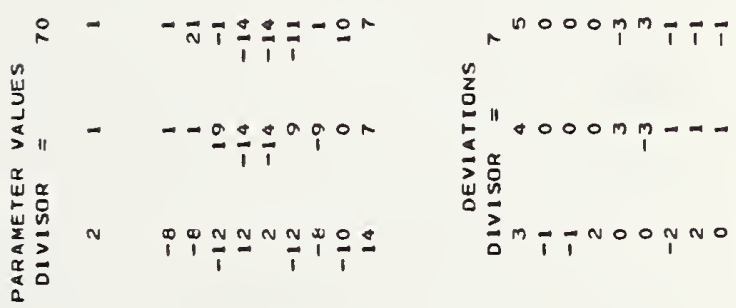

Pִบำกำ

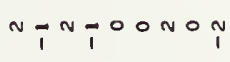

N

n

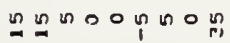

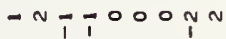

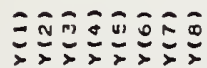



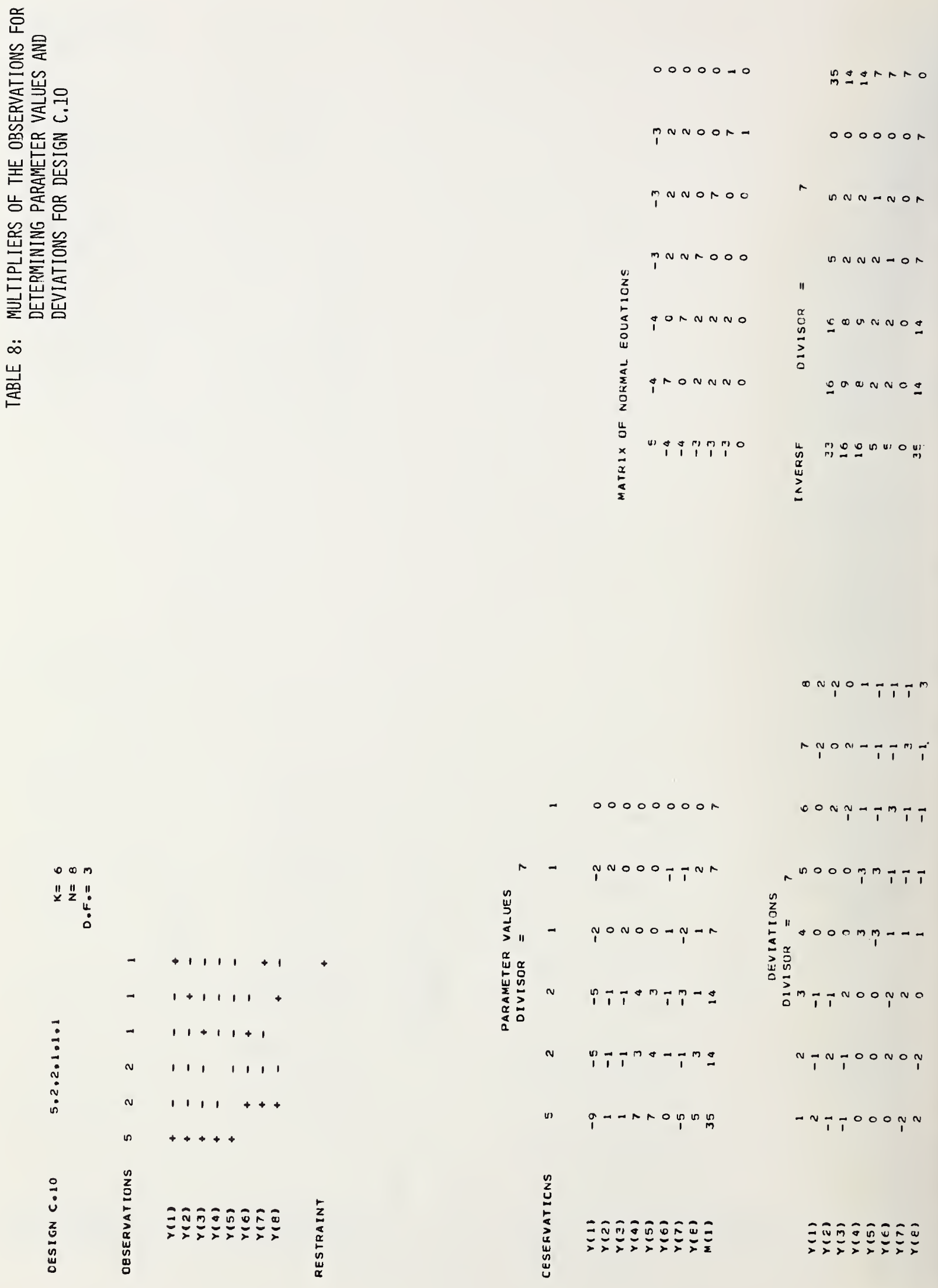

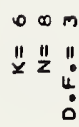

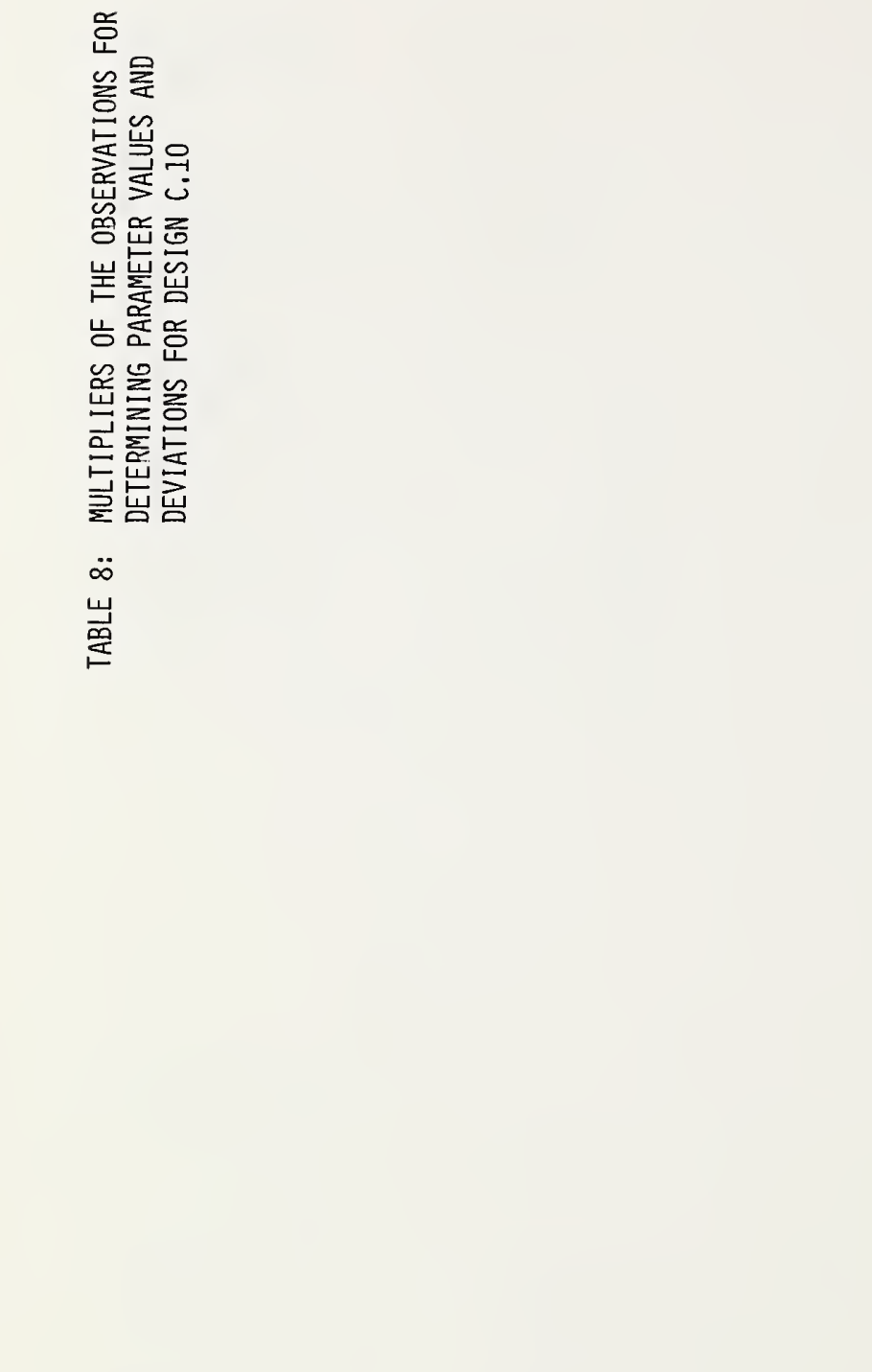

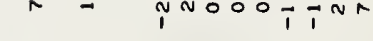

$\ddot{\vdots}$
$\vdots$
$\dot{N}$
$\dot{0}$

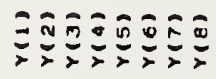


웅

릉

足岁

总昰学

哭品之

$00000 \substack{0 \\ 0}_{0}^{0}$

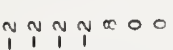

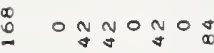

岁產颔
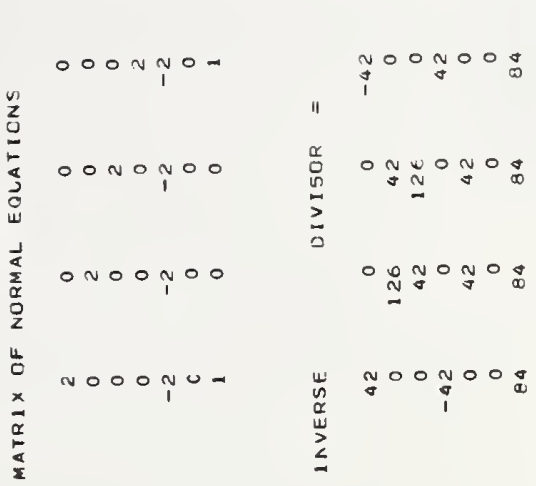

$\sigma$
程

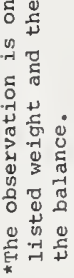

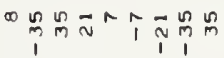

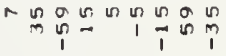

**puaxi

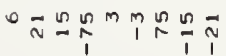

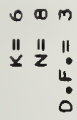

* * puard

*axed ププ

- $000-1000$

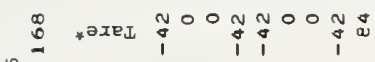

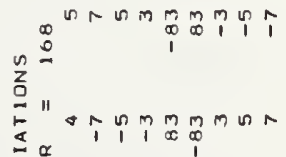

- $\mathfrak{j}^{1} 00$ 每

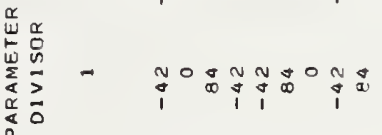

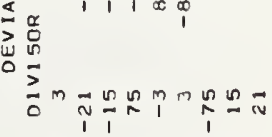

- $00-00-00$

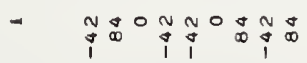

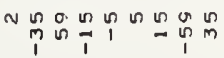

$-0-0000-0$

- $\operatorname{lom}^{1} \frac{1}{4}$

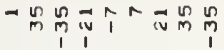

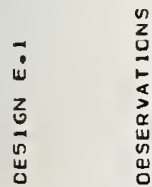

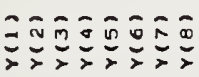

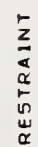



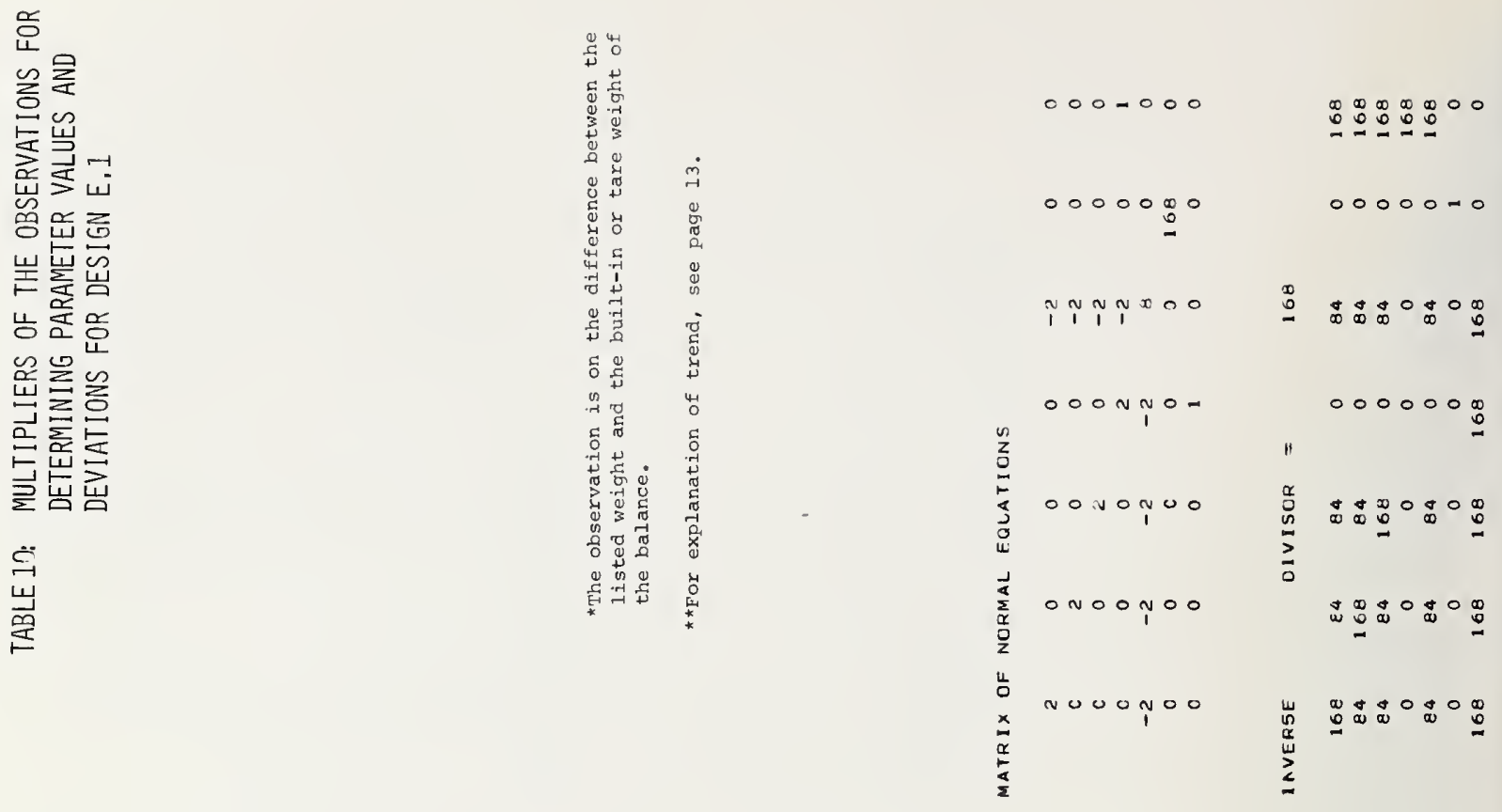

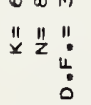

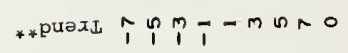

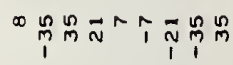

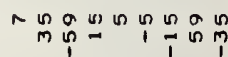$$
\text { ลำกับ }
$$
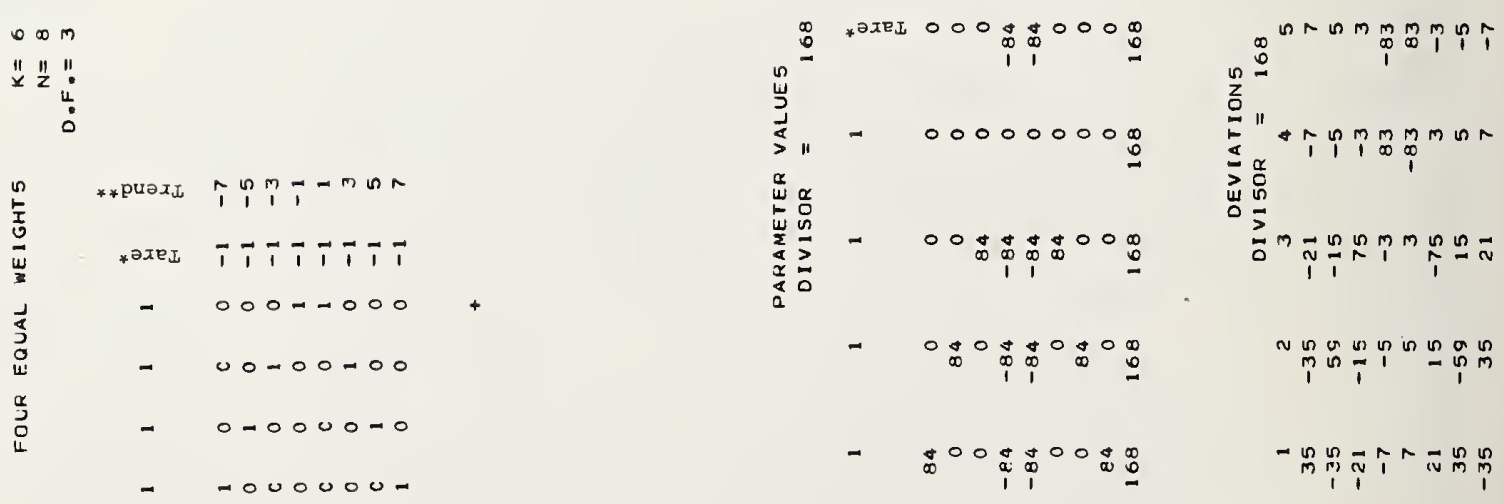

-

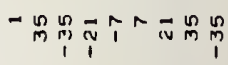

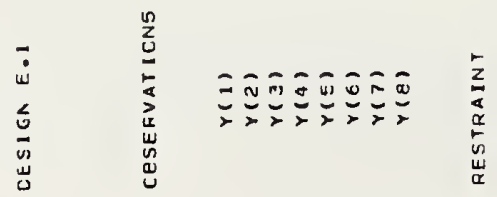

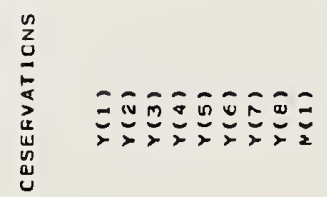

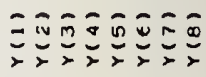




\section{REFERENCES}

[1] Benoit, M. J. R., L'Etalonnage des Series de Poids, Travaux et Memoires du Bureau International des Poids et Mesures, No. 13, $1-47$ (1907)

[2] Bose, R. C. and Cameron, J. M., The Bridge Tournament Problem and Calibration Designs for Comparing Pairs of objects, National Bureau of Standards Journal of Research 69B, 323-332 (1965)

[3] Bose, R. C. and Cameron, J. M., Calibration Designs Based on Solutions to the Tournament Problem, National Bureau of Standards Journal of Research 71B, 149-160 (1967)

[4] Cameron, J. M. and Hailes, G. E., Designs for the Calibration of Small Groups of Standards in the Presence of Drift, NBS Technical Note 844 (August 1974)

[5] Chakravarti, I. M. and Suryanarayana, K. V., Partial Difference Sets and Partially Balanced Weighing Designs for Calibration and Tournaments, Journal of Combinatorial Theory 13(3), 426-431 (1972)

[6] Goldman, A. J. and Zelen, M., Weak Generalized Inverses and Minimum Variance Linear Unbiased Estimation, NBS Journal of Research 68B, No. 4, 151-172 (1964)

[7] Hayford, John A., On the Least Squares Adjustment of Weighings, U.S. Coast \& Geodetic Survey Report for 1892, Appendix 10, USCGS (1893)

[8] National Bureau of Standards Circular 3, Design and Test of Standards of Mass, 1918. This circular is out of print but 
its contents have been incorporated in NBS Handbook 77, Precision Measurement and Calibration, Volume III, Optics, Metrology and Radiation, pp. 588-706. This handbook is available for reference or circulation in most Government Depository Libraries throughout the United States.

[9] Pontius, P. E., Mass and Mass Values, NBS Monograph 133, 39 pages (1974)

[10] Pontius, P. E., Measurement Philosophy of the Pilot Program for Mass Calibration, NBS Technical Note 288, 39 pages (1966)

[11] Suryanarayana, K. V., Contributions to Partially Balanced Weighing Designs, Ph.D. dissertation submitted to the Department of statistics, University of North Carolina at Chapel Hill, Institute of Statistics Mimeo Series No. 621 (1969)

[12] Zelen, M., Linear Estimation and Related Topics, Survey of Numerical Analysis, Chapter 17, edited by J. Todd, McGraw Hill, New York City, 558-584 (1962) 
NBS-114A (REV. 7-73)

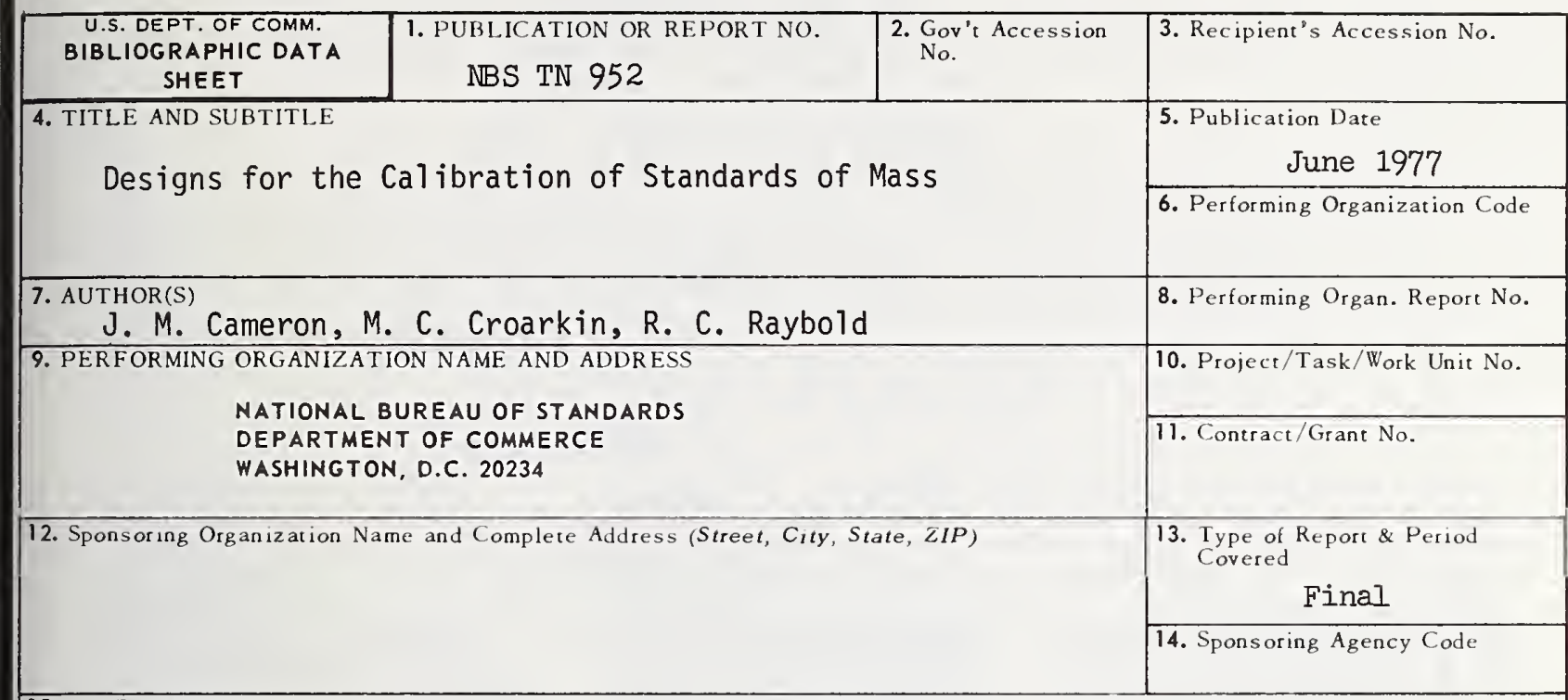

15. SUPPLEMENTARY NOTES

16. ABSTRACT (A 200-word or less factual summary of most significant information. If document includes a significant bibliography or literature survey, mention it here.)

This report presents a collection of designs for the intercomparison of sets of weights for use in precision calibration of standards of mass. These include a number of previously unpublished designs which have an additional weight in each set to serve as the check standard for monitoring the performance of the weighing process. Also included are the classical designs of Benoit and Hayford. The complete least squares analysis is presented in integer form (i.e., with a common division) for the most widely used designs; and for the others, the standard deviations are given for various weight combinations when used as an ascending or as a descending series. Designs for sets of nominally equal objects, the $22 \ldots 11 \ldots$ series, the binary sequences, the 52211 series, and the 53211 and some miscellaneous series are given.

17. KEY WORDS (six to twelve entries; alphabetical order; capitalize only the first letter of the first key word unless a proper name; separated by semicolons)

Design of experiments; least squares; mass calibration; statistical design; weighing design

18. AVAILABILITY

For Official Distribution. Do Not Release to NTIS

XX Order From Sup, of Doc., U.S. Government Printing Office Washington, D.C. 20402, SD.Cat. No. C13 $46: 952$

Order From National Technical Information Service (NTIS) Springfield, Virginia 22151

\begin{tabular}{|l|c|}
\hline $\begin{array}{l}\text { 19. SECURITY CLASS } \\
\text { (THIS REPURT) } \\
\text { UNCL ASSIFIED }\end{array}$ & 64 \\
\hline $\begin{array}{l}\text { 20. SECURITY CLASS } \\
\text { (THIS PAGE) }\end{array}$ & 22. Price \\
UNCLASSIFIED & USCOMM-DC 29042-P74 \\
\hline
\end{tabular}




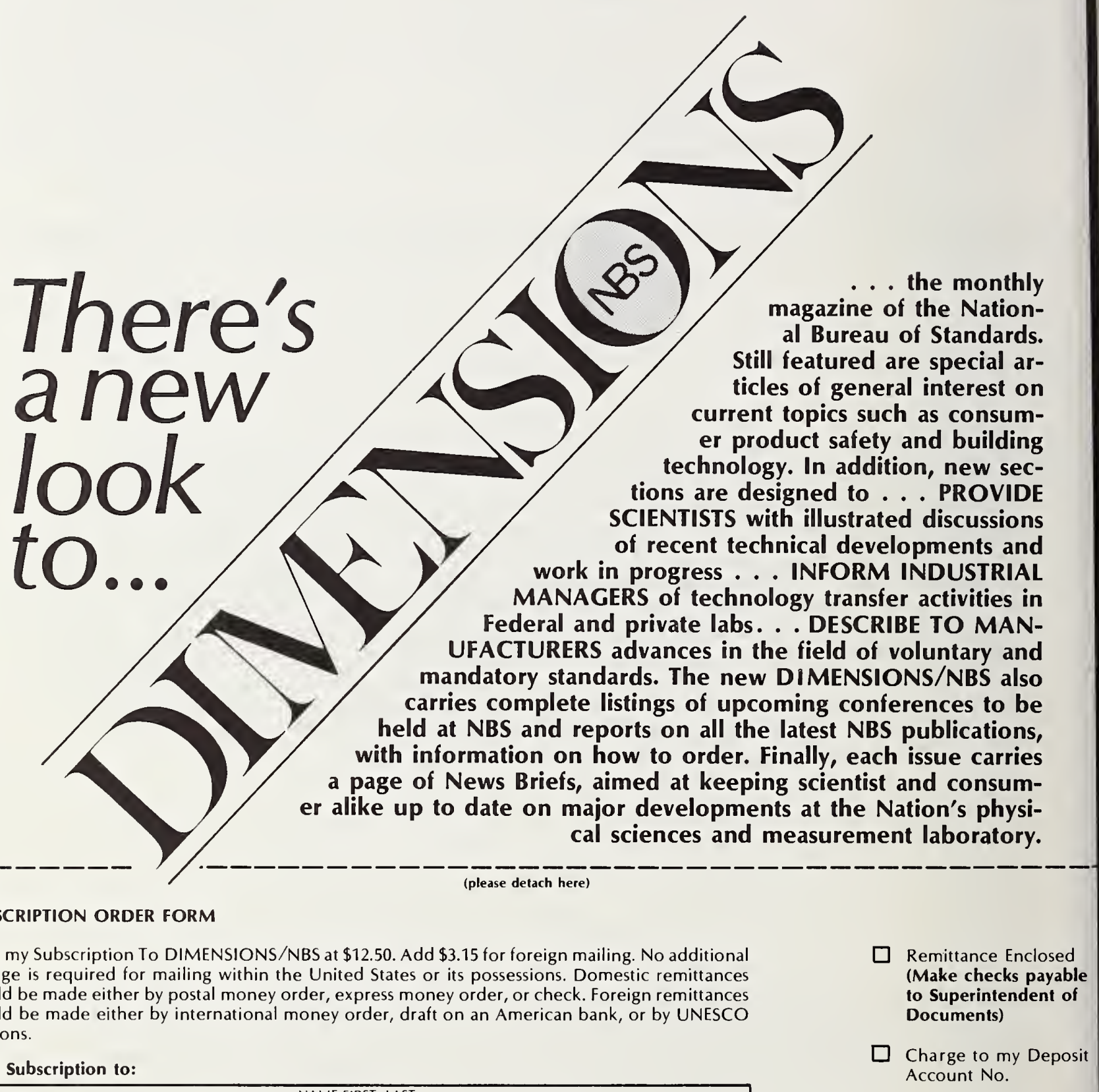

Send Subscription to

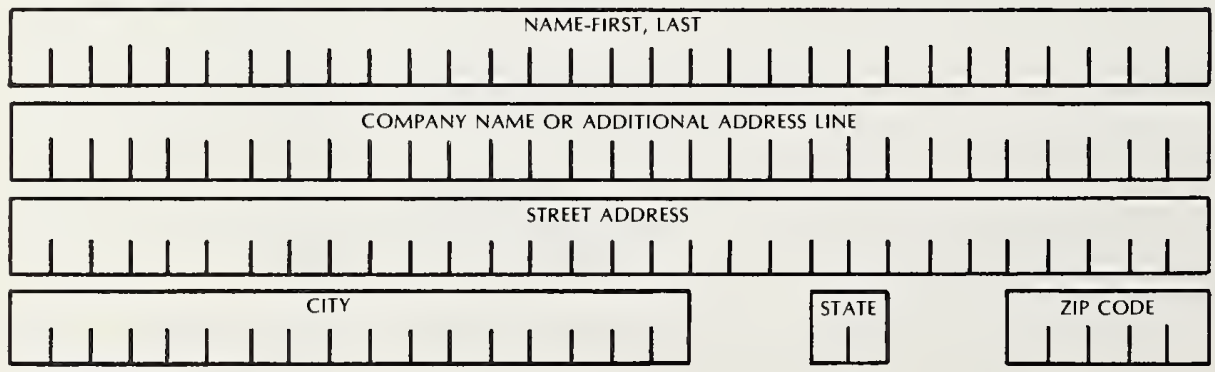
Account No.

MAIL ORDER FORM TO: Superintendent of Documents Government Printing Office Washington, D.C. 20402 


\section{SINGEE
CRYSTAL \\ DATA \\ REVISED! UPDATED!}

In 1954, the first edition of CRYS-

TAL DATA (Determinative Tables and Systematic Tables) was published as Memoir 60 of the Geological Society of America. In 1960 , the second edition of the Determina. tive Tables was issued as Monograph 5 of the American Crystallographic Association, and in 1967, the Systematic Tables were issued as Monograph 6. These editions proved extremely valuable to crystallographers throughout the world. Recognizing the need for updated crystallographic information, the National Bureau of Standards Office of Standard Reference Data has sponsored the issuance of a new edition.

This, the THIRD EDITION, should be of particular interest not only to crystal. lographers but also to chemists, mineralogists, physicists and individuals in related fields of study. The current edition, which comprises two volumes, Organic and Inorganic, is a thoroughly revised and up. dated work, containing over 25,000 entries.

The entries are listed, within each crystal sys. tem, according to increasing values of a determinative number: $a / b$ ratio in trimetric systems, c/a ratio in dimetric systems, and cubic cell edge $a$, in the isometric system. In addition, the following information is given:

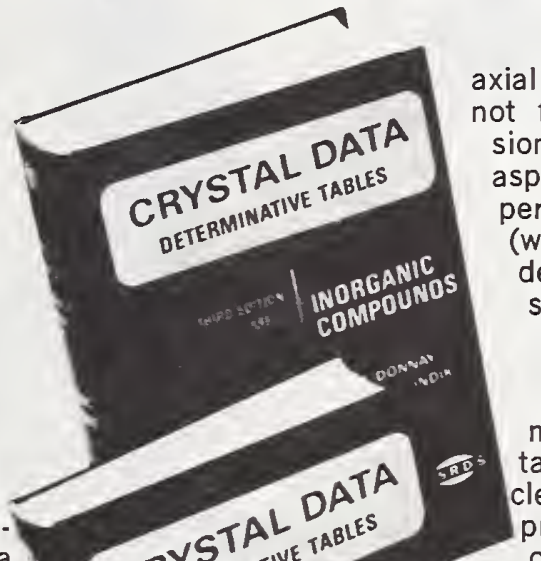

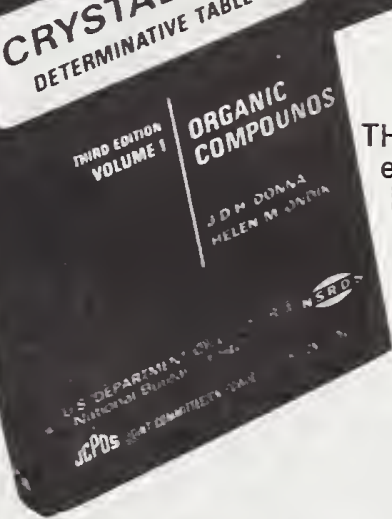

INORGANIC VOLUME $\$ 50.00$

ORGANIC VOLUME $\$ 30.00$

xial ratio(s) and interaxial angles not fixed by symmetry, cell dimen. sions, space group or diffraction aspect, number of formula units per unit cell, crystal structure, (whether determined), measured density and $\mathrm{x}$-ray calculated den. sity. Also listed is the name of the compound and synonym(s), chemical formula, literature ref. erence and transformation matrix. When available, the crystal structure type, crystal habit, cleavages, twinning, color, optical properties, indices of refraction, optical orientation, melting point and transition point are also listed.

THIS EDITION culminates years of effort by J. D. H. Donnay, Johns Hopkins University, Helen M. Ondik, National Bureau of Standards, Sten Samson, California Institute of Technology, Quintin Johnson, Lawrence Radiation Laboratory, Melvin H. Mueller, Argonne National Laboratory, Gerard M. Wolten, Aerospace Corporation, Mary E. Mrose, U.S. Geological Survey, Olga Ken. nard and David G. Watson, Cam. bridge University, England and Murray Vernon King, Massachu. setts General Hospital.

Plus shipping and handling

Shipments are made via insured parcel post. Additional charges for shipments by air or commercial carrier.

TERMS: Domestic-30 days Foreign-prepayment required. Address all orders to:

JOINT COMMITTEE ON POWDER DIFFRACTION STANDARDS 1601 Park Lane, Swarthmore, Pennsylvania 19081

Please accept my order for CRYSTAL DATA, DETERMINATIVE TABLES, Third Edition, Donnay/Ondik.

Organic Volume

Inorganic Volume

Ship to:

Signature

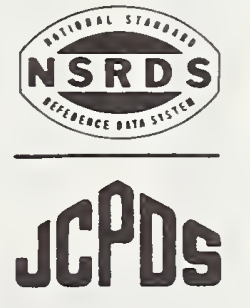



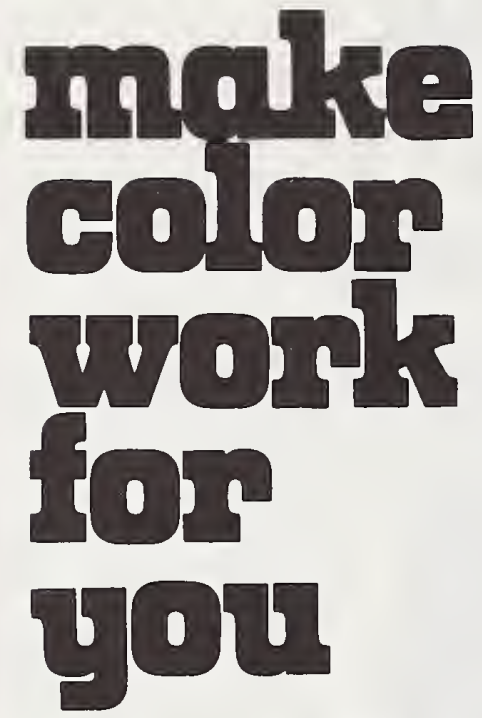

Color in our Daily Lives, a new consumer booklet from the National Bureau of Standards, takes the reader step by step through the fundamental principles of color and light, families of color, influence of colors upon other colors, and color harmony. This fullcolor, 32-page illustrated booklet highlights practical applications of color, including:

- Your personal color plan.

- Your color environment.

- Color plans for the home.

- Using color to drama. tize or to hide.

- Color and illumination.

- Experimenting with color.

This new basic guide can serve as your handbook in helping you make decisions about how to use color in your life and make it work for you. Order Color in Our Daily Lives prepaid for $\$ 1.70$ from the Superintendent of Documents, U.S. Government Printing Office, Washington, D.C. 20402. Use SD Catalog No. C13.53:6.

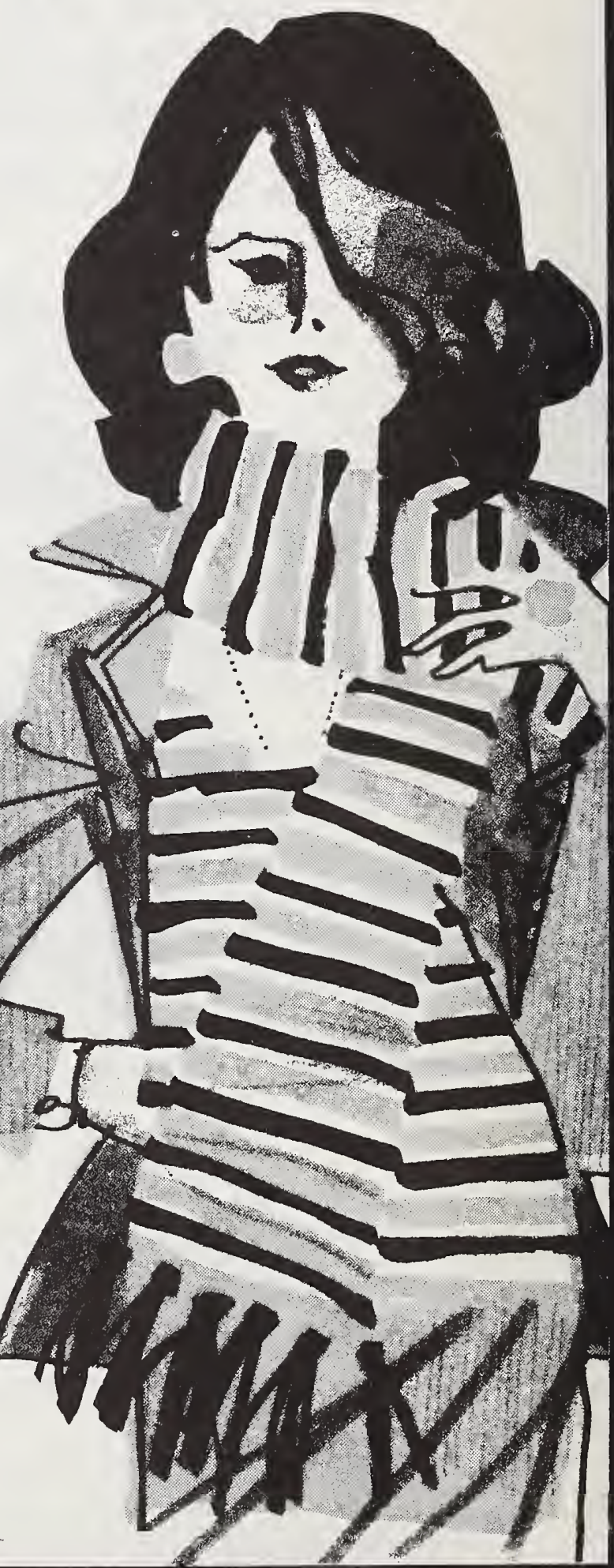




\section{PERIODICALS}

JOURNAL OF RESEARCH reports National Bureau of Standards research and development in physics, mathematics, and chemistry. It is published in two sections, available separately:

- Physics and Chemistry (Section A)

Papers of interest primarily to scien

these fields. This section covers a br cal and chemical research, wit ${ }^{2}$ or emphasis on standards of physical measur jut fundamental constants, and properties of $\mathrm{m}^{\circ}$ o Annual subscription: D 10 ? - Mathematical Scir sing 9 ( Section B)

Studies and comr ${ }^{8}$. Is designed mainly for the mathematician and $00^{5}$ etical physicist. Topics in mathemat-

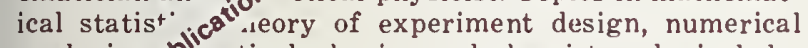
analysir 400 retical physics and chemistry, logical design in rogramming of computers and computer systr 1009 nort numerical tables. Issued quarterly. Annual si ${ }^{20}$ cription: Domestic, $\$ 9.00$; Foreign, $\$ 11.25$.

DIMENSIONS/NBS (formerly Technical News Bulletin)-This monthly magazine is published to inform scientists, engineers, businessmen, industry, teachers, students, and consumers of the latest advances in science and technology, with primary emphasis on the work at NBS. The magazine highlights and reviews such issues as energy research, fire protection, building technology, metric conversion, pollution abatement, health and safety, and consumer product performance. In addition, it reports the results of Bureau programs in measurement standards and techniques, properties of matter and materials, engineering standards and services, instrumentation, and automatic data processing. Annual subscription: Domestic, $\$ 12.50$; For eign, $\$ 15.65$.

\section{NONPERIODICALS}

Monographs-Major contributions to the technical literature on various subjects related to the Bureau's scientific and technical activities.

Handbooks-Recommended codes of engineering and industrial practice (including safety codes) developed in cooperation with interested industries, professional organizations, and regulatory bodies.

Special Publications-Include proceedings of conferences sponsored by NBS, NBS annual reports, and other special publications appropriate to this grouping such as wall charts, pocket cards, and bibliographies.

Applied Mathematics Series-Mathematical tables, manuals, and studies of special interest to physicists, engineers, chemists, biologists, mathematicians, computer programmers, and others engaged in scientific and technical work.

National Standard Reference Data Series-Provides quantitative data on the physical and chemical properties of materials, compiled from the world's literature and critically evaluated. Developed under a world-wide program coordinated by NBS. Program under authority of National Standard Data Act (Public Law 90-396).
NOTE: At present the principal publication outlet for these data is the Journal of Physical and Chemical Reference Data (JPCRD) published quarterly for NBS by the American Chemical Society (ACS) and the American Institute of Physics (AIP). Subscriptions, reprints, and supplements available from ACS, 1155 Sixteenth St. N.W., Wash. D. C. 20056.

Building Science Series-Disseminates technical information developed at the Bureau on building materials, components, systems, and whole structures. The series presents research results, test methods, and performance criteria related to the structural and environmental functions and the durability and safety characteristics of building elements and systems.

Technical Notes-Studies or reports which are complete in themselves but restrictive in their treatment of a subject. Analogous to monographs but not so comprehensive in scope or definitive in treatment of the subject area. Often serve as a vehicle for final reports of work performed at NBS under the sponsorship of other government agencies.

Voluntary Product Standards-Developed under procedures published by the Department of Commerce in Part 10, Title 15, of the Code of Federal Regulations. The purpose of the standards is to establish nationally recognized requirements for products, and to provide all concerned interests with a basis for common understanding of the characteristics of the products. NBS administers this program as a supplement to the activities of the private sector standardizing organizations.

Consumer Information Series-Practical information, based on NBS research and experience, covering areas of interest to the consumer. Easily understandable language and illustrations provide useful background knowledge for shopping in today's technological marketplace.

Order above NBS publications from: Superintendent of Documents, Government Printing Office, Washington, D.C. 20402 .

Order following NBS publications-NBSIR's and FIPS from the National Technical Information Services, Springfield, Va. 22161.

Federal Information Processing Standards Publications (FIPS PUBS)-Publications in this series collectively constitute the Federal Information Processing Standards Register. Register serves as the official source of information in the Federal Government regarding standards issued by NBS pursuant to the Federal Property and Administrative Services Act of 1949 as amended, Public Law 89-306 (79 Stat. 1127), and as implemented by Executive Order 11717 ( 38 FR 12315, dated May 11, 1973) and Part 6 of Title 15 CFR (Code of Federal Regulations).

NBS Interagency Reports (NBSIR) - A special series of interim or final reports on work performed by NBS for outside sponsors (both government and non-government). In general, initial distribution is handled by the sponsor; public distribution is by the National Technical Information Services (Springfield, Va. 22161) in paper copy or microfiche form.

\section{BIBLIOGRAPHIC SUBSCRIPTION SERVICES}

The following current-awareness and literature-survey bibliographies are issued periodically by the Bureau: Cryogenic Data Center Current Awareness Service. A literature survey issued biweekly. Annual subscription: Domestic, $\$ 25.00$; Foreign, $\$ 30.00$.

Liquified Natural Gas. A literature survey issued quarterly. Annual subscription: $\$ 20.00$.
Superconducting Devices and Materials. A literature survey issued quarterly. Annual subscription: $\$ 30.00$. Send subscription orders and remittances for the preceding bibliographic services to National Bureau of Standards, Cryogenic Data Center (275.02) Boulder, Colorado 80302. 
